San Jose State University

SJSU ScholarWorks

Mineta Transportation Institute Publications

$4-2020$

\title{
Evaluation of Coordinated Ramp Metering (CRM) Implemented By Caltrans
}

Amir Molan

California Polytechnic State University, San Luis Obispo

Nivedha Murugesan

San Jose State University

Alireza Shams

California Polytechnic State University, San Luis Obispo

Cristina Tortora

San Jose State University

Faridur Rahman

GHD

See next page for additional authors

Follow this and additional works at: https://scholarworks.sjsu.edu/mti_publications

Part of the Civil Engineering Commons, and the Transportation Engineering Commons

\section{Recommended Citation}

Amir Molan, Nivedha Murugesan, Alireza Shams, Cristina Tortora, Faridur Rahman, Jacky Loh, and Anurag Pande. "Evaluation of Coordinated Ramp Metering (CRM) Implemented By Caltrans" Mineta Transportation Institute Publications (2020). https://doi.org/10.31979/mti.2020.1812

This Report is brought to you for free and open access by SJSU ScholarWorks. It has been accepted for inclusion in Mineta Transportation Institute Publications by an authorized administrator of SJSU ScholarWorks. For more information, please contact scholarworks@sjsu.edu. 


\section{Authors}

Amir Molan, Nivedha Murugesan, Alireza Shams, Cristina Tortora, Faridur Rahman, Jacky Loh, and Anurag Pande 


\section{SJSU UNIVSESSTYY}

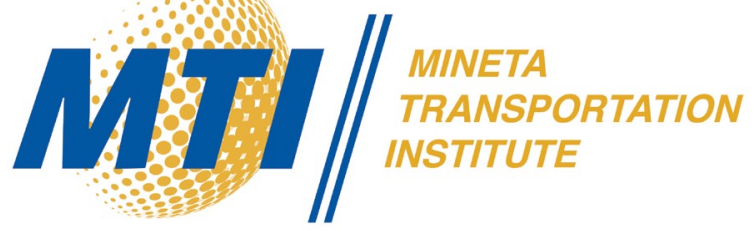

\section{Evaluation of Coordinated Ramp Metering (CRM) Implemented by Caltrans}

Amirasalan Molan, PhD Nivedha Murugesan Alireza Shams, PhD Cristina Tortora, PhD
Faridur Rahman Jacky Loh Anurag Pande, PhD

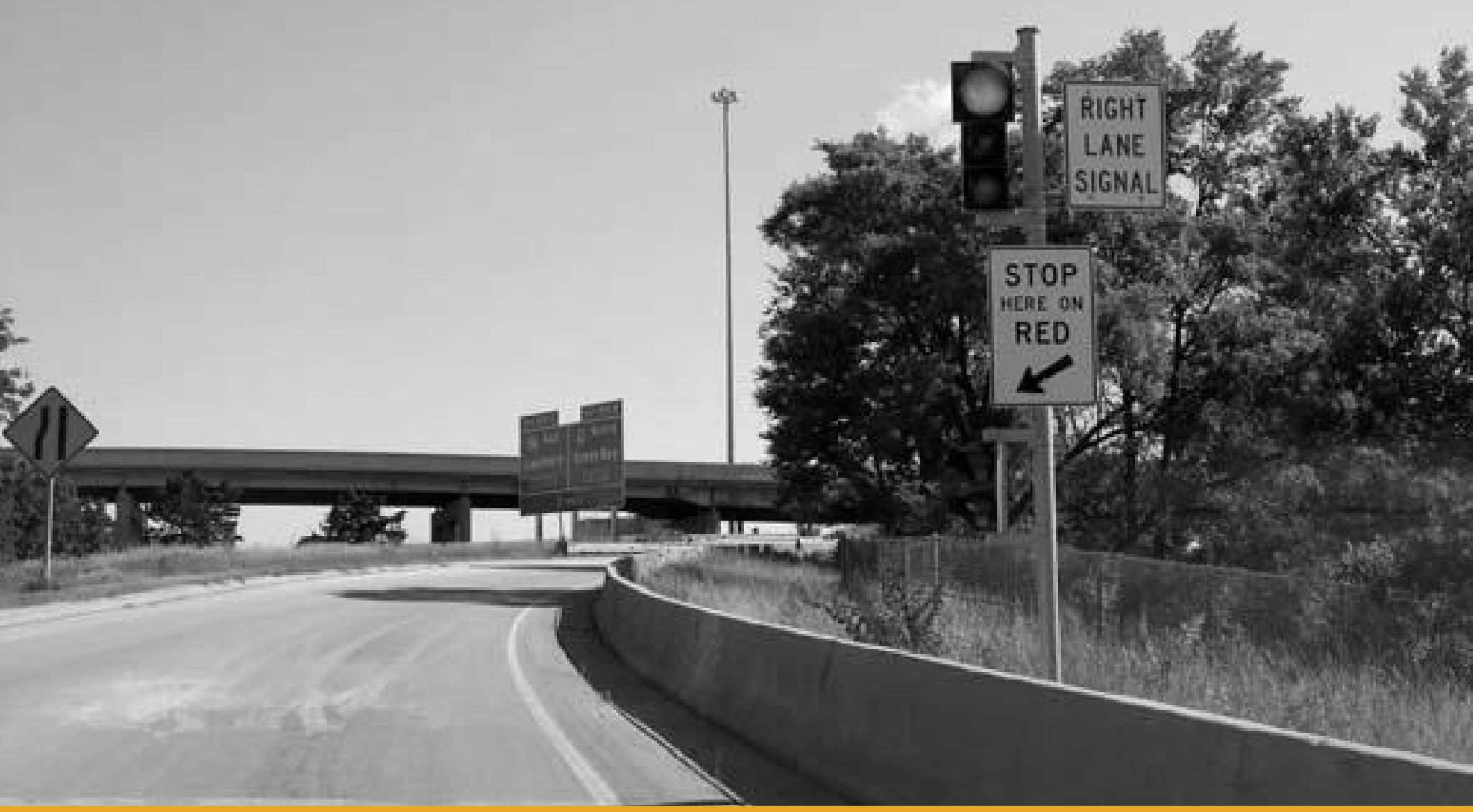




\section{MINETA TRANSPORTATION INSTITUTE \\ LEAD UNIVERSITY OF \\ Mineta Consortium for Transportation Mobility}

Founded in 1991, the Mineta Transportation Institute (MTI), an organized research and training unit in partnership with the Lucas College and Graduate School of Business at San José State University (SJSU), increases mobility for all by improving the safety, efficiency, accessibility, and convenience of our nation's transportation system. Through research, education, workforce development, and technology transfer, we help create a connected world. MTI leads the four-university Mineta Consortium for Transportation Mobility, a Tier I University Transportation Center funded by the U.S. Department of Transportation's Office of the Assistant Secretary for Research and Technology (OST-R), the California Department of Transportation (Caltrans), and by private grants and donations.

MTl's transportation policy work is centered on three primary responsibilities:

\section{Research}

MTI works to provide policy-oriented research for all levels of government and the $P$ rivate sector to foster the development of optimum surface transportation systems. Research areas include: bicycle and pedestrian issues; financing public and private sector transportation improvements; intermodal connectivity and integration; safety and security of transportation systems; sustainability of transportation systems; transportation / land use / environment; and transportation planning and policy development. Certified Research Associates conduct the research. Certification requires an advanced degree, generally a Ph.D., a record of academic publications, and professional references. Research projects culminate in a peer-reviewed publication, available on TransWeb, the MTI website (http://transweb.sjsu.edu).

\section{Education}

The Institute supports education programs for students seeking a career in the development and operation of surface transportation systems. MTI, through San José State University, offers an AACSBaccredited Master of Science in Transportation Management and graduate certificates in Transportation Management,Transportation Security, and High-Speed Rail Management that serve to prepare the nation's transportation managers for the 2 I st century. With the active assistance of the California Department of Transportation (Caltrans), MTI delivers its classes over a state-of-the-art videoconference network throughout the state of California and via webcasting beyond, allowing working transportation professionals to pursue an advanced degree regardless of their location. To meet the needs of employers seeking a diverse workforce, MTl's education program promotes enrollment to under-represented groups.

\section{Information and Technology Transfer}

MTI utilizes a diverse array of dissemination methods and media to ensure research results reach those responsible for managing change. These methods include publication, seminars, workshops, websites, social media, webinars, and other technology transfer mechanisms. Additionally, MTI promotes the availability of completed research to professional organizations and journals and works to integrate the research findings into the graduate education program.MTI's extensive collection of transportation- related publications is integrated into San José State University's world-class Martin Luther King, Jr. Library.

\section{Disclaimer}

The contents of this report reflect the views of the authors, who are responsible for the facts and accuracy of the information presented herein. This document is disseminated in the interest of information exchange. The report is funded, partially or entirely, by a grant from the U.S. Department of Transportation's University Transportation Centers Program. This report does not necessarily reflect the official views or policies of the U.S. government, State of California, or the Mineta Transportation Institute, who assume no liability for the contents or use thereof. This report does not constitute a standard specification, design standard, or regulation. 
REPORT 20-15

\title{
COORDINATED RAMP METERING (CRM) IMPLEMENTED BY CALTRANS
}

\author{
Amirasalan Molan, PhD \\ Nivedha Murugesan \\ Alireza Shams, PhD \\ Cristina Tortora, PhD \\ Faridur Rahman \\ Jacky Loh \\ Anurag Pande, PhD
}

April 2020

A publication of

Mineta Transportation Institute

Created by Congress in 1991

College of Business

San José State University

San José, CA 95192-0219 


\section{TECHNICAL REPORT DOCUMENTATION PAGE}

1. Report No. 20-15

4. Title and Subtitle

Evaluation of Coordinated Ramp Metering (CRM) Implemented By Caltrans

2. Government Accession No.
3. Recipient's Catalog No.

5. Report Date

April 2020

6. Performing Organization Code

8. Performing Organization Report CA-MTI-1812

Amir Molan, PhD, https://orcid.org/0000-0002-8540-1174

Nivedha Murugesan, https://orcid.org/0000-0002-4030-6042

Alireza Shams, PhD, https://orcid.org/0000-0001-5369-1122

Cristina Tortora, PhD, https://orcid.org/0000-0001-8351-3730

Faridur Rahman, https://orcid.org/0000-0003-1443-6190

Jacky Loh, https://orcid.org/0000-0002-6769-310X

Anurag Pande, PhD, https://orcid.org/0000-0002-3456-7932

9. Performing Organization Name and Address

Mineta Transportation Institute

College of Business

San José State University

San José, CA 95192-0219

12. Sponsoring Agency Name and Address

California Department of Transportation

Division of Research, Innovation and

Systems Information

MS-42, PO Box 942873

10. Work Unit No.

Sacramento, CA 94273-0001

15. Supplemental Notes

DOI: $10.31979 / \mathrm{mti} .2020 .1812$

\section{Abstract}

Coordinated ramp metering (CRM) is a critical component of smart freeway corridors that rely on real-time traffic data from ramps and freeway mainline to improve decision-making by the motorists and Traffic Management Center (TMC) personnel. CRM uses an algorithm that considers real-time traffic volumes on freeway mainline and ramps and then adjusts the metering rates on the ramps accordingly for optimal flow along the entire corridor. Improving capacity through smart corridors is less costly and easier to deploy than freeway widening due to high costs associated with right-of-way acquisition and construction. Nevertheless, conversion to smart corridors still represents a sizable investment for public agencies. However, in the U.S. there have been limited evaluations of smart corridors in general, and CRM in particular, based on real operational data. This project examined the recent Smart Corridor implementation on Interstate 80 (I-80) in the Bay Area and State Route 99 (SR-99, SR99) in Sacramento based on travel time reliability measures, efficiency measures, and before-and-after safety evaluation using the Empirical Bayes (EB) approach. As such, this evaluation represents the most complete before-and-after evaluation of such systems. The reliability measures include buffer index, planning time, and measures from the literature that account for both the skew and width of the travel time distribution. For efficiency, the study estimates the ratio of vehicle miles traveled vs. vehicle hour traveled. The research contextualizes before-and-after comparisons for efficiency and reliability measures through similar measures from another corridor (i.e., the control corridor of I-280 in District 4 and I-5 in District 3) from the same region, which did not have CRM implemented. The results show there has been an improvement in freeway operation based on efficiency data. Post-CRM implementation, travel time reliability measures do not show a similar improvement. The report also provides a counterfactual estimate of expected crashes in the post-implementation period, which can be compared with the actual number of crashes in the "after" period to evaluate effectiveness.

\section{Key Words}

Coordinated Ramp Metering; Before-After Analysis; Travel time reliability; INRIX data; Performance Measurement System (PeMS) Data

19. Security Classif. (of this report) Unclassified

\section{Distribution Statement}

No restrictions. This document is available to the public through The National Technical Information Service, Springfield, VA 22161

20. Security Classif. (of this page)

Unclassified
21. No. of Pages

77
22. Price 


\title{
Copyright $\odot 2020$ \\ by Mineta Transportation Institute \\ All rights reserved
}

DOI: 10.31979/mti.2020.1812

\author{
Mineta Transportation Institute \\ College of Business \\ San José State University \\ San José, CA 95192-0219 \\ Tel: (408) 924-7560 \\ Fax: (408) 924-7565 \\ Email: mineta-institute@sjsu.edu
}

transweb.sjsu.edu 


\section{ACKNOWLEDGMENTS}

The authors thank Cal Poly undergraduate students Katherine Lee and Alexander Galano who helped with part of the data collection. We also thank Jose Perez from Caltrans HQ for coordinating this project and Caltrans District 3 and District 4 staff for providing data and feedback.

The authors thank Editing Press, for editorial services, as well as MTI staff, including Executive Director Karen Philbrick, PhD; Deputy Executive Director Hilary Nixon, PhD; Graphic Designer Alverina Eka Weinardy; and Executive Administrative Assistant Jill Carter.

Cover Image: Patriarca12 via Wikimedia Commons. 


\section{TABLE OF CONTENTS}

$\begin{array}{ll}\text { Executive Summary } & 1\end{array}$

$\begin{array}{ll}\text { I. Introduction } & 3\end{array}$

Ramp Metering Overview 3

Motivation and Context $\quad 5$

$\begin{array}{ll}\text { Organization of the Report } & 7\end{array}$

$\begin{array}{lr}\text { II. Literature Review } & 8\end{array}$

Ramp Metering Effectiveness $\quad 8$

Coordinated Ramp Metering $\quad 8$

Travel Time Reliability $\quad 9$

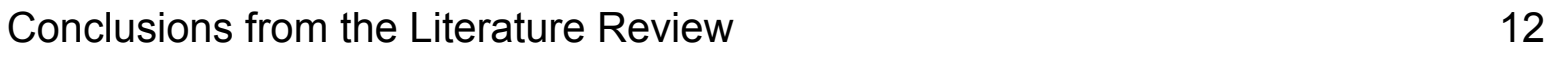

III. Operational Analysis: Travel Time Reliability 13

Data Sources 13

Analysis Corridors $\quad 13$

Analysis and Results $\quad 15$

Demand 16

Traditional Reliability Measures 16

Unreliability Indicator $\quad 29$

Conclusions from the Reliability Analysis $\quad 32$

IV. Operational Analysis: System Efficiency 34

Data, Preliminary Exploration, and Methodology 34

Analysis and Results 36

Efficiency Analysis Conclusions $\quad 46$

$\begin{array}{ll}\text { V. Safety Analysis } & 48\end{array}$

$\begin{array}{ll}\text { Research Scope } & 48\end{array}$

$\begin{array}{ll}\text { Data } & 48\end{array}$

$\begin{array}{ll}\text { Methodology } & 49\end{array}$

Safety Analysis of SR-99 Corridor $\quad 51$

Safety Analysis of I-80 Corridor 56

$\begin{array}{ll}\text { Conclusions from Safety Analysis } & 63\end{array}$

$\begin{array}{lr}\text { VI. Conclusions } & 65\end{array}$

$\begin{array}{lc}\text { Endnotes } & 66\end{array}$ 
Bibliography

70

About the Authors

75

Peer Review 


\section{LIST OF FIGURES}

1. Typical Detector Requirements for Coordinated Ramp Metering (DKS Associates, 2011)

2. Typical Single Lane Metered On-Ramp on I-80 SMART Corridor (Low, 2017) 6

3. Factors Influencing the Distribution of Travel Times 10

4. Screenshot of INRIX Insights 13

5. 19-mile Smart Corridor Project Map I-80 (Caltrans District 4)(Low, 2017) 14

6. CRM Study Corridor for SR-99 in Sacramento, CA (Caltrans District 3) 15

7. Before/After PM Peak Period Buffer Index on I-80 EB-D4 Corridor and its Control Corridor

8. Before/After AM Peak period Buffer Index on I-80 WB-D4 Corridor and its Control Corridor

9. Before/After AM Peak Period Buffer Index on SR-99 NB-D3 Corridor and its Control Corridor

10. Before/After PM Peak Period Buffer Index on SR 99 SB-D3 Corridor and its Control Corridor

11. Before/After PM Peak Period Planning Time Index on I-80 EB-D4 Corridor and its Control Corridor

12. Before/After AM Peak Period Planning Time Index on I-80 WB-D4 Corridor and its Control Corridor

13. Before/After AM Peak Period Planning Time Index on SR-99 NB-D3 Corridor and its Control Corridor

14. Before/After PM Peak Period Planning Time Index on SR 99 SB-D3 Corridor and its Control Corridor

15. Before/After PM Peak Period TTI on I-80 EB-D4 Corridor and its Control Corridor22

16. Before/After AM Peak Period TTI on I-80 WB-D4 Corridor and its Control Corridor

17. Before/After AM Peak Period TTI on SR-99 NB-D3 Corridor and its Control Corridor 
18. Before/After PM Peak Period TTI on SR-99 SB-D3 Corridor and its Control Corridor

19. Before/After PM Peak Period $\mathrm{TTI}_{80}$ on I-80 EB-D4 Corridor and its Control Corridor

20. Before/After AM Peak Period $\mathrm{TTI}_{80}$ on I-80 WB-D4 Corridor and its Control Corridor

21. Before/After AM Peak Period $\mathrm{TTI}_{80}$ on SR-99 NB-D3 Corridor and its Control Corridor

22. Before/After PM Peak Period $\mathrm{TTI}_{80}$ on SR-99 SB-D3 Corridor and its Control Corridor

23. Before/After PM Peak Period Misery Index on I-80 EB-D4 Corridor and its Control Corridor

24. Before/After AM Peak Period Misery Index on I-80 WB-D4 Corridor and its Control Corridor

25. Before/After PM Peak Period Misery Index on SR-99 NB-D3 Corridor and its Control Corridor

26. Before/After AM Peak Period Misery Index on SR-99 SB-D3 Corridor and its Control Corridor

27. Before/After PM Peak Period Unreliability Indicator on I-80 EB-D4 Corridor and its Control Corridor

28. Before/After AM Peak Period Unreliability Indicator on I-80 WB-D4 Corridor and its Control Corridor

29. Before/After AM Peak Period Unreliability Indicator on SR-99 NB-D3 Corridor and its Control Corridor

30. Before/After PM Peak Period Unreliability Indicator on SR-99 SB-D3 Corridor and its Control Corridor

31. Trends in the Efficiency Measured During the PM Peak Period from 2012 through 2017

32. Average $Q$ per Month on I-80 East

33. Time Series Decomposition of Average Monthly $Q$ Values of I-80 East 
34. Average Observed $Q$ per Month and Average Predicted $Q$ per Month on I-80 Eastbound

35. Average Observed $\boldsymbol{Q}$ per Month and Average EB Estimates of $\boldsymbol{Q}$ per Month on I-80 Eastbound

36. Average $Q$ per Month Along with Predicted Counterfactual Estimates

37. Average $Q$ per Month along with Predicted Counterfactual Estimates for SR-99 NB

38. EB-Based Before/After Evaluation Framework

39. Expected Safety Performance in Segments 1-20 of SR-99 Corridor in 2018-2020

40. Expected Safety Performance in Segments $21-40$ of SR-99 Corridor in 2018-2020

41. Figure 41. Expected Safety Performance in Segments 41-59 of the SR99 Corridor in 2018-2020

42. Number of Total Crashes Expected on the SR-99 Corridor in 2018-2020 Based on ISATe Analysis

43. Expected Safety Performance in Segments 1-20 of I-80 Corridor in 2018-2020 58

44. Expected Safety Performance in Segments $21-40$ of I-80 Corridor in 2018-202059

45. Expected Safety Performance in Segments $41-60$ of I-80 Corridor in 2018-202060

46. Expected Safety Performance in Segments $61-80$ of I-80 Corridor in 2018-202061

47. Expected Safety Performance in Segments $81-98$ of the I-80 Corridor in 2018-2020

48. Number of Total Crashes Expected on I-80 Corridor in 2018-2020 Based on Historical Crashes in 2012-2016 


\section{LIST OF TABLES}

1. $\mathrm{I}-80$ and I-280 (District 4 Corridors) Traffic Volumes from Caltrans

2. Coefficients for $\mathbf{I - 8 0}$ Eastbound Regression Model

3. Regression Model Coefficients for Estimating Q* on I-280 Using Five-Year Pre-Deployment Data

4. Correlation Between Counterfactual Estimate $Q^{*}$ and Actual Post-

Deployment Values Q on I-80 and I-280

5. Efficiency Gains on I-80 Eastbound Compared to the Counterfactual Estimates

6. Regression Model Coefficients on SR-99 NB Using Four-Year PreDeployment Data

7. Regression Model Coefficients on I-5 Using Four-Year Pre-Deployment Data

8. The Expected Safety Performance of the SR-99 Corridor Based on the ISATe Prediction Model

9. The Expected Safety Performance of the I-80 Corridor Based on the ISATe Prediction Model 


\section{EXECUTIVE SUMMARY}

Caltrans has recently implemented Coordinated Ramp Metering (CRM) algorithms on two of its corridors, I-80 in the Bay Area (District 4 (D4)) and SR-99 in the Sacramento area (District 3 (D3); NB direction during AM peak period only). With CRM, an algorithm calculates the optimal metering rate in real-time for each ramp along a corridor. This study conducted a before-and-after evaluation of the two CRM systems. The evaluation is based on travel time reliability, system efficiency, and safety measures.

For reliability and efficiency analysis, for each of the CRM corridors, the researchers identified a corresponding control corridor with no CRM from the same region similar to the CRM corridors. Following the recommendation from the Strategic Highway Research Program 2 (SHRP2) program research, the reliability measures are evaluated over the long term. Each before-and-after comparison of travel time reliability measures on the CRM corridor is examined in light of the comparison with its control corridor.

Several travel time reliability measures were estimated over each month to account for the confounding effect of seasons. These measures include Buffer Index, Planning Time Index, Travel-Time Index (based on mean and $80^{\text {th }}$ percentile travel time), and Misery Index. All these measures capture the variability or the width of the travel time distribution. In addition, the researchers explored a relatively new travel time reliability measure named Unreliability indicator (UI). The UI accounts not only for the width of the distribution but also for the skew of the travel time distribution. Accounting for skew allows the researchers to capture the relative gains made by travelers who experienced lower than usual travel time vis-à-vis travelers who experienced higher than usual travel time. Based on the analysis of these measures in the before and after period, none of the travel time reliability measures indicated consistent improvement following the implementation of the CRM.

For the efficiency analysis, the measure used was $Q$ (the ratio Vehicle Miles Traveled/Vehicle Hours Traveled ). The preliminary analysis of the $Q$ value trend was conducted on I-80 Eastbound (CRM corridor) and its control corridor I-280 Southbound in the Bay Area. The $Q$ value has displayed a declining trend since at least 2012 on both I-80 and I-280. However, since the implementation of CRM on I-80, Eastbound data showed a stabilizing trend while I-280 continued the decline in $Q$ value. An Empirical Bayesian approach was formulated to quantify the effectiveness of CRM in terms of improving efficiency. The analysis involved estimating the counterfactual $Q$ using a statistical model to predict future $Q$ values (for both CRM and the control corridor) and comparing the predicted $Q$ to the actual $Q$ value in the "after" period. The model was able to capture the "after" period $Q$ value for the control corridor but underestimated $Q$ on the CRM corridors. The difference between the model prediction and the actual $Q$ value for the CRM corridor may be attributed to CRM implementation. The analysis showed efficiency gains of over $6 \%$ for certain months in the "after" period.

The last set of analysis consisted of the before and after safety evaluations. Here the empirical Bayesian approach is the gold standard and has been recommended by the Highway Safety Manual (HSM). The critical component of the approach is to obtain the counterfactual estimate of the number of crashes obtained using a negative binomial regression model from reference sites and trends from the CRM corridor itself. Based 
on the analysis, the counterfactual estimates of crashes per year on the 1-80 and SR99 were 1,882 and 1,724 crashes, respectively. These estimates may be compared with actual long-term crash counts ( $\sim 3$ years) from the "after" period to estimate the safety effectiveness of CRM on either corridor.

In conclusion, the CRM systems in Districts 3 and 4 have made significant improvements in terms of system efficiency. However, travel time reliability indicators don't show consistent improvement. Estimation of safety improvements requires additional crash data collected over the next two years to be compared with the counterfactual estimates provided here. 


\section{INTRODUCTION}

Smart corridors that implement various Intelligent Transportation Systems (ITS) technologies are a key component of addressing congestion issues, especially in regions where freeway expansion is not a feasible option.

This research analyzed coordinated ramp metering systems implemented by Caltrans in two districts, District 4 in the Bay Area and District 3 in the Sacramento area. In District 4 , the algorithm was implemented on a 19-mile section of I-80. Interstate 80 (I-80) is a transcontinental freeway connecting the two major metropolitan areas of San Francisco and New York City. In the San Francisco Bay Area in northern California, the freeway serves as a heavily traveled corridor connecting the San Francisco Bay Area with Sacramento. In the Bay Area, the 19-mile section between the Carquinez Bridge and the I-80/I-580/I-880 interchange (near the San Francisco-Oakland Bay Bridge) is one of the most congested and heavily traveled corridors in the region with over 270,000 vehicles per day. The freeway ranges in width from four to five lanes per direction, including a High Occupancy Vehicle (HOV) lane in effect during peak commute times requiring three or more persons per vehicle. The California Department of Transportation (Caltrans) estimates there are 4 to 5 collisions and 16,000 vehicle-hours of delay each day. Furthermore, an estimated $25 \%$ of congestion is incident-related. ${ }^{1}$

In District 3, CRM is implemented on California State Route 99 (SR-99; Northbound direction only) in Sacramento between Elk Grove and the SR50 interchange after $12^{\text {th }}$ Ave (CA PostMile 10 to 32.767; or Absolute Post-Mile 284.57 to 299.467) during AM peak period (6 AM to 9 AM). It is a 13-mile-long corridor with 16 on-ramps and 11 off-ramps.

The researchers examined the effects of CRM on travel time reliability, efficiency, and safety. Additionally, new measures of travel time reliability are analyzed using data from the study corridors. Analysis of travel time reliability in addition to efficiency is critical. As noted by the Federal Highway Administration (FHWA), many drivers either adjust their schedules or budget extra time to allow for traffic delays but are less tolerant of unexpected delays. ${ }^{2}$ This makes travel time reliability an important performance measure to consider.

\section{RAMP METERING OVERVIEW}

First implemented in 1963 on Chicago's Eisenhower Expressway, ramp metering is now a widely used active traffic management technique. Ramp metering regulates on-ramp flows before and during congestion, breaks up platoons, and smoothly converts multiple on-ramp lanes to one. It is generally considered to be one of the most cost-effective freeway management strategies. ${ }^{3}$

\section{Ramp Metering Strategies}

There are three primary methods for determining metering rates, each requiring different infrastructure investments. ${ }^{4}$ With fixed time ramp metering, the rate is programmed by time of day based on historical patterns. Typically used in locations with predictable traffic conditions, the equipment required for this strategy is the simplest but does not allow for any 
optimization based on actual traffic conditions. As a result, meter violation rates are typically the highest when using a fixed time strategy. For example, on a day when congested conditions end earlier than usual, a fixed time meter would continue using a restrictive metering rate, causing unnecessary delay and emissions at the ramp and likely resulting in user frustration.

With Local Traffic Responsive ramp metering, freeway mainline detectors in the vicinity of the ramp determine its metering rate. The controller utilizes pre-defined relationships between freeway flow and ramp demand. Ramps are treated as discrete units rather than as part of a system. Violation rates are more reasonable with this strategy, because it responds intelligently to current conditions by, for example, using a higher metering rate when freeway flow is lower. This strategy can utilize a predictive algorithm that anticipates the onset of freeway congestion and proactively adjusts the metering rate.

With Coordinated Ramp Metering (CRM) (also referred to as System-wide Adaptive Ramp Metering or SWARM), an algorithm calculates the optimal metering rate in real-time for each ramp along a corridor, often with the ultimate goal of controlling a bottleneck. While it is similar to Local Traffic Responsive ramp metering, CRM uses a virtual intelligence engine to deploy a response strategy based on modeled conditions. CRM can also help with freeway incidents by using more restrictive metering upstream of the incident and less restrictive metering downstream.

A CRM system operates by detecting traffic speed and volume immediately upstream and downstream of the on-ramp, as well as the on-ramp traffic volume. It also communicates with ramp metering nodes at upstream locations to determine the volume and speed of freeway traffic approaching the on-ramp. The system then coordinates the regulation of on-ramp traffic along the corridor to prevent the loss of freeway capacity. Metering rates are adjusted based on conditions on the freeway downstream of the on-ramp, conditions on the freeway at the on-ramp, and conditions on the on-ramp itself.

The CRM system is controlled from a traffic operations center, where the controllers can be remotely overridden or reprogrammed. CRM necessitates the most complex hardware and software of the three ramp metering strategies. Requirements include detectors upstream and downstream of the ramps, a communication medium, and a central computer linked to the ramps. The detector technologies must measure vehicle volume, occupancy, and speed. A downstream detector may also be used as the upstream detector for the next location in cases where ramps are spaced in relatively close proximity. The typical detector requirements for CRM are shown schematically in Figure 1. 


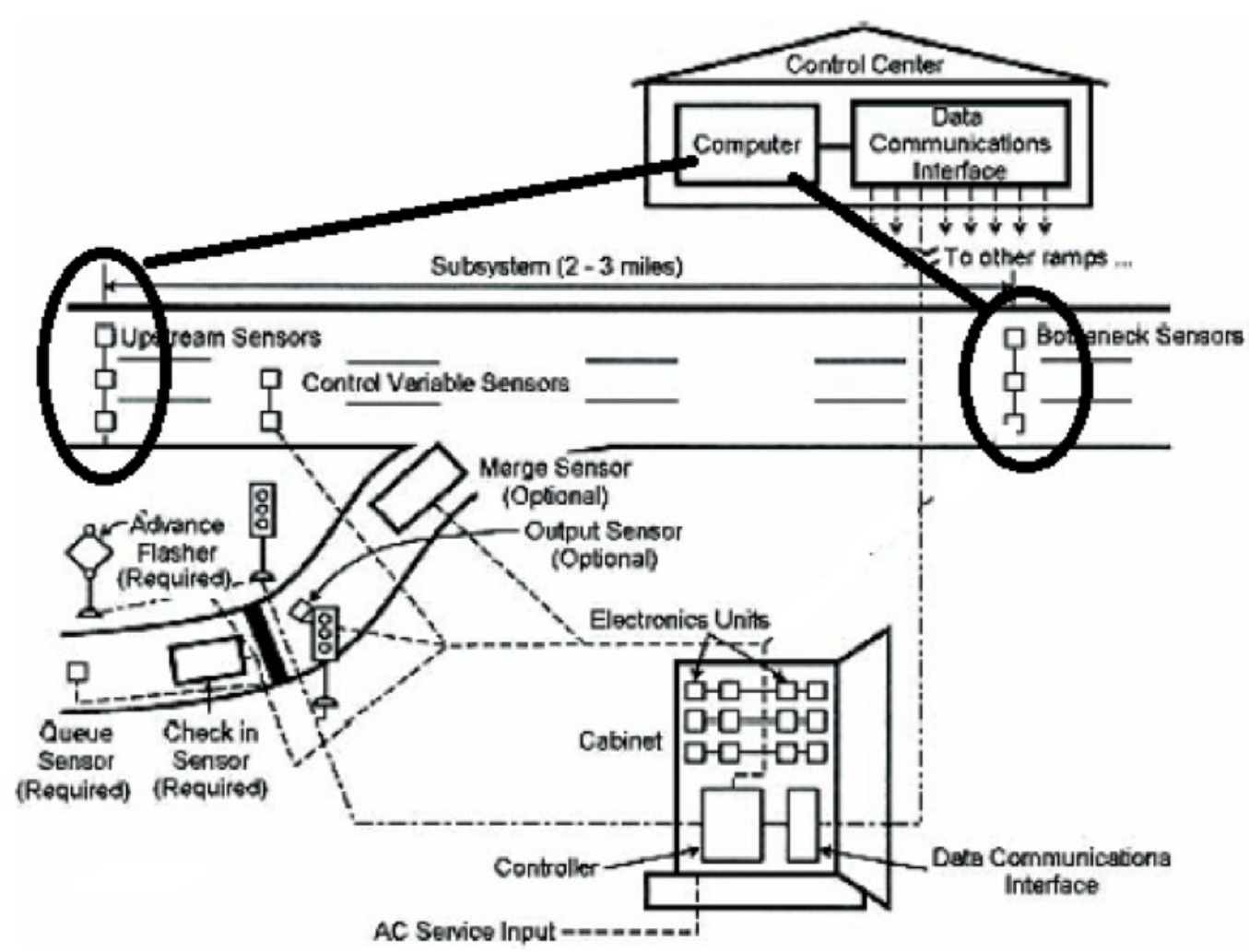

Figure 1. Typical Detector Requirements for Coordinated Ramp Metering (DKS Associates, 2011)

All three of these ramp metering strategies can be made responsive to queues spilling back onto local streets. Queue length detectors can be implemented at the upstream end of the on-ramp to alert the ramp meter when the queue is about to spill into the local cross street. The ramp meter then adjusts its rate accordingly.

\section{Ramp Metering in California}

The California Department of Transportation (Caltrans) states in their Ramp Metering Design Manual $^{5}$ and their Ramp Metering Development Plan ${ }^{6}$ that they are committed to using ramp metering as an effective traffic management strategy. Caltrans considers ramp metering to be an integral strategy for reducing congestion, reducing travel times, and increasing safety. Ramp metering is used to maintain efficient operations by keeping freeways operating at or near capacity, thus optimizing the transportation system for travelers. Caltrans uses ramp metering as a part of a coordinated and integrated traffic management system; it is consistent with their goal of maximizing capacity while providing good stewardship of public investment and minimizing environmental impacts.

\section{MOTIVATION AND CONTEXT}

For numerous reasons, freeway widening would have been a poor choice for the study corridors. For example, much of the freeway right-of-way is physically constrained by fully developed communities or by environmentally sensitive areas bordering San Francisco Bay. The estimated cost to widen would have been prohibitive, in the hundreds of millions of 
dollars. ${ }^{7}$ Regardless of cost, freeway widening would likely have been politically unpopular as well as ineffective over time. The congested nature of the corridors means that adding capacity would have likely induced even more demand, such as from choice transit users or from drivers who currently shift their trips to off-peak periods.

An Active Traffic Management (ATM) system was identified by Caltrans as the best solution for the corridor, addressing recurring congestion as well as incidents and being a sustainable transportation infrastructure investment. The project goals for the ATM system were to optimize corridor performance, provide real-time information to users, improve travel time reliability, improve access for first responders, and reduce secondary collisions and their related congestion.

Even though ramp metering has been used throughout California and the San Francisco Bay Area for decades, the study corridor in District 4 was historically never included under a ramp metering system due to complicated political and institutional concerns. With CRM instrumentation installed and operational along the study corridor, it has become the first Bay Area corridor to utilize CRM rather than Local Traffic Responsive ramp metering. The project's construction work included installing ramp meters on 43 on-ramps in total, plus "end of queue" detectors and, in a few instances, preferential HOV lanes.

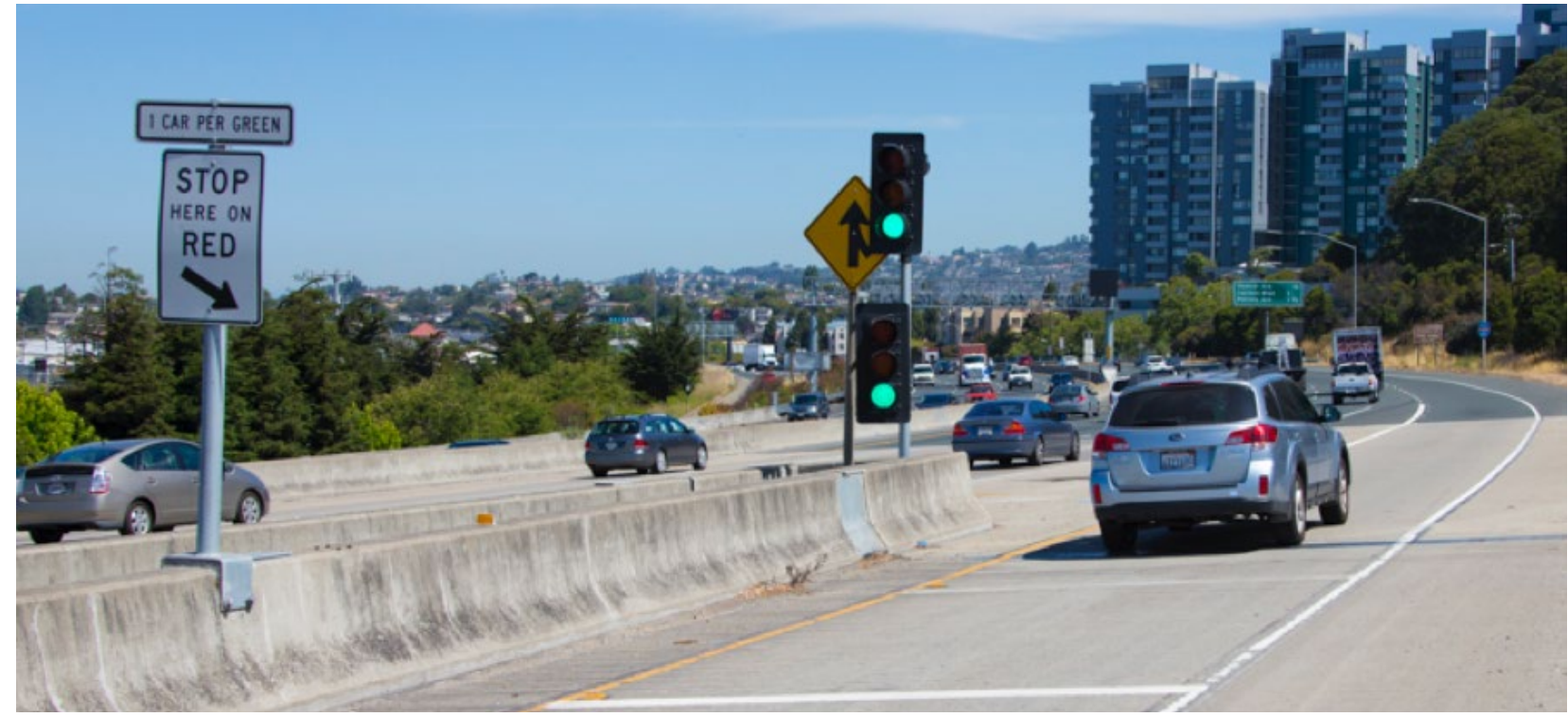

Figure 2. Typical Single Lane Metered On-Ramp on I-80 SMART Corridor (Low, 2017)

On I-80 in District 4, the ramp meters were first activated in July 2016 with Local Traffic Responsive ramp metering. The CRM system of operation began in April $2017 .{ }^{8}$ All traffic operations for the project corridor, including the CRM system, are controlled from the Caltrans/ California Highway Patrol Traffic Management Center in Oakland.

For this project, the investigators, in consultation with the local sponsor, determined two ways to evaluate the performance of the CRM system implemented as part of the Smart Corridor:

- The operational performance was estimated using parameters such as average speed, average travel time, and most critically travel time reliability. Data from INRIX 
and Caltrans PeMS are utilized to estimate these parameters before and after the implementation of the project.

- System Efficiency measured using the ratio of Vehicle Miles Traveled (VMT) and Vehicle Hours Traveled (VHT) (i.e., Q). A higher value of this ratio indicates better system efficiency since it is a measure of space mean speed (SMS).

- Change in safety index after CRM implementation as measured using the Empirical Bayes approach, which is the gold standard for measuring the change in safety.

\section{ORGANIZATION OF THE REPORT}

The chapter following this introduction provides a review of the literature on Coordinated Ramp Metering, System Performance, Travel Time Reliability, and before-and-after safety evaluation. Chapter 3 provides the results of the analysis to evaluate the travel time reliability parameters before and after the implementation of CRM. Chapter 3 also details the source of the data, the scope of the study area, and the methodologies used for estimating operational performance. Chapter 4 provides results from the efficiency analysis conducted as part of this project. Chapter 5 provides the details of the empirical Bayes approach adopted for the safety evaluation of CRM along with the results. Chapter 6 draws conclusions about the effectiveness of the CRM system. 


\section{LITERATURE REVIEW}

This literature review covers studies looking at the general effectiveness of ramp metering, studies looking specifically at Coordinated Ramp Metering, and various studies of travel time reliability measures. As noted in the introduction, the study also involves a user opinion survey, and therefore a review of the literature on that subject is also provided.

\section{RAMP METERING EFFECTIVENESS}

Implementing ramp metering has been found to be a worthwhile investment and has resulted in benefits including increased speeds, reduced travel times, reduced collisions, and reduced emissions. ${ }^{9}$

Despite these benefits, the public often perceives ramp meters as an unnecessary impediment, resulting in the systems being unpopular. In Twin Cities of Minneapolis and St. Paul, Minnesota ramp meters had been in use since 1969 to optimize freeway safety and efficiency, though their effectiveness was being questioned following increases in congestion and meter wait times. To assess the effectiveness of the existing system in MN the ramp meters were shut off for eight weeks. The MN study found numerous benefits from ramp metering in the metro area. ${ }^{10}$ The use of ramp metering resulted in a $22 \%$ savings in freeway travel time and a $14 \%$ increase in freeway throughput. Throughout the system, collisions increased by $26 \%$ without ramp metering. For the entire congestion management system, the benefit:cost ratio was determined to be 5:1. Traveler surveys showed an increased appreciation for ramp metering after the shut-off, though they also revealed support for modifications, including shortened wait times. Another study of the shutoff investigated several performance measures with and without the ramp meters. ${ }^{11}$ It was found that the ramp meters were particularly helpful for long trips relative to short trips. Another finding was that the ramp meters reduced travel time variation. The authors of the $\mathrm{MN}$ study recommended a more refined ramp control algorithm that explicitly considers ramp delay [2] .

\section{COORDINATED RAMP METERING}

One of the first tests in California of Coordinated Ramp Metering occurred in Los Angeles County and found increases in mainline speed, decreases in travel time, and reductions in freeway delay compared to the existing local mainline responsive strategy. ${ }^{12}$ The greatest benefits occurred when using a combined global and local ramp metering strategy. In a simulation model of CRM on the I-405 freeway in southern California, it was found that Coordinated Ramp Metering can reduce freeway congestion effectively compared to a fixedtime control..$^{13}$ It was also found that ramp metering becomes less effective under incident scenarios with severe traffic congestion.

A study of a newly deployed Coordinated Ramp Metering system in Portland, Oregon found mixed results, with an increase in freeway delay possibly being traded for lower onramp delay. ${ }^{14} \mathrm{~A}$ study in Australia found that a CRM strategy led to a significant increase in throughput and reduction of travel times compared with the previous metering system. ${ }^{15}$

A simulation model of an adaptive system in Minnesota found that freeway performance 
was compromised in favor of reducing ramp delays. A Dutch CRM algorithm was simulated and found to outperform non-coordinated metering. ${ }^{16}$ Another coordinated ramp metering algorithm was implemented in Germany and showed promising results. ${ }^{17}$

Despite the valuable results found in past studies, it is essential to conduct new studies to evaluate the performance of CRMs in locations with different contexts. The driver population and cultural differences could affect system compliance. Therefore, the outcomes may not be similar to the past studies.

\section{TRAVEL TIME RELIABILITY}

Most of the studies involving field evaluations of ramp metering in the U.S. have focused on measures of on-ramp delays, mainline delays, fuel consumption, and resulting emissions. This research will instead focus on assessing the effects of ramp metering on measures of travel time reliability. Several relevant studies of travel time reliability are examined in detail below.

\section{Assessments of Traditional Measures}

In some of the earliest research into travel time reliability measures for use as practical performance measures, Lomax and colleagues grouped measures into three broad categories based on differences in communication and calculation: Statistical Range, Buffer Time Measures, and Tardy Trip Indicators. ${ }^{18}$ The study recommended the following measures for travel time reliability evaluations: Percent Variation, Misery Index, and Buffer Time Index.

Pu compared numerous reliability measures and explored their mathematical relationships. ${ }^{19}$ It was found that the coefficient of variation, instead of the standard deviation, is a good proxy for several other measures. It was also found that, especially in cases where travel time distributions are heavily skewed, the average-based buffer index or average-based failure rate is not always appropriate. In these cases, the author recommends the medianbased buffer index or failure rate (percent of on-time arrival).

\section{New Measure Based on Width and Skew of Travel Times}

Van Lint, Van Zuylen, and Tu challenged existing travel time reliability measures, based predominantly on the variance of travel times, and proposed a new measure based on both width and skew. ${ }^{20}$ Their research included an empirical investigation of a 19-km study segment on the A20 freeway in The Netherlands with a free-flow travel time of around 11 minutes.

First, a schematic overview of factors influencing the distribution of travel times was presented (shown below in Figure 3). The authors note that the list is not exhaustive. 


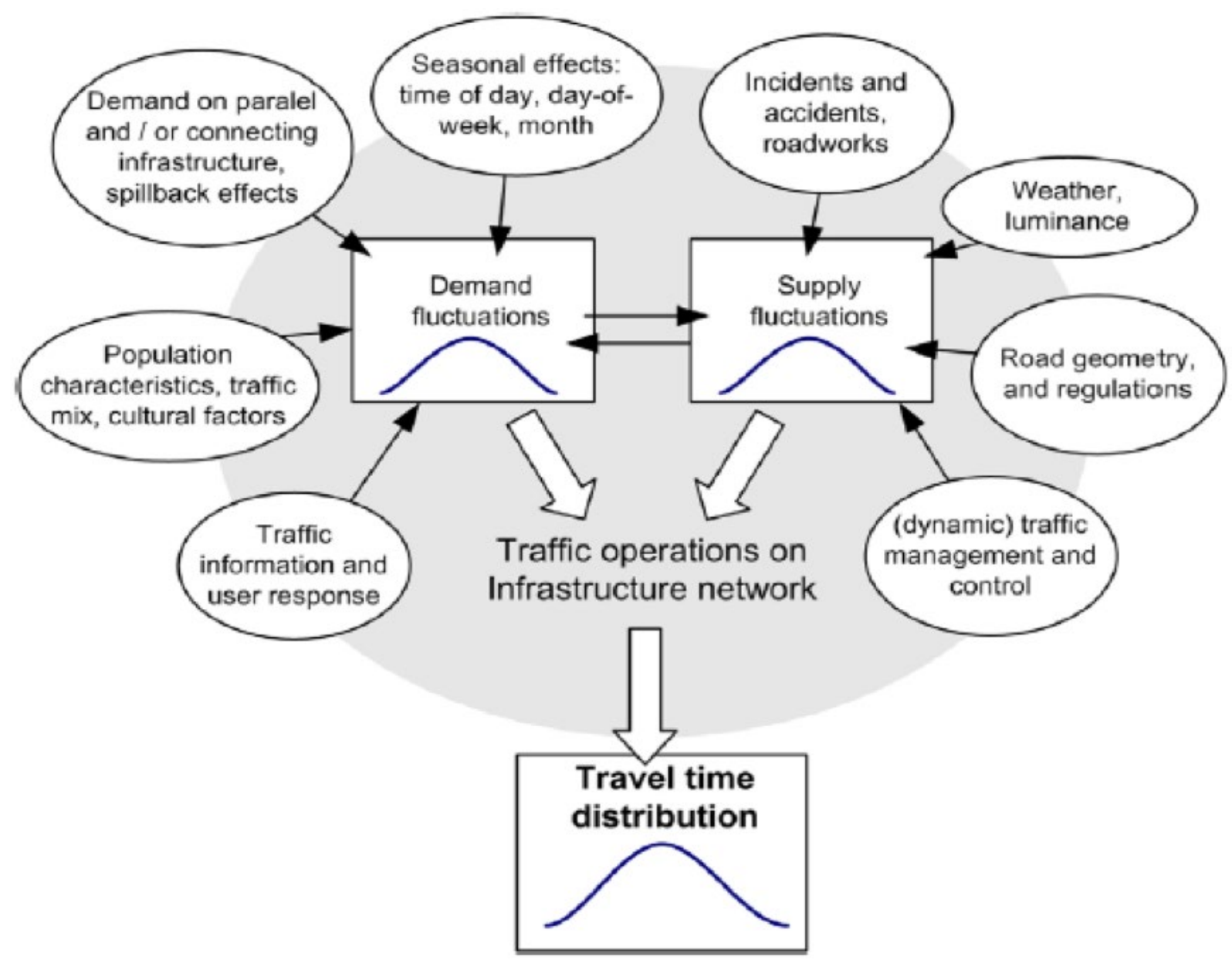

Figure 3. Factors Influencing the Distribution of Travel Times ${ }^{21}$

Their empirical investigation supported the claim that heavy skewing in travel distributions can have substantial economic consequences. For example, in 2002, close to 350,000 travelers traversed the study segment on Thursday afternoons between 5:00 and 6:00 pm. It was found that the $5 \%$ most delayed travelers had encountered more than 25 minutes of delay, amounting to more than 17,000 travelers incurring at least 7,200 hours of delay in total. Similarly, approximately $7,500-8,000$ hours of delay had been incurred by the $50 \%$ least delayed travelers. Therefore, the authors argue, this left-skewed travel time distribution is extremely undesirable, especially since extremely long delays are likely to have much more serious consequences than modest delays. They conclude that not only the variance but also the skewness should guide reliability discussions.

A new measure for travel time reliability based on both width and skew was derived: namely, Unreliability Indicator (UIr) ${ }^{22}$. The measure incorporates two new percentile-based indicators for width and skew that are insensitive to outliers. Ulr can be interpreted as the likelihood, relative to the median, of incurring a very high travel time.

\section{Assessment of the Unreliability Indicator}

Bhouri, Aron, and Kauppila assessed travel time reliability following hard shoulder running implementation on the A4-A86 motorway in France. ${ }^{23}$ The study segment is $3 \mathrm{~km}$ in length. 
The authors stated that a smaller planning time increases driver satisfaction. Even if planning time does not decrease, a smaller buffer time implies greater reliability.

The authors then addressed the lambda-var and lambda-skew indicators proposed by Van Lint et al ${ }^{24}$ used to measure, respectively, the width and the skew of a travel time distribution. They report that the lambda-var indicator is robust for both reliability and congestion. However, the lambda-skew indicator was found to have a weakness, since the travel time in non-congested traffic, used in the calculation, was determined largely by the roadway's automatic speed control systems. The authors concluded that UIr was therefore not an effective indicator since it incorporates lambda-skew.

\section{Effects of Ramp Metering Strategy}

Bhouri, Haj-Salem, and Kauppila evaluated the ramp metering on the A6W motorway in France by studying the impacts on traffic and travel time reliability. Their focus was on reducing daily uncertainty in travel times to provide travelers with greater consistency. ${ }^{25}$ The evaluation used measurements of traffic volume, occupancy rate, and speed in addition to estimated travel time. The paper compared the reliability and travel time impacts of two different freeway ramp metering strategies: ALINEA, a local strategy that maintains freeway density around the critical value, and CORDIN, a coordinated strategy.

Four traffic indices were considered: Total Time Spent (TTS), expressed in vehicles times hours; Total Travel Distance (TTD), expressed in vehicles times kilometers; Mean Speed, defined as TTD/TTS; and Travel Time, calculated using the real speed measurements of consecutive measurement stations. Congestion mapping of iso-occupancy curves in space and time was drawn using the loop detector occupancy measurements and the real data collection time slice of 6 minutes. Several reliability measures were considered: Standard Deviation and Coefficient of Variation; Buffer Time and Planning Time; Misery Index; and Probabilistic Indicators.

The field test site comprised a 20-km motorway with five on-ramps. Traffic flow, occupancy rate, and speed measurement stations were available at roughly $500-\mathrm{m}$ spacing intervals. The three strategies (No Control, ALINEA, and CORDIN) were applied over alternate weeks for about 16 months. Data were then extracted from the traffic management system database and screened to discard major detector failures, atypical traffic patterns (weekends and holidays), and significant traffic incidents. Demand variation impacts were minimized by averaging the selected days for each strategy.

The evaluation results for the traffic indices, examining the period of 6:00-11:00 am, showed that CORDIN performed better than ALINEA. Both metering strategies improved TTS and TTD compared to No Control. The quantitative results of the TTS indices were qualitatively confirmed. The CORDIN strategy was found to give better results for Total Travel Time.

Studying travel time variability, both ALINEA and CORDIN were found to reduce the average travel time and the travel time variability, with no significant differences between the resulting daily variabilities of the two. Depending on the measure used, both metering strategies reduced travel time variability by $24-37 \%$. For both, the planning time was reduced by 
about 14 minutes. Since the mean travel time only improved by 3-4 minutes with metering, the authors argued that the reduced travel time variability, evidenced by the planning time, should be the main improvement from the user perspective. The implication for our work is to evaluate CRM systems not just in terms of system efficiency but also in travel time reliability.

\section{CONCLUSIONS FROM THE LITERATURE REVIEW}

Several previous studies investigating Coordinated Ramp Metering were simulation-based. In this study, the researchers examine its effectiveness empirically with long-term data. The primary performance measures used in this study relate to travel time reliability, since users typically plan for expected delays but are less tolerant of unexpected delays. Overall, the impact of Coordinated Ramp Metering as part of Smart Corridor implementation on travel time reliability and efficiency has not been thoroughly studied in the U.S. context. Hence, this study is important not just for the evaluation of the specific Caltrans systems but for addressing this gap in the scientific literature. 


\section{OPERATIONAL ANALYSIS: TRAVEL TIME RELIABILITY}

\section{DATA SOURCES}

Travel time data for this research have been obtained from INRIX Insights (see Figure 4) using probe vehicle data. INRIX Insights provides data fields for speed, travel time, and several user-oriented travel time reliability measures. Data are available down to oneminute granularity. INRIX Insights provides additional data visualization and retrieval tools which allow for the analysis of bottlenecks, traffic incidents and events, and the cost of delays. The suite of tools is meant to allow agencies to support operations, planning, analysis, research, and performance measures generation. The focus is on providing effective information on metrics that departments of transportation can use to communicate with the public or decision-makers.

Region Explorer
Explore the relationships between bottlenecks and traffic
events in real-time and in the past.
Tutorial I FAQ

\section{Figure 4. Screenshot of INRIX Insights}

The data on operational measures (VMT, VHT, and $Q$ for segments) are obtained from the Caltrans' PeMS system. PeMS provides cleaned historical five-minute data for any instrumented freeway segment in California.

\section{ANALYSIS CORRIDORS}

The analysis corridor in District 4 (D4) begins at the Powell Street eastbound off-ramp just after the I-80/I-580/I-880 interchange, and it ends at the Pomona Street on-ramp, just before the Carquinez Bridge, for a total distance of 19 miles. The extent of the project corridor is shown in Figure $5 .{ }^{26}$ Also, to create a baseline for the analysis measures, a corridor that did not have the CRM implemented was also selected. I-280 in San José was chosen as the comparison or control segment due to similar traffic patterns in the PM peak periods and similar land use in surrounding neighborhoods. Both I-280 and I-80 will 
experience similar weather patterns. The extent of the I-280 segment (the comparison corridor for Caltrans D4) analyzed is from the CA 85/I-280 interchange to the I-280 offramp to $S 11^{\text {th }}$ Street for a total of about 11 miles.

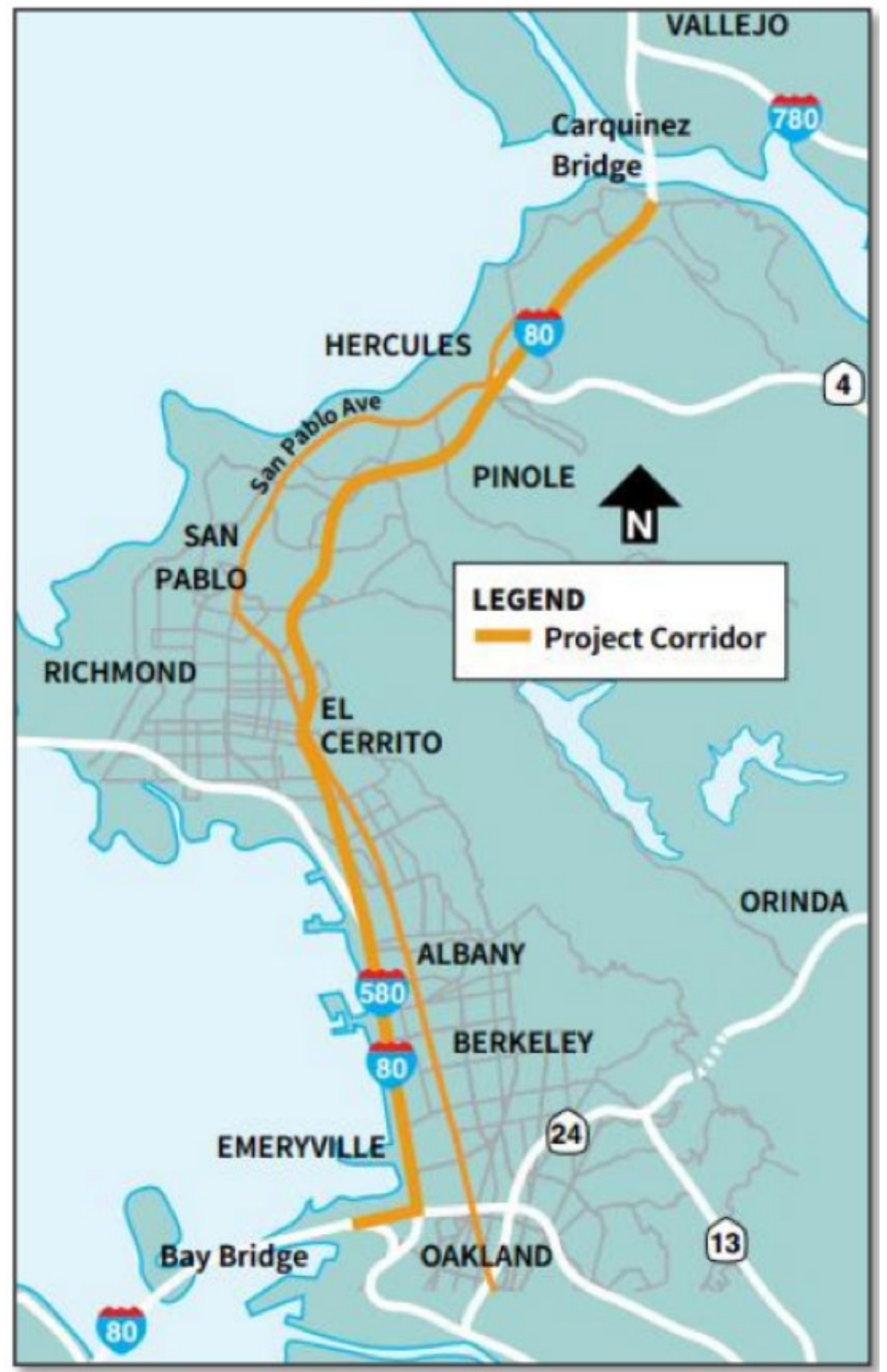

Figure 5. 19-mile Smart Corridor Project Map I-80 (Caltrans District 4)(Low, 2017) 


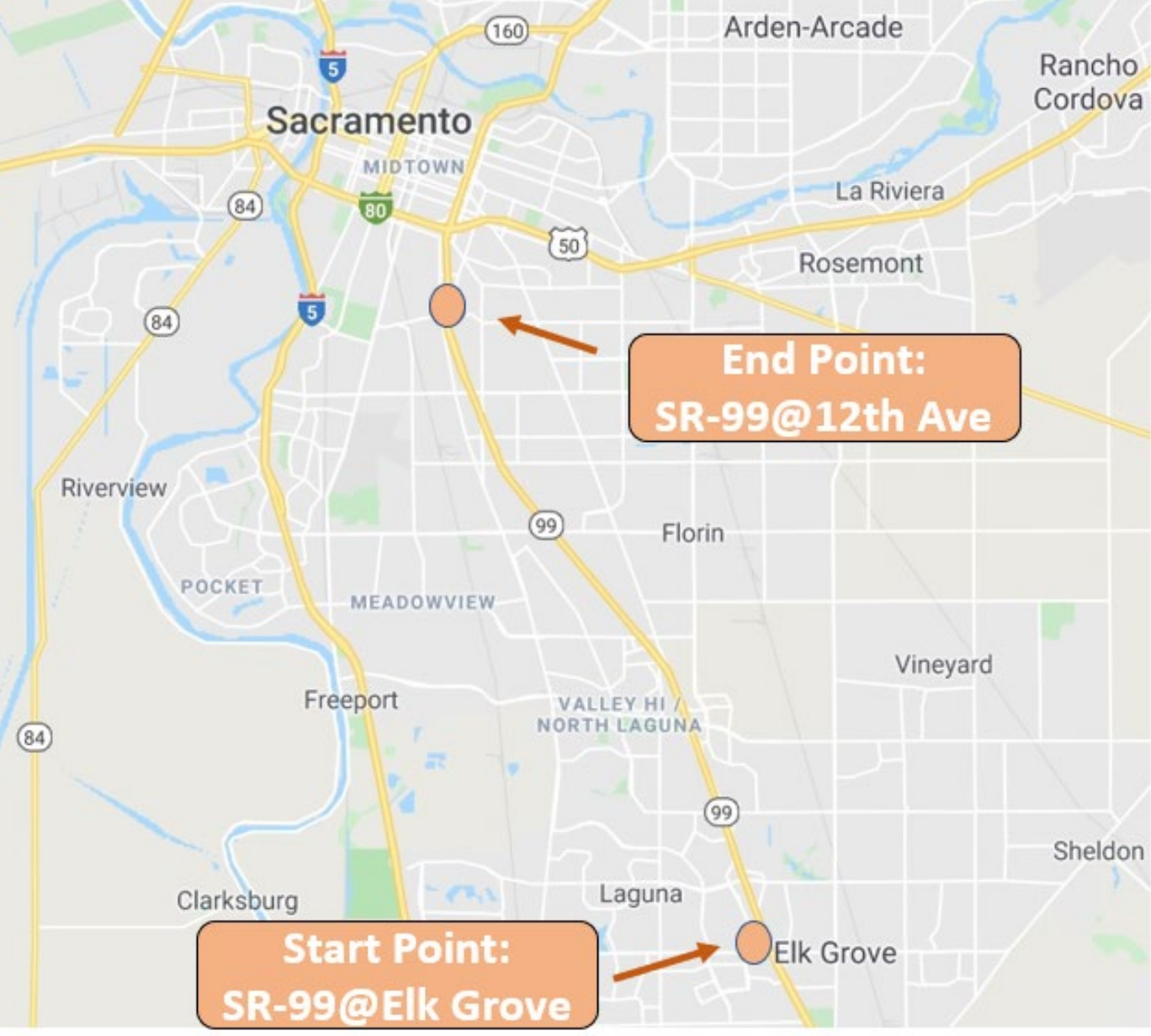

Figure 6. CRM Study Corridor for SR-99 in Sacramento, CA (Caltrans District 3)

To capture the most typical commute congestion patterns, the data analyzed in this research represent a typical weekday (Monday, Tuesdays, Wednesdays, and Thursdays). Data are analyzed for all months separately.

In District 3 (D3), CRM is implemented on California State Route 99 (SR-99; Northbound AM Peak period only) in Sacramento between Elk Grove and the SR50 interchange after $12^{\text {th }}$ Ave (CA Post-Mile 10 to32.767; or Absolute Post-Mile 284.57 to 299.467). It is a 13-mile-long corridor with 16 on-ramps and 11 off-ramps. The comparison corridor for SR-99 was the I-80 corridor in District 3. The extent of the CRM corridor is shown in Figure 6.

\section{ANALYSIS AND RESULTS}

The results in this section are organized by the travel time reliability measures. First, each travel time reliability measure is introduced; then, before-and-after comparison of each measure is depicted in a graph for the treatment corridor (i.e., corridor with CRM) and control corridor (i.e., corridor in the same district without CRM) for "before" and "after" periods. The results are shown by peak period/direction: for instance, PM peak period for I-80 Eastbound, and AM peak period for SR-99 Northbound. For the treatment corridors, the analysis involves an examination of long-term averages of travel time 
reliability measures over a five-year period (when available).

The CRM system on the I-80 was officially started in April 2017. Similarly, for SR-99, the CRM was implemented in October 2016 only in the Northbound direction during AM peak hours. The months of January, April, July, and October was chosen to represent the seasonal variation of travel behavior. These months were chosen because they are typical of the four seasons and they avoid significant holiday commute patterns like Thanksgiving and Christmas. For each of the four corridors, I-80 EB-D4, I-80 WB-D4, SR-99 NB-D3, and SR 99 SB-D3, peak direction and hours were identified and compared to the peak direction and hours of the comparison (or control) corridor. Change in the reliability measures on the control corridors provided context for the observed change on the CRM corridors. Note that while the results for the before-after period here are reported for SR 99 SB-D3 during PM peak period for completeness; no CRM system is implemented during PM peak period on SR 99 and hence no real improvement was expected for this corridor.

\section{DEMAND}

Traffic volume data from Caltrans at several points along the I-80 study corridor as well as the control corridor from 2012 to 2017 showed a pattern of generally increasing demand, as shown in Table 1.27

Table 1. I-80 and I-280 (District 4 Corridors) Traffic Volumes from Caltrans

\begin{tabular}{c|c|c|c}
\hline \multicolumn{4}{|c}{ Annual Average Daily Traffic (AADT) } \\
\hline \multirow{2}{*}{ Year } & \multicolumn{3}{|c}{ I-80 } \\
\cline { 2 - 4 } & West of Ashby & West of Pinole Valley & West of Pomona \\
\hline 2012 & 270,000 & 185,000 & 112,000 \\
\hline 2013 & 270,000 & 185,000 & 112,000 \\
\hline 2014 & 277,000 & 189,000 & 116,000 \\
\hline 2015 & 270,000 & 188,000 & 118,000 \\
\hline 2016 & 270,000 & 173,000 & 118,000 \\
\hline 2017 & 283,000 & 182,000 & 124,000 \\
\hline \multirow{2}{*}{ Year } & & $\underline{\mathbf{l - 2 8 0}}$ & North of CA 87 \\
\cline { 2 - 4 } & North of CA 85 & North of I-880 & 193,000 \\
\hline 2012 & 137,000 & 181,000 & 193,000 \\
\hline 2013 & 137,000 & 181,000 & 187,000 \\
\hline 2014 & 140,000 & 185,000 & 191,000 \\
\hline 2015 & 143,000 & 189,000 & 195,000 \\
\hline 2016 & 149,000 & 195,000 & 213,000 \\
\hline 2017 & 155,000 & 177,000 & \\
\hline
\end{tabular}

\section{TRADITIONAL RELIABILITY MEASURES}

In this section, the researchers discuss travel time reliability measures (buffer index, planning time index, travel time index, misery index, and UI) that are recommended by SHRP 2 research, the rationale for which was described in the Introduction section. Some 
of these measures were also estimated by Low. ${ }^{28}$

\section{Buffer Index}

Buffer Time (BT) refers to the time travelers should add to average travel time to account for unexpected delays on the route in order to arrive at the destination on-time $95 \%$ of the time..$^{29}$ Buffer Time Index (BI) is the ratio of buffer time and mean travel time. It is calculated by taking the difference of $95^{\text {th }}$ percentile travel time $\left(T_{95}\right)$ and mean travel time $(M)$ and dividing the difference by mean travel time (M). The equation for Buffer Time is as follows:

$$
\mathrm{BI}=\frac{\mathrm{T}_{95}-\mathrm{M}}{\mathrm{M}}
$$

Equation 1

Buffer Time is an estimate of how much time commuters should add to their typical commute to reliably be on time. Buffer Index is a percent of mean travel time. For example, if the $\mathrm{BI}$ is 0.25 or $25 \%$ and the mean travel time is 20 minutes, the buffer time is five minutes $(25 \%$ of 20 minutes). In this case, the traveler should allocate 25 minutes total to arrive at their destination on time $95 \%$ of the time. Since lower BI results in a smaller proportion of mean travel time, a lower value of $\mathrm{BI}$ is preferred.

Figures 7 through 10 show Buffer Index values for CRM corridors and their respective control corridors for four representative months.

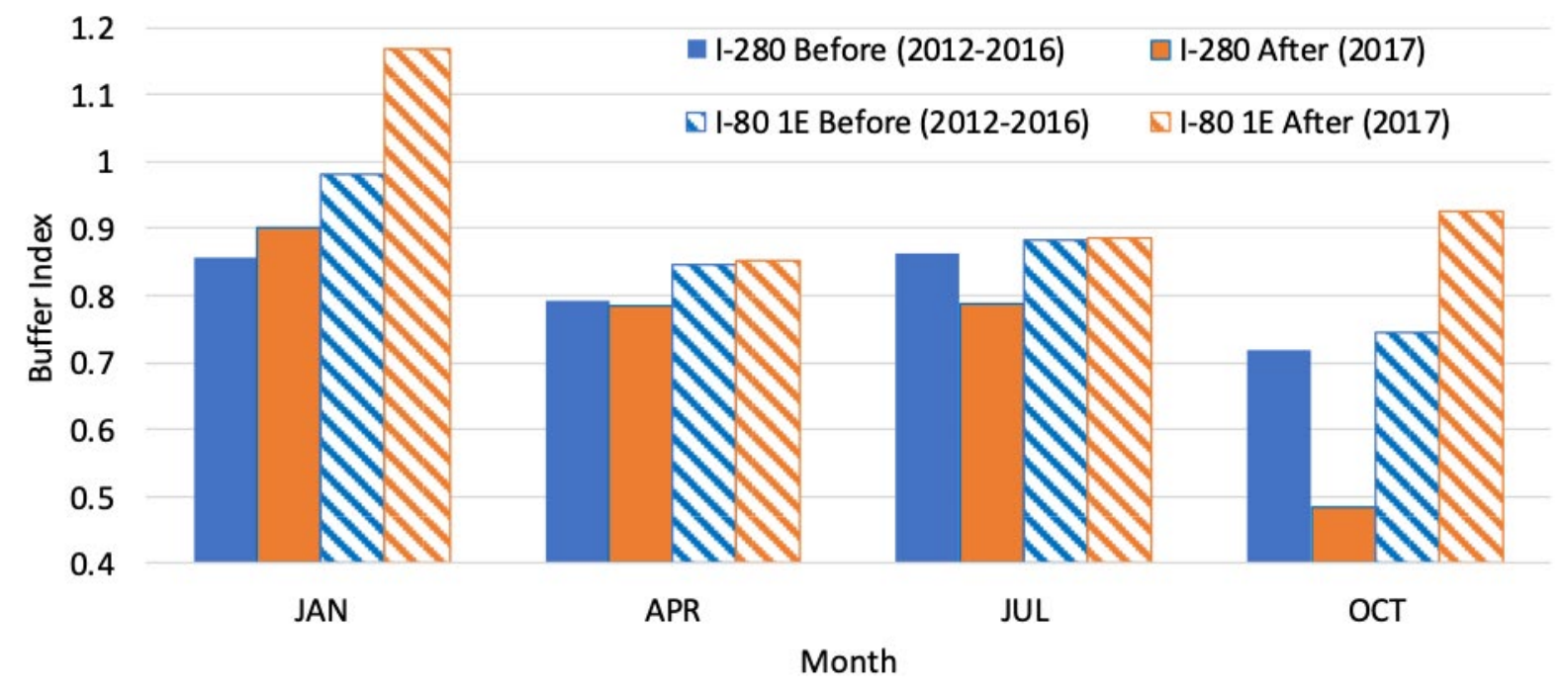

Figure 7. Before/After PM Peak Period Buffer Index on I-80 EB-D4 Corridor and its Control Corridor

On I-80 EB-D4, the Buffer Index (BI) in the "after" period increased for the months of January and October. On the control corridor, the Buffer Index had a smaller increase in the month of January and a decrease in the month of October. For months of April and July, there is no difference in the BI during the "before" and "after" period. 


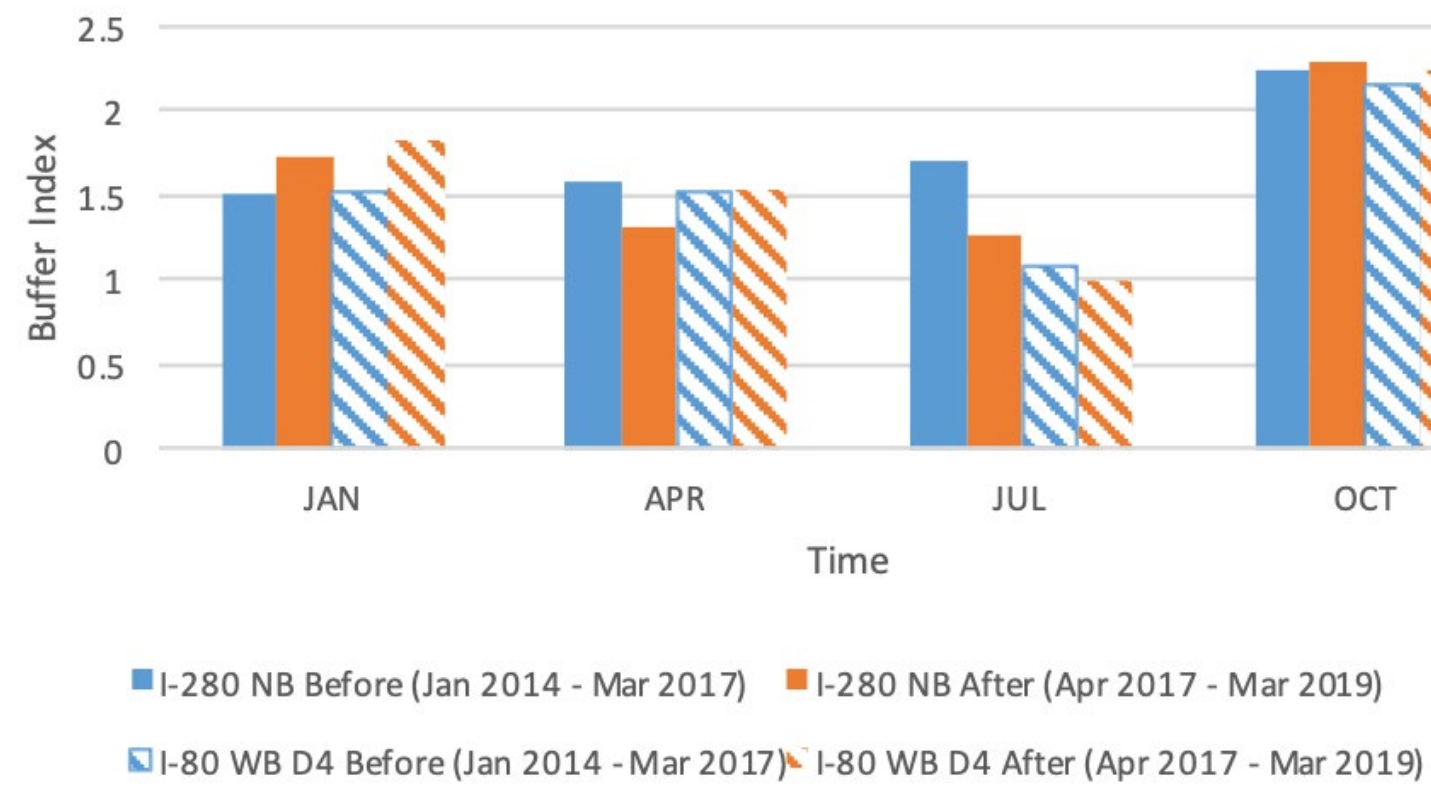

Figure 8. Before/After AM Peak period Buffer Index on I-80 WB-D4 Corridor and its Control Corridor

For the I-80 WB-AM peak period, the "after" CRM BI decreased for the month of July but increased for the months of January, April, andOctober. A similar decrease in $\mathrm{Bl}$ for the month of July was also noticed for the control corridor (Figure 8). This indicates that one may not attribute the decrease in $\mathrm{BI}$ in the month of July to the CRM implementation.

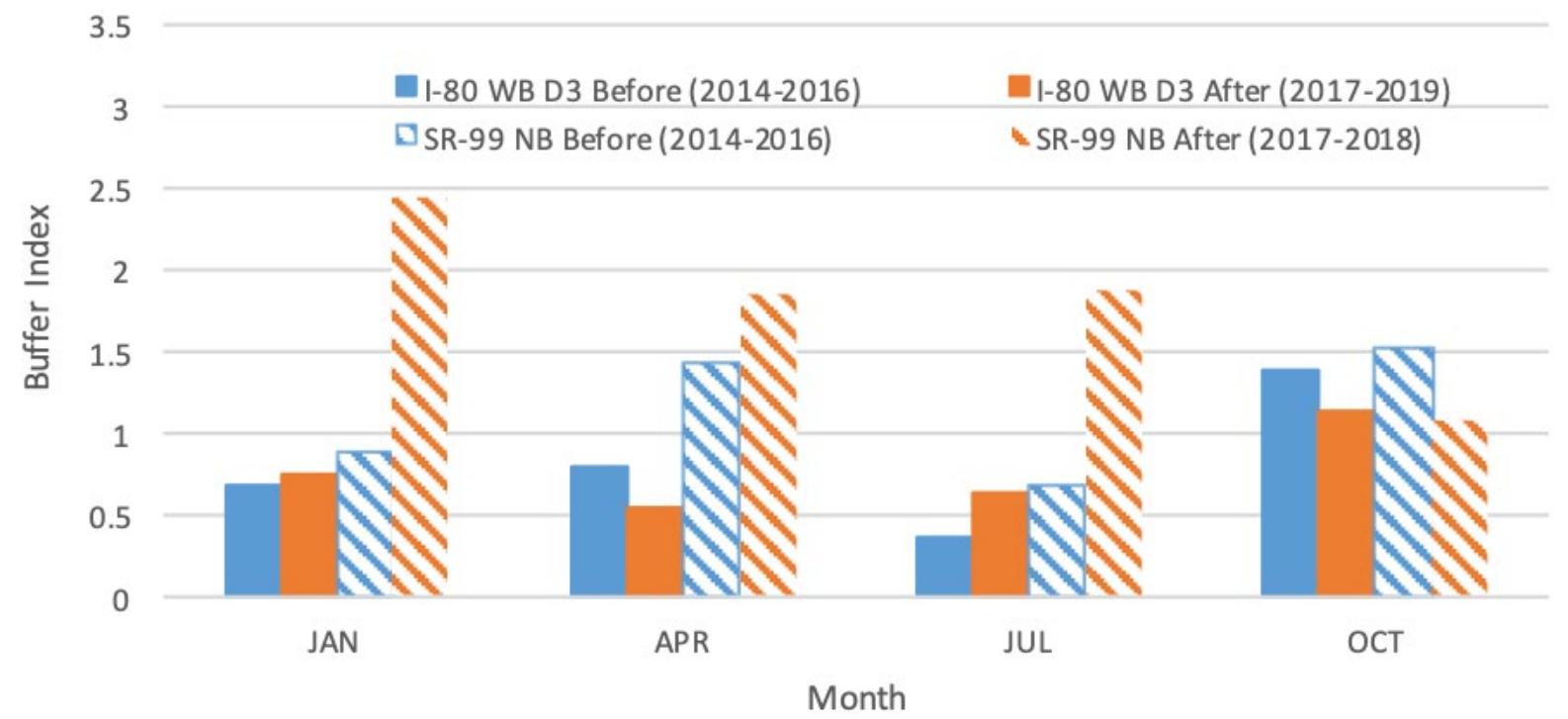

Figure 9. Before/After AM Peak Period Buffer Index on SR-99 NB-D3 Corridor and its Control Corridor

In District 3, SR-99 NB, there was a similar pattern. The BI decreased for the month of October, but the decrease may not be attributable to CRM since a similar decrease was observed for the control corridor as well (Figure 9). It should be noted that there was no CRM implemented during the PM peak period for SR 99. Hence, during the PM peak hour, one would expect no patterns of improvement in the SB direction (Figure 10). There was, in fact, an increase in BI on SR-99 SB-D3 during the PM peak period. 


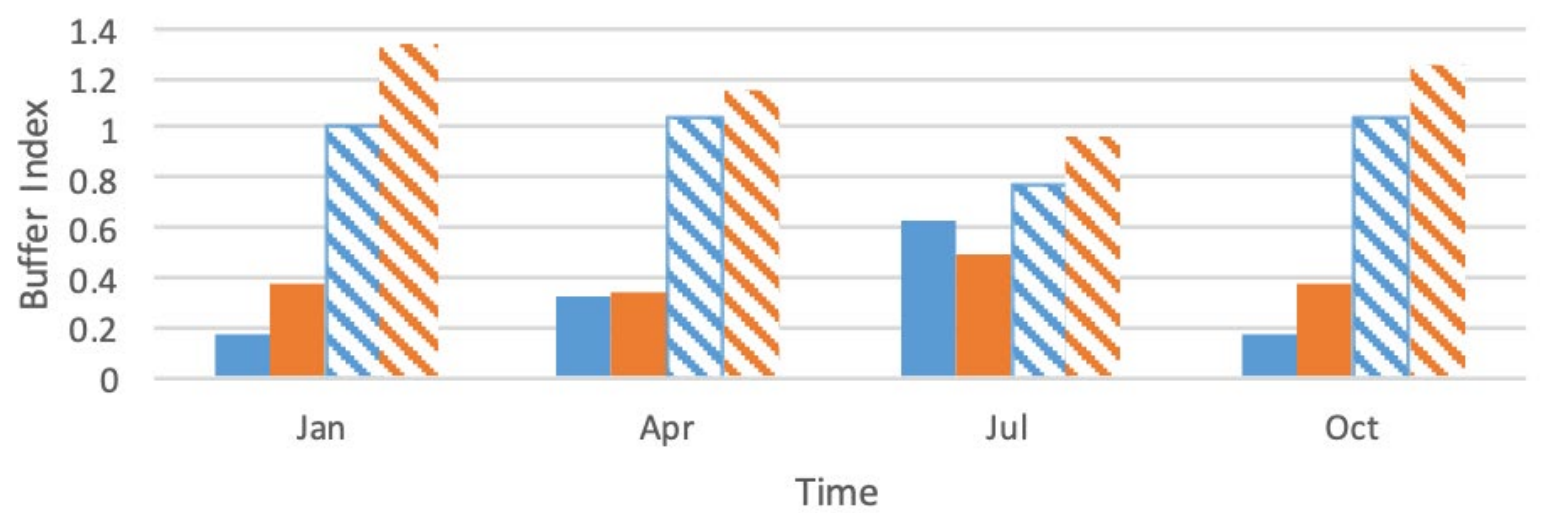

I-80 EB D3 Before (Jan 2014 - Sept 2016)= I-80 EB D3 After (Oct 2016 - Sept 2018)

口SR-99 SB Before (Jan 2014 - Sept 2016) SR-99 SB After (Oct 2016 - Sept 2018)

Figure 10. Before/After PM Peak Period Buffer Index on SR 99 SB-D3 Corridor and its Control Corridor ${ }^{1}$

Overall, there is no evidence of a significant impact of $\mathrm{CRM}$ on $\mathrm{BI}$, since the patterns observed on CRM corridors are similar to what is seen on the corresponding control corridors.

\section{Planning Time Index}

Planning Time (PT) is the total time required to ensure on-time arrival $95 \%$ of the time. Ontime travel is determined by the free-flow travel time, which is based on the free-flow speed. The research team determined free-flow speed by taking the spatially weighted average of observed speed at a non-peak hour. The planning time index is the percent of free-flow time required to ensure on-time arrival $95 \%$ of the time. For example, if a segment has a freeflow travel time of 10 minutes and the planning time index (PTI) is 1.5, then the total time that should be allocated to reach a destination on-time $95 \%$ of the time (planning time) is 15 minutes. The buffer methods use the $95^{\text {th }}$ percentile value of the travel time distribution as a reference for their definitions. As a result, the extreme values of travel time delay play a key role in the buffer method. ${ }^{30}$ Since the planning time index is a percent of free-flow travel time, minimizing it would result in better reliability (i.e., lower PTI means more reliability). The PTI is calculated by dividing $95^{\text {th }}$ percentile travel time $\left(T_{95}\right)$ by free-flow travel time $\left(T_{f f}\right)$ :

$$
\mathrm{PTI}=\frac{\mathrm{T}_{95}}{\mathrm{~T}_{\mathrm{ff}}}
$$

Equation 2

Figures 11 through 14 show PTI values for CRM corridors and their respective control corridors for four representative months. Data from I-80 show an increase or no change in the PTI values for all four months shown in Figures 11 and 12. SR-99 NB-D3 (Figure 13) in the month of October is the only corridor that shows a reduction in the PTI value after CRM implementation. However, a similar decrease is observed in the control corridor as well during the same period. Hence, the reduction in PTI is not attributable to CRM. Regarding

1. Note that SR 99 did not have CRM implemented during PM peak period and hence no difference should be expected between case and control corridor. 
Figure 14, it should be mentioned that no CRM was implemented on SR 99 during the PM peak period.

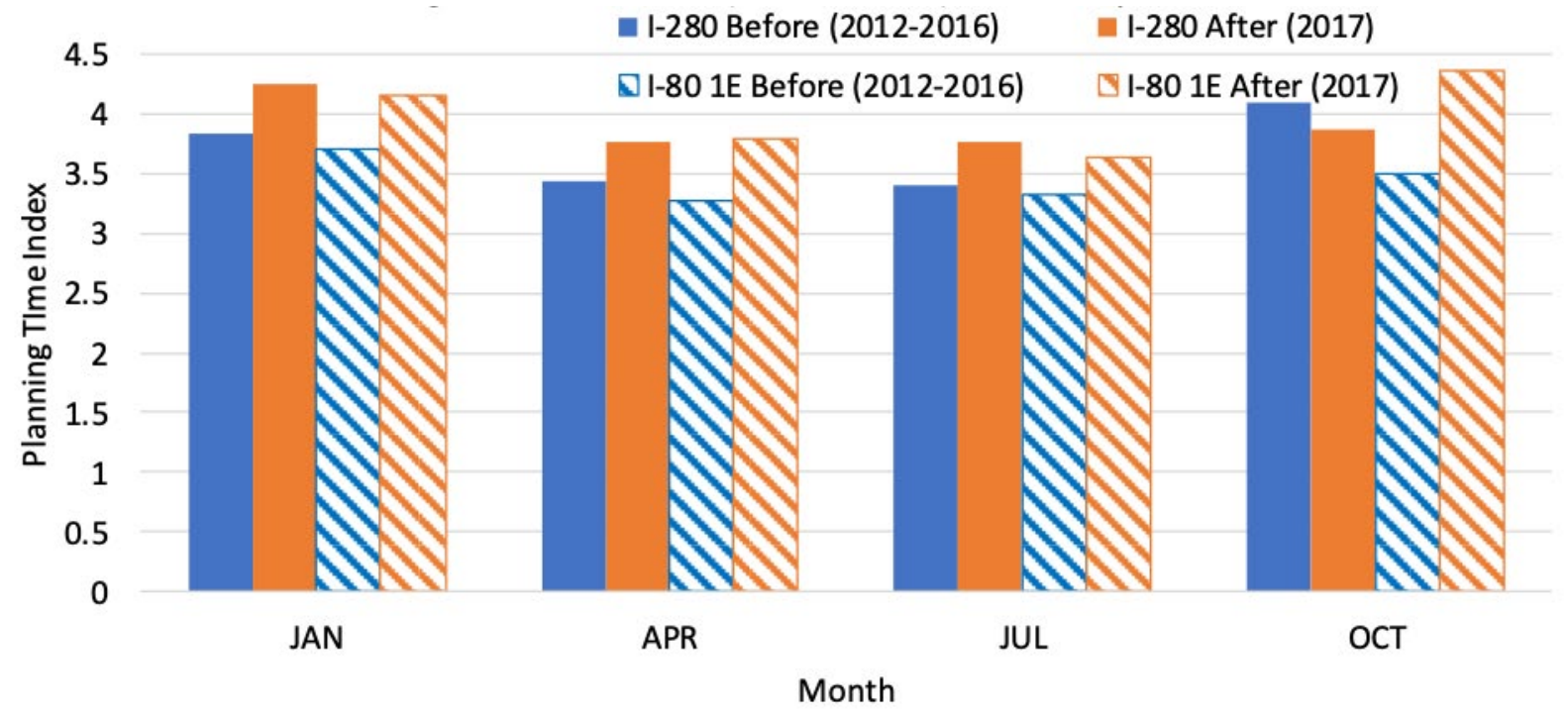

Figure 11. Before/After PM Peak Period Planning Time Index on I-80 EB-D4 Corridor and its Control Corridor

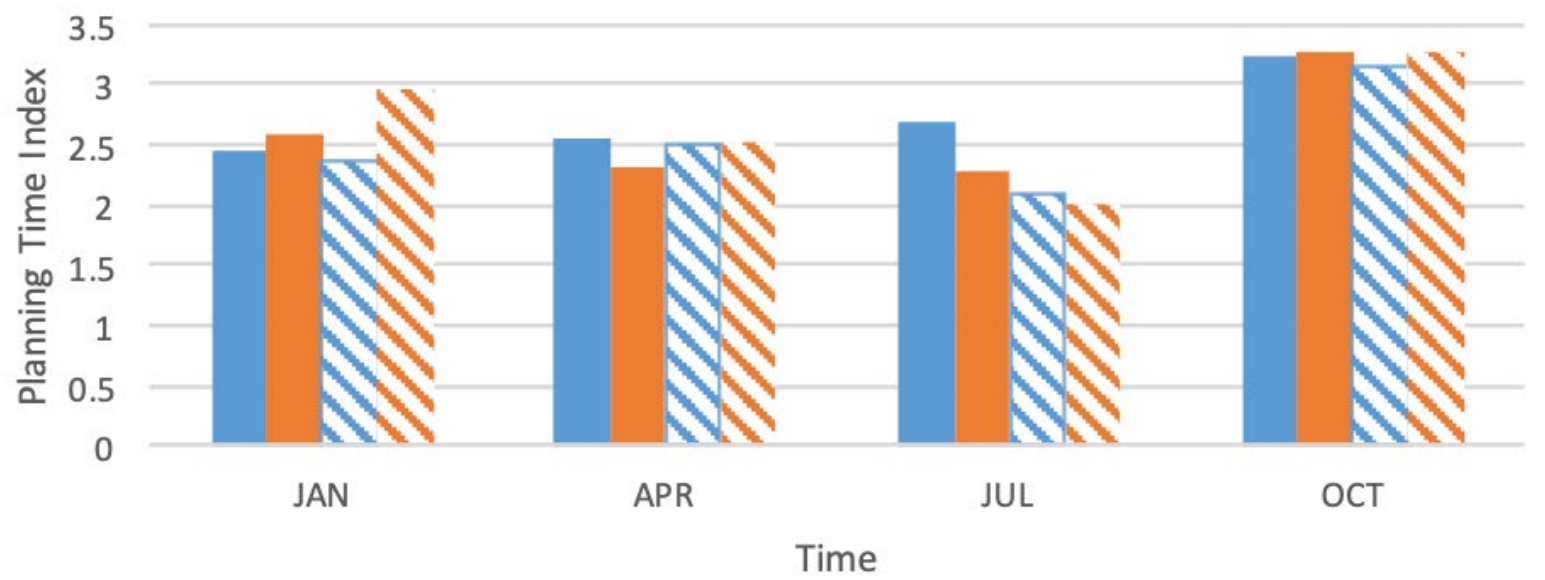

- I-280 NB Before (Jan 2014 - Mar 2017) I-280 NB after (Apr 2017 - Mar 2019)

I-80 WB D4 Before (Jan 2014 - Mar 2017)ㄴ I-80 WB D4 After (Apr 2017 - Mar 2019)

Figure 12. Before/After AM Peak Period Planning Time Index on I-80 WB-D4 Corridor and its Control Corridor 


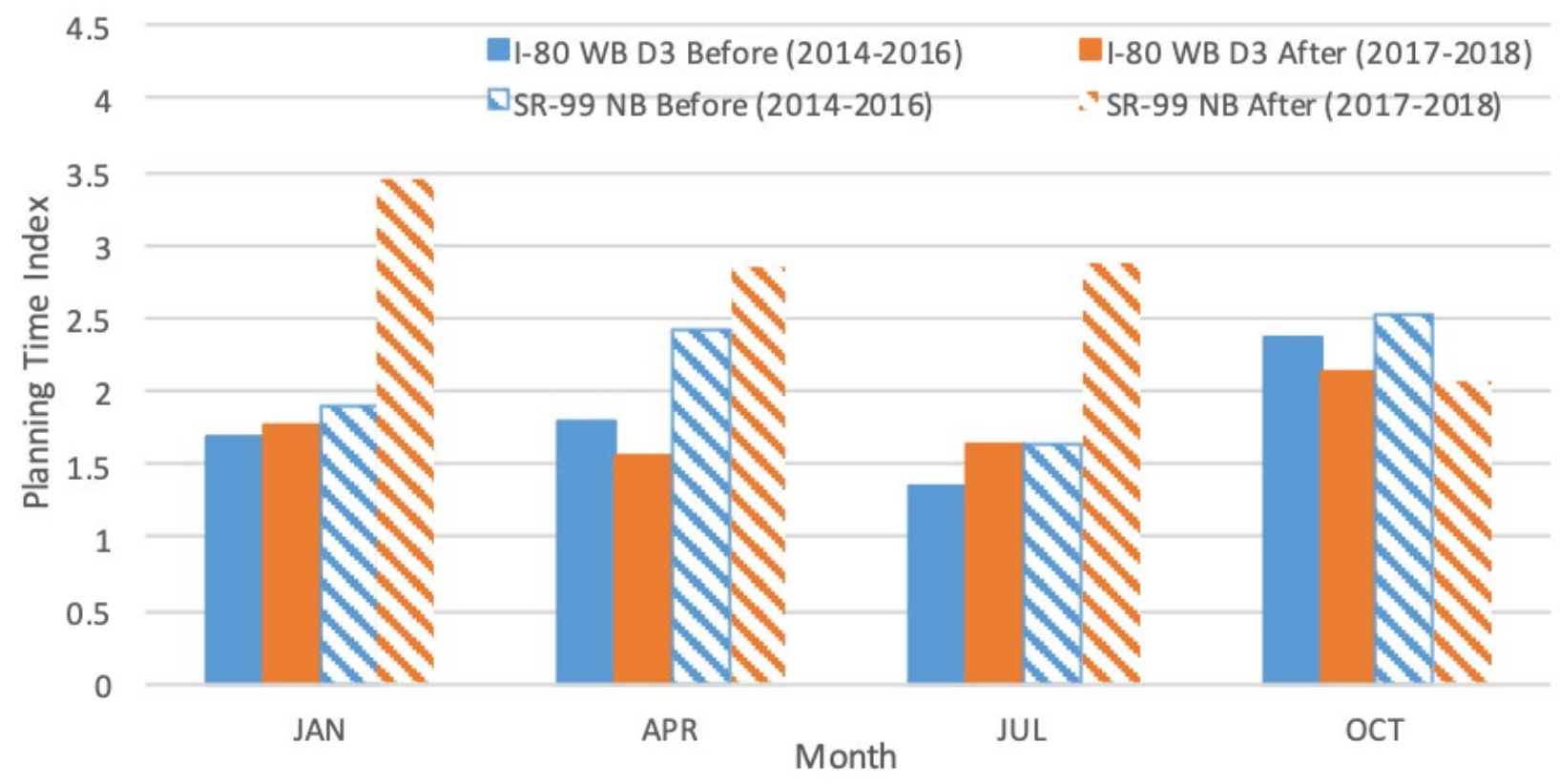

Figure 13. Before/After AM Peak Period Planning Time Index on SR-99 NB-D3 Corridor and its Control Corridor

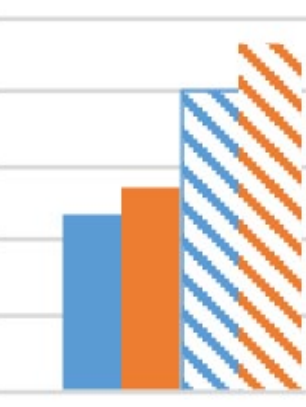

Jan

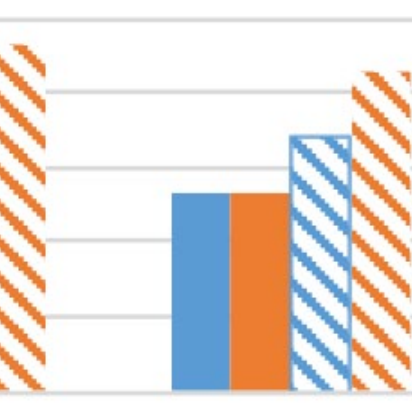

Apr

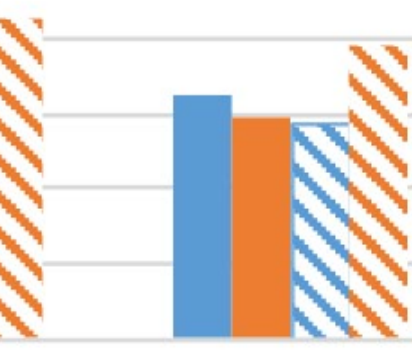

Jul

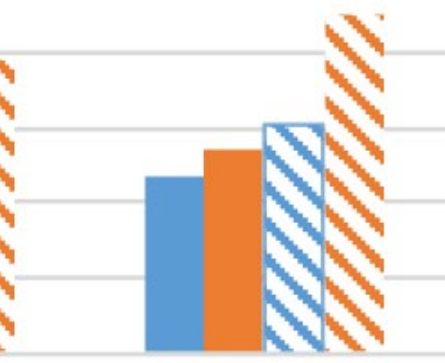

Oct

Time

- I-80 EB D3 Before (Jan 2014 - Sept 2016) I-80 EB D3 After (Oct 2016 - Sept 2018)

DSR-99 SB Before (Jan 2014 - Sept 2016) SR-99 SB After (Oct 2016 - Sept 2018)

Figure 14. Before/After PM Peak Period Planning Time Index on SR 99 SB-D3 Corridor and its Control Corridor ${ }^{2}$

\section{Travel Time Index (Mean Travel Time Based)}

Travel Time Index (TTI) generally compares an observed travel time to the free-flow travel time. For the I-80 corridor, one of the Travel Time Indices (TTIs) that was looked at is TTI

2. Note that SR 99 did not have CRM implemented during PM peak period and hence no difference should be expected between case and control corridor. 
based on mean observed travel time $\left(\mathrm{TTI}_{\text {mean }}\right)$. This measure will show the percent of freeflow travel time that the average user experiences during congestion. For example, if a segment has a free-flow travel time of 10 minutes and the $\mathrm{TTI}_{\text {mean }}$ is 1.5 , then the average user is experiencing a travel time of 15 minutes during congestion. Since smaller values of $\mathrm{TTI}_{\text {mean }}$ lead to less total travel time, $\mathrm{TTI}_{\text {mean }}$ should be minimized. $\mathrm{TTI}_{\text {mean }}$ can be calculated by dividing average travel time $\left(T_{\text {mean }}\right)$ by free-flow travel time $\left(T_{f f}\right)$ :

$$
T T I_{\text {mean }}=\frac{T_{\text {mean }}}{T_{f f}}
$$

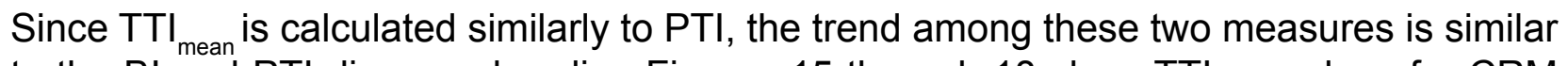
to the $\mathrm{BI}$ and PTI discussed earlier. Figures 15 through 18 show TTI mean values for CRM corridors and their respective control corridors for four representative months. $\mathrm{TTI}_{\text {mean }}$ either increased or was virtually unchanged in the after-CRM period on the treatment corridors, indicating no significant improvement in reliability post-CRM.

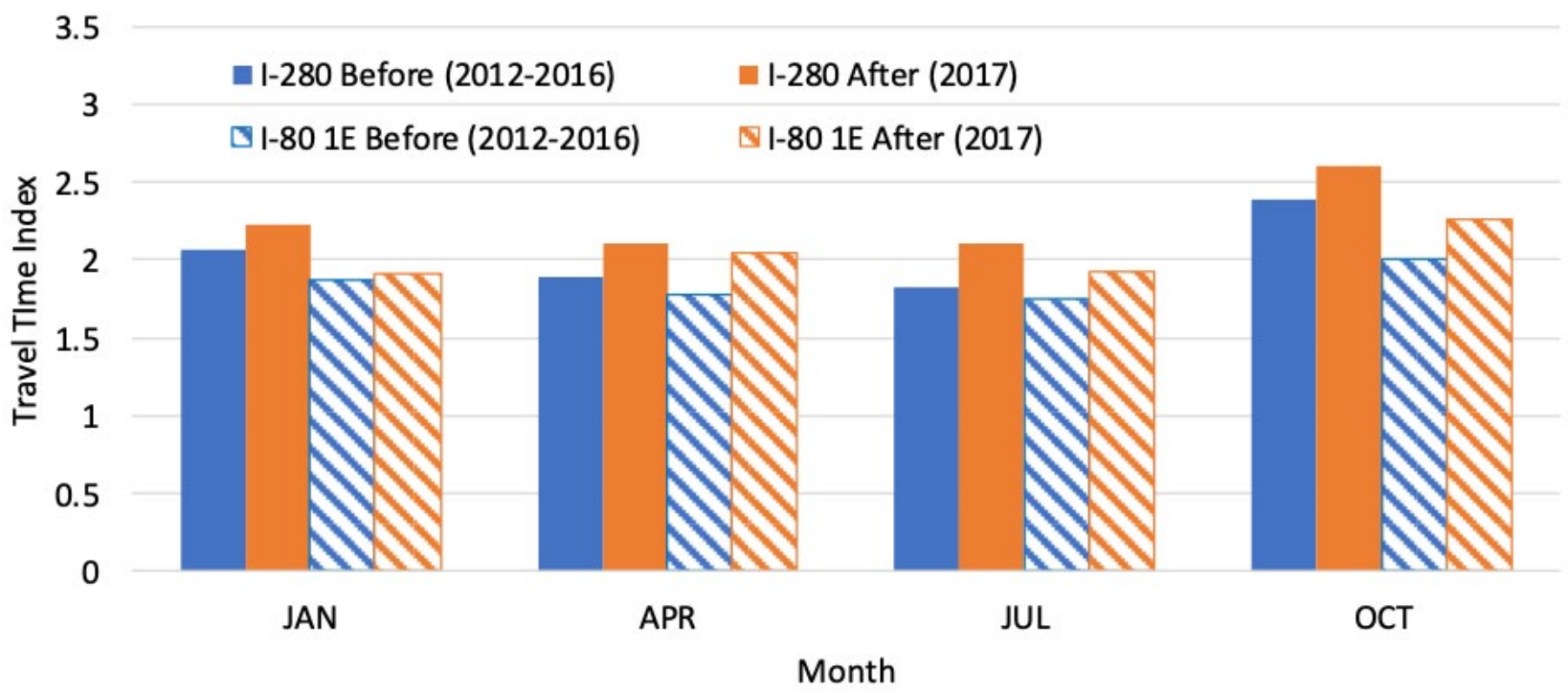
Figure 15. Before/After PM Peak Period TTI on I-80 EB-D4 Corridor and its
Control Corridor 


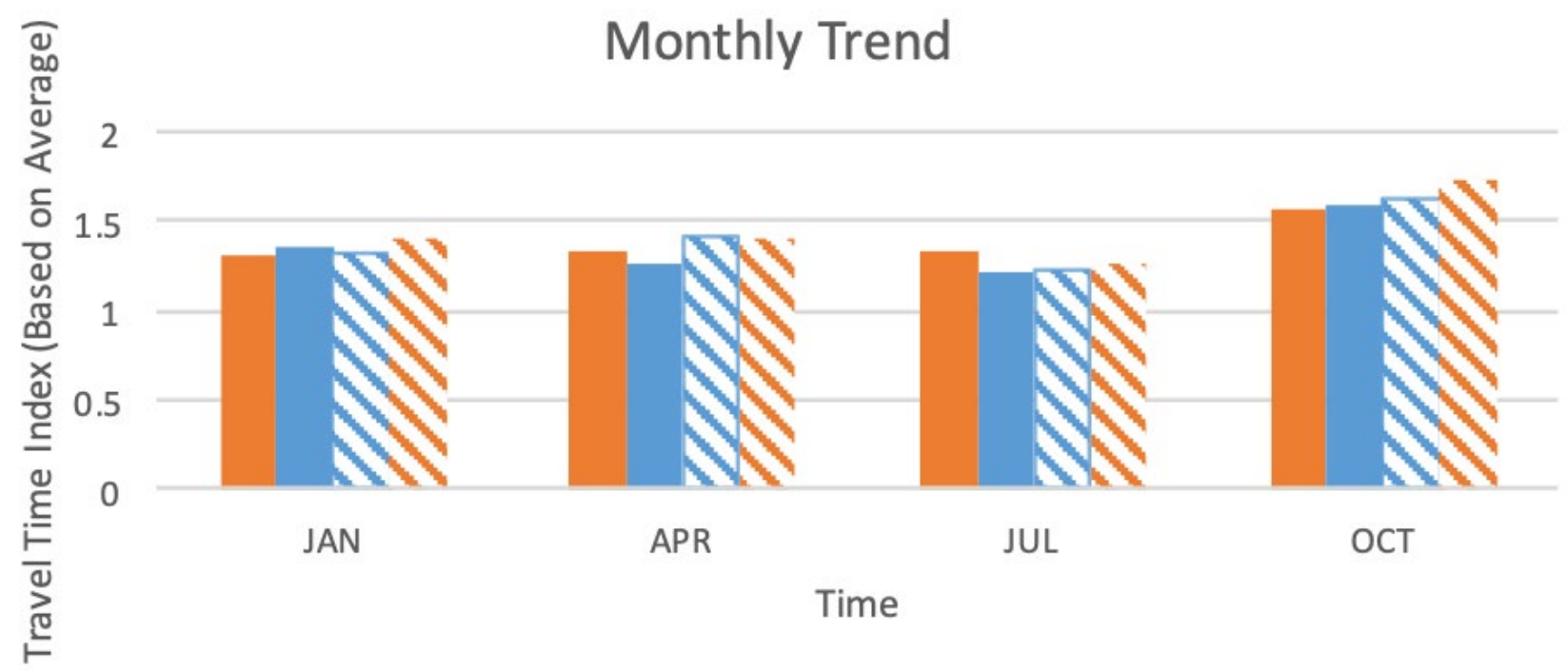

-I-280 NB Before (Jan 2014 - Mar 2017) ㅁ-280 NB After (Apr 2017 - Mar 2019)

I-80 WB D4 Before (Jan 2014 - Mar 2017) I-80 WB D4 After (Apr 2017 - Mar 2019)

Figure 16. Before/After AM Peak Period TTI on I-80 WB-D4 Corridor and its Control Corridor

3.5

3

I-80 WB D3 Before (2014-2016) I-80 WB D3 After (2017-2018)

\SR-99 NB Before (2014-2016) \SR-99 NB After (2017-2018)

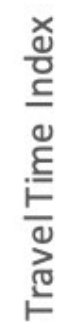

2.5

2

1.5

W

1

0.5

0

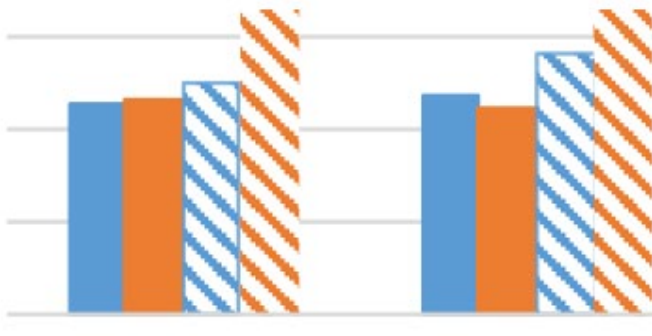

JAN

APR

Month

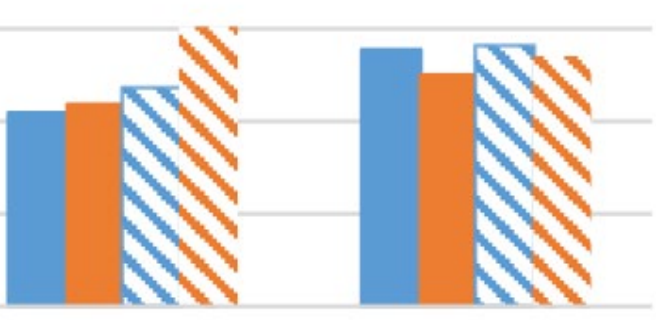

JUL

OCT

Figure 17. Before/After AM Peak Period TTI on SR-99 NB-D3 Corridor and its Control Corridor 


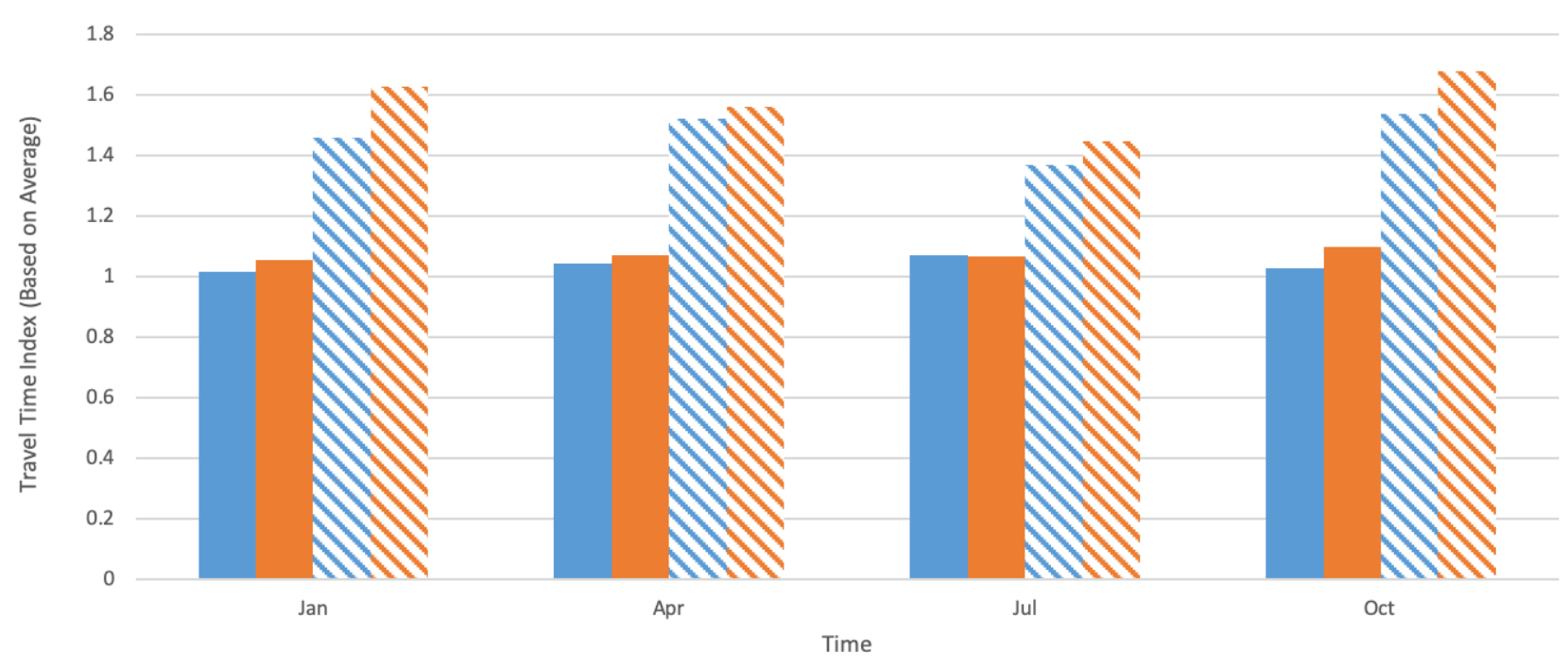

- I-80 EB D3 PM Before (Jan 2014 - Oct 2016) 1-80 EB D3 PM After (Oct 2016 - Sept 2018)

$\checkmark$ SR-99 SB PM Before (Jan 2014 - Oct 2016)

Figure 18. Before/After PM Peak Period TTI on SR-99 SB-D3 Corridor and its Control Corridor ${ }^{3}$

\section{Travel Time Index (80 ${ }^{\text {th }}$ Percentile Travel Time Based)}

$\mathrm{TTI}_{80}$ is very similar to $\mathrm{TTI}_{\text {mean }}$, but $80^{\text {th }}$ percentile travel time instead of average travel time is used in the numerator to estimate it. $\mathrm{TTI}_{80}$ shows the relationship between $80^{\text {th }}$ percentile travel time and free-flow travel time. For example, if the free-flow travel time for a segment is 20 minutes and the $\mathrm{TTI}_{80}$ is 1.5 , then $80 \%$ of the travelers in the corridor experience travel time of 30 minutes or less. Segments with low $\mathrm{TTI}_{80}$ may be considered more reliable. $\mathrm{TTI}_{80}$ is calculated by dividing the $80^{\text {th }}$ percentile travel time $\left(T_{80}\right)$ by free-flow travel time $\left(T_{f f}\right)$ :

$$
\operatorname{TTI}_{80}=\frac{T_{80}}{T_{f f}}
$$

Equation 4

$\mathrm{TTI}_{80}$ shows a similar trend to $\mathrm{TTI}_{\text {mean }}$ through the PM peak period. $\mathrm{TTI}_{80}$ is higher than $\mathrm{TTI}_{\text {mean }}$ because $T_{80}$ is higher than $T_{\text {mean }}$.

The monthly analysis shows no significant trend in I-80. The monthly average $\mathrm{TTI}_{80}$ after implementation of CRM is higher than before implementation in all three CRM corridors. The trends are also apparent in the control corridors, indicating that CRM has not had any impact on $\mathrm{TTI}_{80}$.

3. Note that SR 99 did not have CRM implemented during PM peak period and hence no difference should be expected between case and control corridor. 


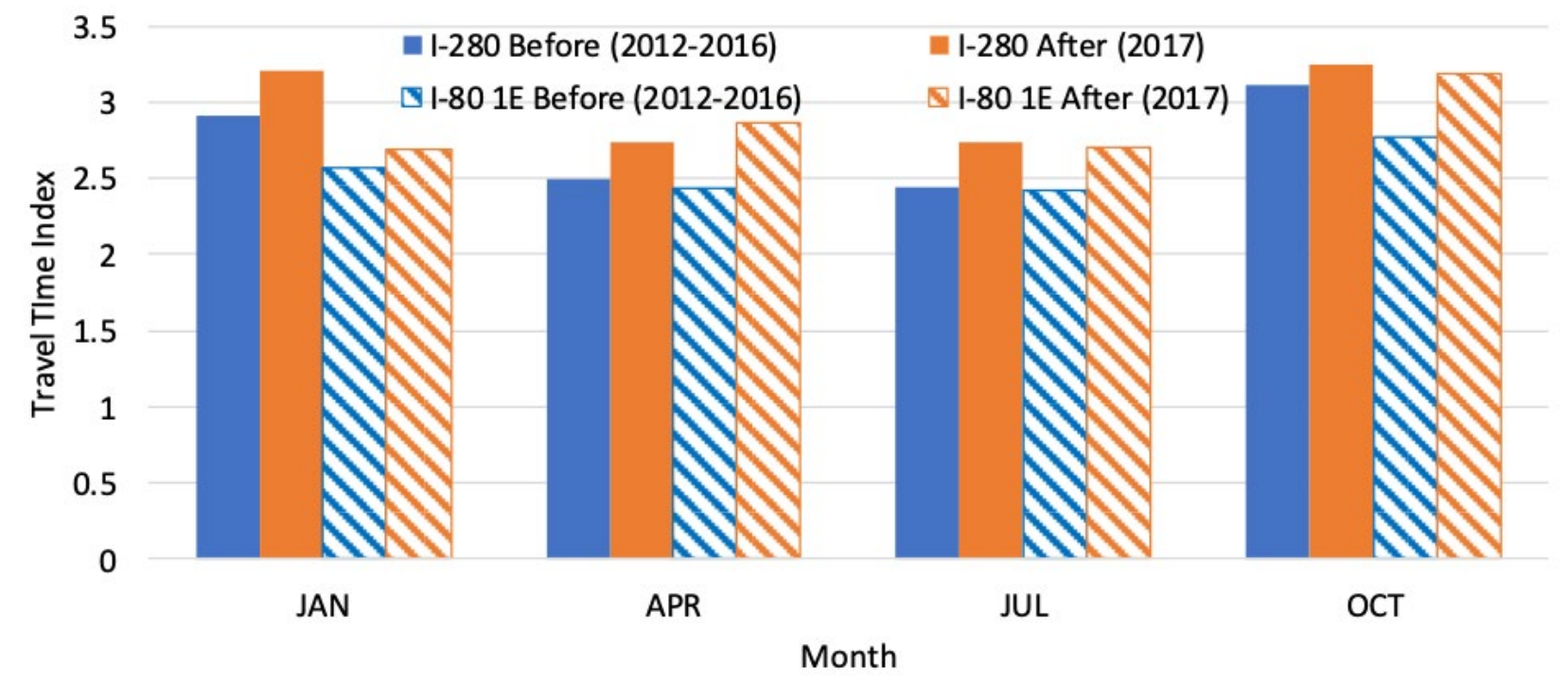

Figure 19. Before/After PM Peak Period TTI ${ }_{80}$ on I-80 EB-D4 Corridor and its Control Corridor

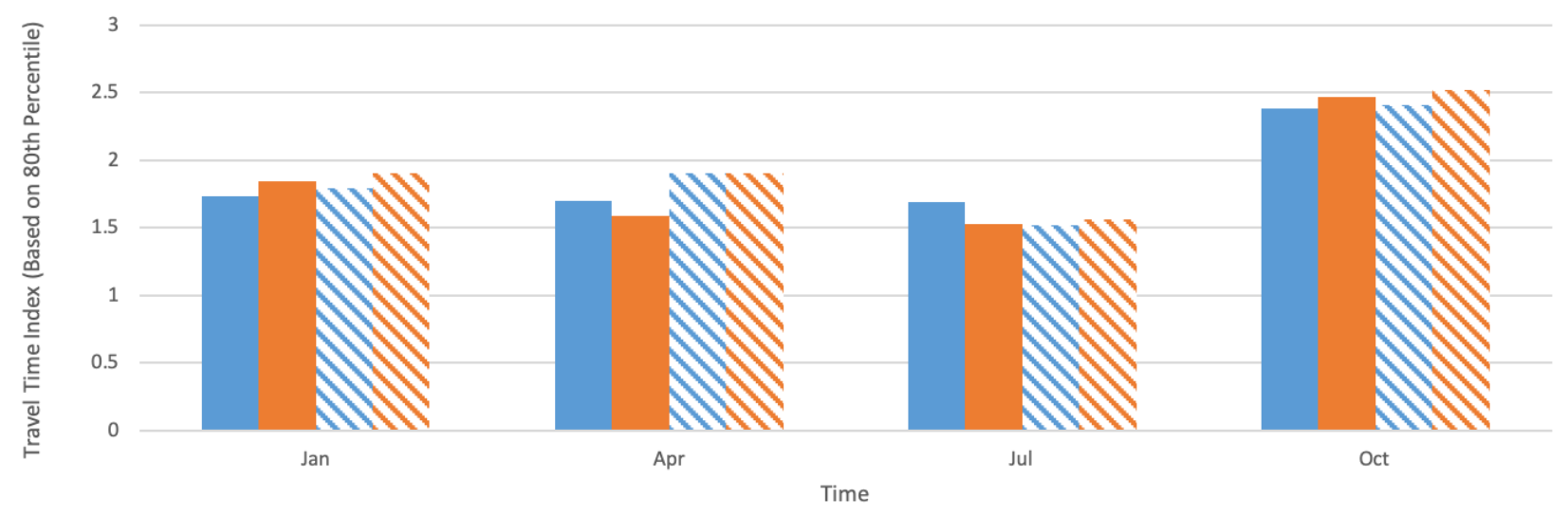

- I-280 NB Before (Jan 2014 - Mar 2017) = I-280 NB After (Apr 2017 - Mar 2019) . I-80 D4 WB Before (Jan 2014 - Mar 2017) 、I-80 D4 WB After (Apr 2017 - Mar 2019)

Figure 20. Before/After AM Peak Period TTI ${ }_{80}$ on I-80 WB-D4 Corridor and its Control Corridor 


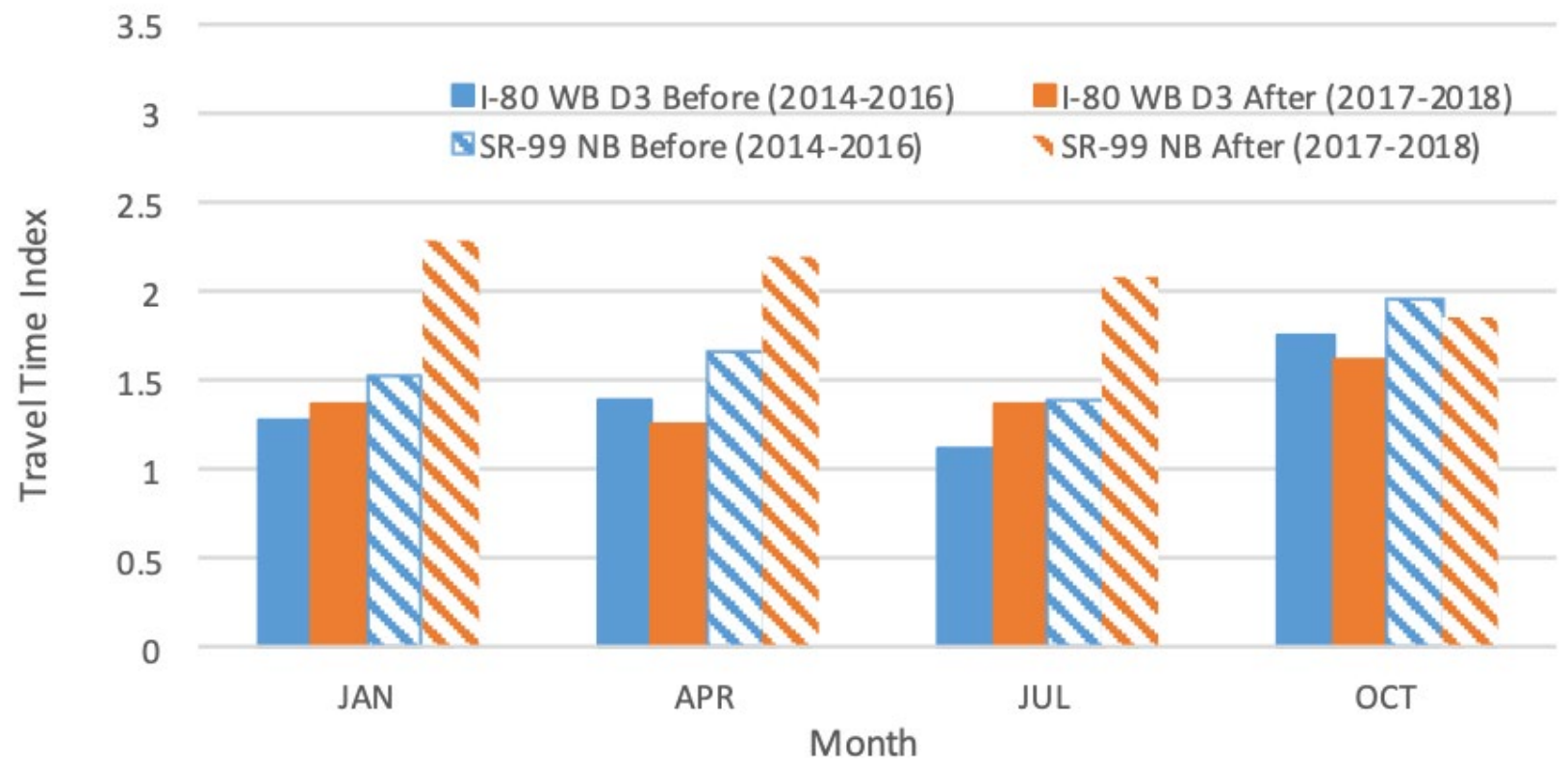

Figure 21. Before/After AM Peak Period $\mathrm{TTI}_{80}$ on SR-99 NB-D3 Corridor and its Control Corridor

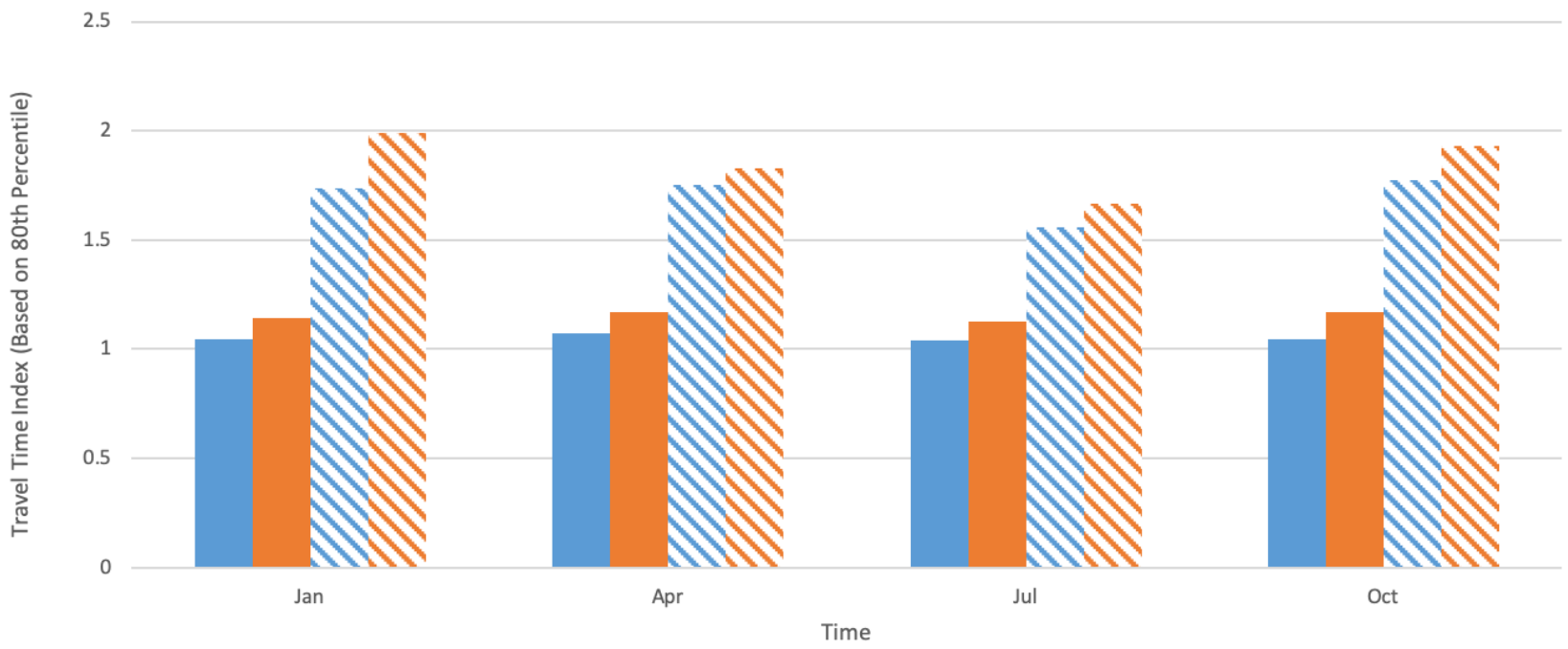

- I-80 EB D3 PM Before (Jan 2014 - Oct 2016) = I-80 EB D3 PM After (Oct 2016 - Sept 2018)

- SR-99 SB PM Before (Jan 2014 - Oct 2016) . SR-99 SB PM After (Oct 2016 - Sept 2018)

Figure 22. Before/After PM Peak Period TTI ${ }_{80}$ on SR-99 SB-D3 Corridor and its Control Corridor ${ }^{4}$

\section{Misery Index}

The Misery Index (MI) is another travel time index that relates travel time to reliability. Misery Index compares the worst travel time in the corridor to the free-flow travel time. The

4. Note that SR 99 did not have CRM implemented during PM peak period and hence no difference should be expected between case and control corridor. 
worst travel time is defined as the $97.5^{\text {th }}$ percentile travel time experienced by travelers. Additionally, the MI represents the total travel time (as a percent of free-flow travel time) required for a traveler to reach their destination on time $97.5 \%$ of the time. For example, if a segment has an average travel time of 20 minutes and an Ml of 1.5, then the $97.5^{\text {th }}$ percentile travel time of the corridor is 30 minutes. Additionally, if a traveler is trying to get to their destination on time $97.5 \%$ of the time then they should allocate 30 minutes for the journey. Since MI is a percent of free-flow travel time, it should be minimized: smaller MI means more reliable travel through the segment. MI for a segment is calculated as:

$$
M I=\frac{T_{97.5}}{T_{f f}}
$$

Equation 5

Since the MI is calculated similarly to the two travel time indices, the hourly trend for MI for the PM peak period has a similar trend as the two TTIs.

In the month of July after implementation of CRM on I-80 EB-D4, there is only a slight increase in $\mathrm{Ml}$ while there is a significant increase in $\mathrm{Ml}$ for the control corridor. This indicates that CRM potentially helped in keeping the MI in check. However, none of the other corridors or months show similar evidence.

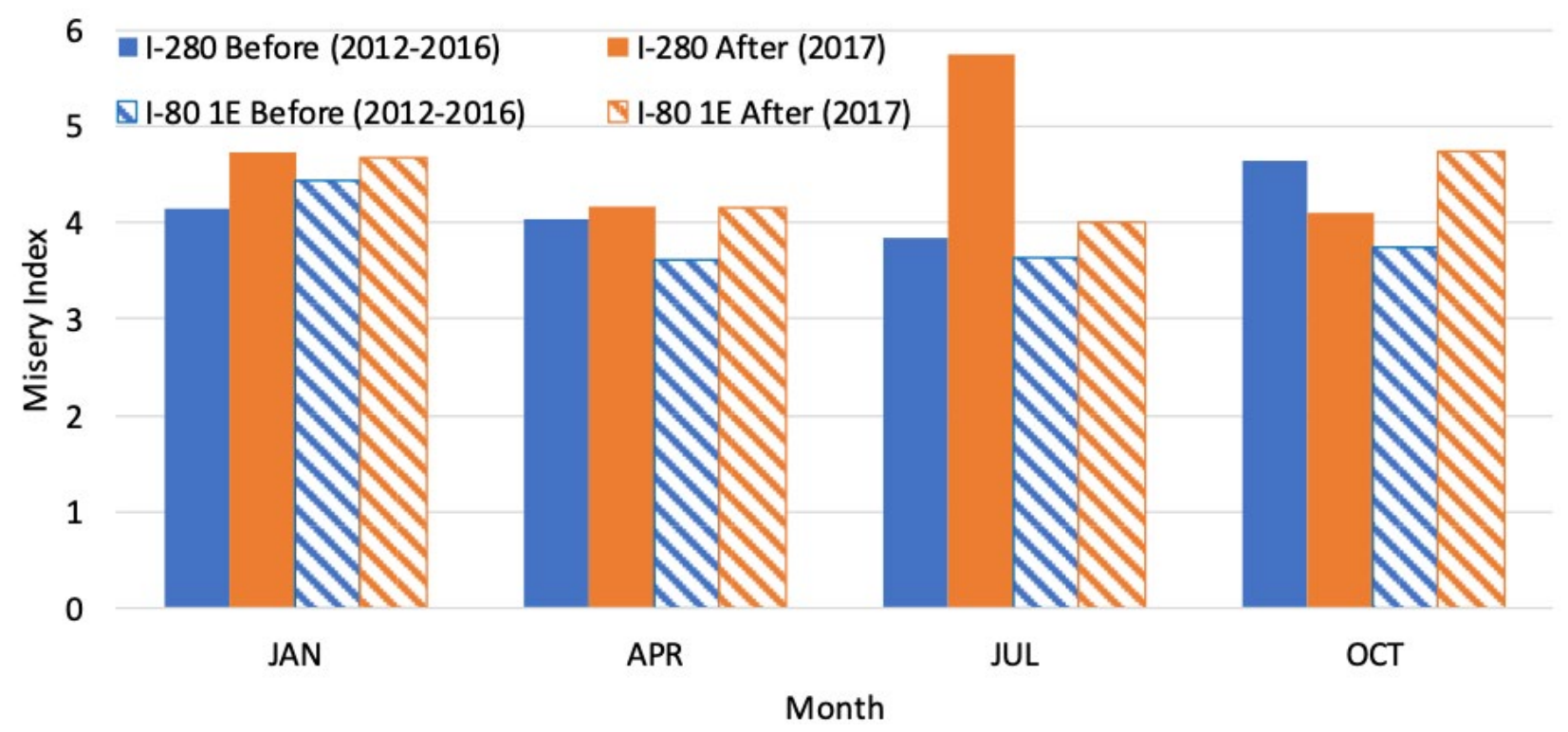

Figure 23. Before/After PM Peak Period Misery Index on I-80 EB-D4 Corridor and its Control Corridor 


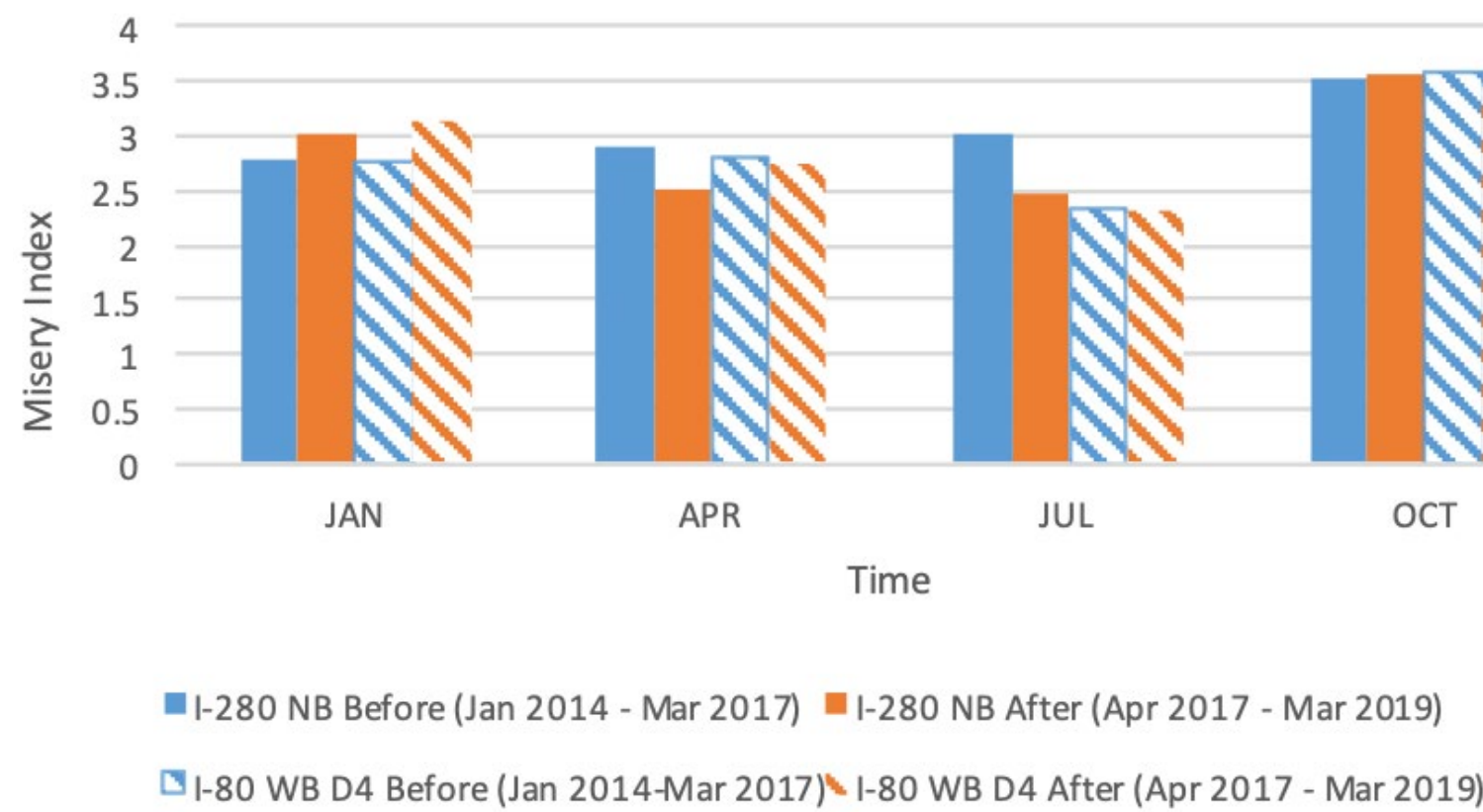

Figure 24. Before/After AM Peak Period Misery Index on I-80 WB-D4 Corridor and its Control Corridor

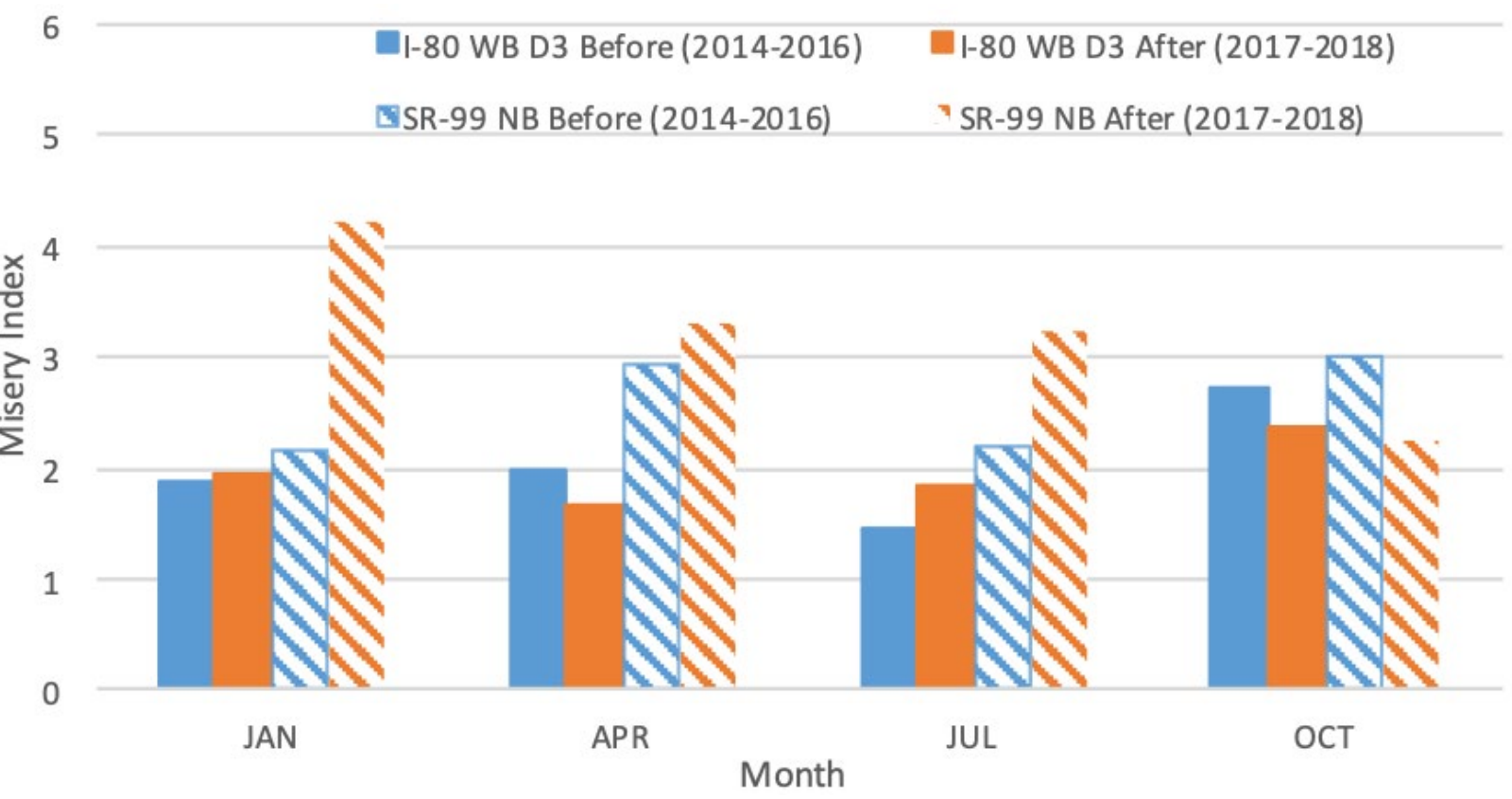

Figure 25. Before/After PM Peak Period Misery Index on SR-99 NB-D3 Corridor and its Control Corridor 


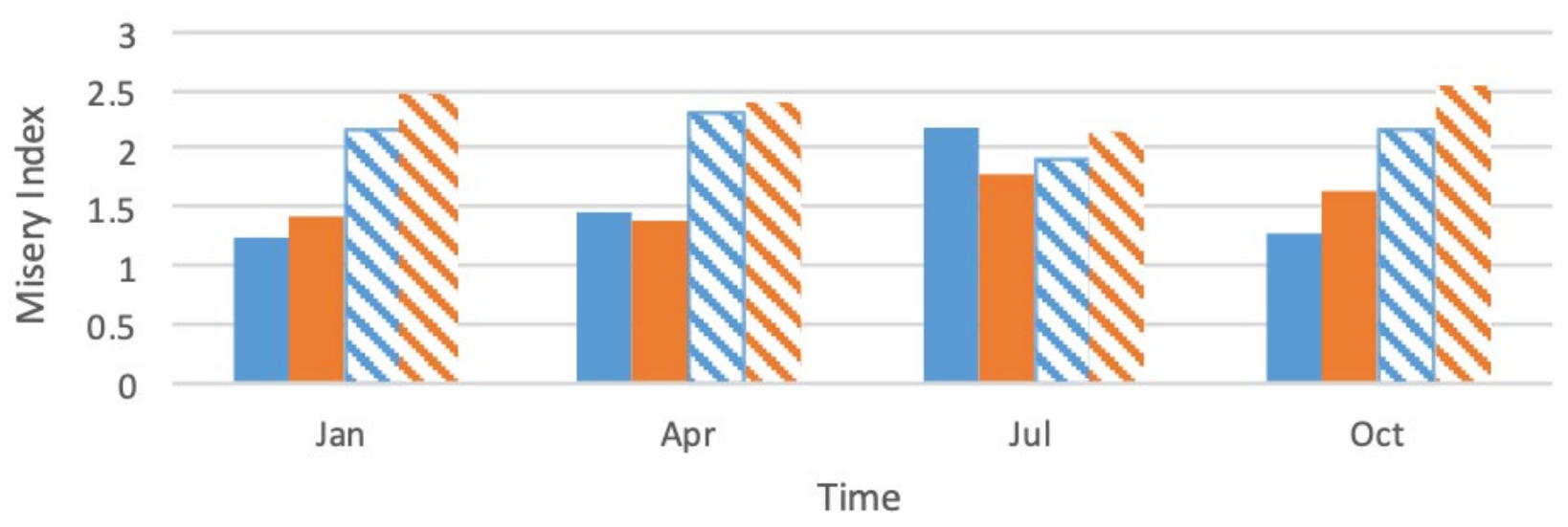

- I-80 EB D3 Before (Jan 2014 - Sept 2016)ㅍ I-80 EB D3 After (Oct 2016 - Sept 2018)

口SR-99 SB Before (Jan 2014 - Sept 2016) W SR-99 SB After (Oct 2016 - Sept 2018)

\section{Figure 26. Before/After AM Peak Period Misery Index on SR-99 SB-D3 Corridor and its Control Corridor ${ }^{5}$}

\section{UNRELIABILITY INDICATOR}

Unreliability Indicator considers the width and skew of the travel time distribution of the corridor. This measure was developed in 2008 by Van Lint et al. and has not been extensively used to compare travel time reliabilities for corridors in the U.S. A wider and/or more skewed distribution of travel time results in a more unreliable segment. The skew of the graph $\left(\lambda_{\text {skew }}\right)$ accounts for the tail of the distribution. For example, if the data distribution for travel time shows a higher percentage of long travel times, then the distribution is generally described as skewed toward longer travel times. $\lambda_{\text {skew }}$ is calculated by dividing the difference between $90^{\text {th }}$ percentile travel time and $50^{\text {th }}$ percentile travel time by the difference between $50^{\text {th }}$ percentile travel time and $10^{\text {th }}$ percentile travel time. Generally, $\lambda_{\text {skew }}$ increases with the likelihood of experiencing high travel time compared to the median. The difference between the two extremes and the median travel time is the time gained or lost by users experiencing those extremes. If the $\lambda_{\text {skew }}$ is greater than one, then users with greater delay lose more time than the users with less delay gain with respect to the median travel time. ${ }^{31}$ The equation for $\lambda_{\text {skew }}$ is as shown:

$$
\lambda_{\text {skew }}=\frac{T_{90}-T_{50}}{T_{50}-T_{10}}
$$

Equation 6

5. Note that SR 99 did not have CRM implemented during PM peak period and hence no difference should be expected between case and control corridor. 
The width of the distribution is calculated by the $\lambda_{\mathrm{var}}$ of the distribution. $\lambda_{\mathrm{var}}$ is defined as the distance between the $90^{\text {th }}$ percentile travel time and $10^{\text {th }}$ percentile travel time as a fraction of median travel time. $\lambda_{\mathrm{var}}$ relates to the spread of the distribution; larger $\lambda_{\mathrm{var}}$ means that the difference between the two extremes is large compared to the median.

$$
\lambda_{\mathrm{var}}=\frac{\mathrm{T}_{90}-\mathrm{T}_{10}}{\mathrm{~T}_{50}}
$$

Equation 7

Van Lint et al. ${ }^{32}$ combined $\lambda_{\mathrm{var}}$ and $\lambda_{\text {skew }}$ to derive a travel time reliability measure based on both skew and width, called the Unreliability Indicator $\left(\mathrm{UI}_{\mathrm{r}}\right)$ :

$$
\begin{aligned}
& \mathrm{UI}_{\mathrm{r}}= \begin{cases}\frac{\lambda_{\text {var }} \ln \left(\lambda_{\text {skew }}\right)}{\mathrm{L}_{\mathrm{r}}} & \lambda_{\text {skew }}>1 \\
\frac{\lambda_{\text {var }}}{L_{\mathrm{r}}} & \text { Otherwise }\end{cases} \\
& \begin{cases}\frac{\lambda_{\text {var }} \ln \left(\lambda_{\text {skew }}\right)}{L_{\mathrm{r}}} & \lambda_{\text {skew }}>1 \\
\frac{\lambda_{\text {var }}}{\mathrm{L}_{\mathrm{r}}} & \text { Otherwise }\end{cases}
\end{aligned}
$$

Equation 8

Unreliability indicator normalizes for the length of the segment and hence is a unit measure independent from the length of the segment. Since $U \mathrm{I}_{\mathrm{r}}$ is a product of multiplied value, $a$ higher value of $\mathrm{UI}_{\mathrm{r}}$ would indicate a higher value of $\lambda_{\mathrm{var}}$ and $\lambda_{\text {skew }}$. A segment with low $U \mathrm{I}_{\mathrm{r}}$ (high width and skew) is more reliable since the researchers mentioned above ${ }^{33}$ noted that this measure indicates the likeliness of incurring a very bad travel time. Since $\mathrm{UI}_{\mathrm{r}}$ takes into account the median travel time and not free-flow travel time, it is not an indicator of the speed or capacity of the segment. A segment that has high median travel time consistently would have a low $\mathrm{UI}_{\mathrm{r}}$ score.

In Figure 27, it may be observed that on the I-80 EB-D4 PM peak, UI did reduce in the postimplementation period during the months of April and July. However, a similar reduction was also observed for the control corridor. For the month of October, the I-80 WB D4 AM peak period experienced a lower $\mathrm{UI}$ and the control corridor showed a slight increase in $\mathrm{UI}$. On the SR-99 NB-D3, there was a reduction in the AM peak period UI in the month of October, and the corresponding reduction in UI was much lower on the control corridor (see Figure 29). UI indicator monthly averages decreased for SR 99 SB-D3 during the PM peak period. However, there was no CRM in place on SR 99 SB during the PM peak period (Figure 30). 


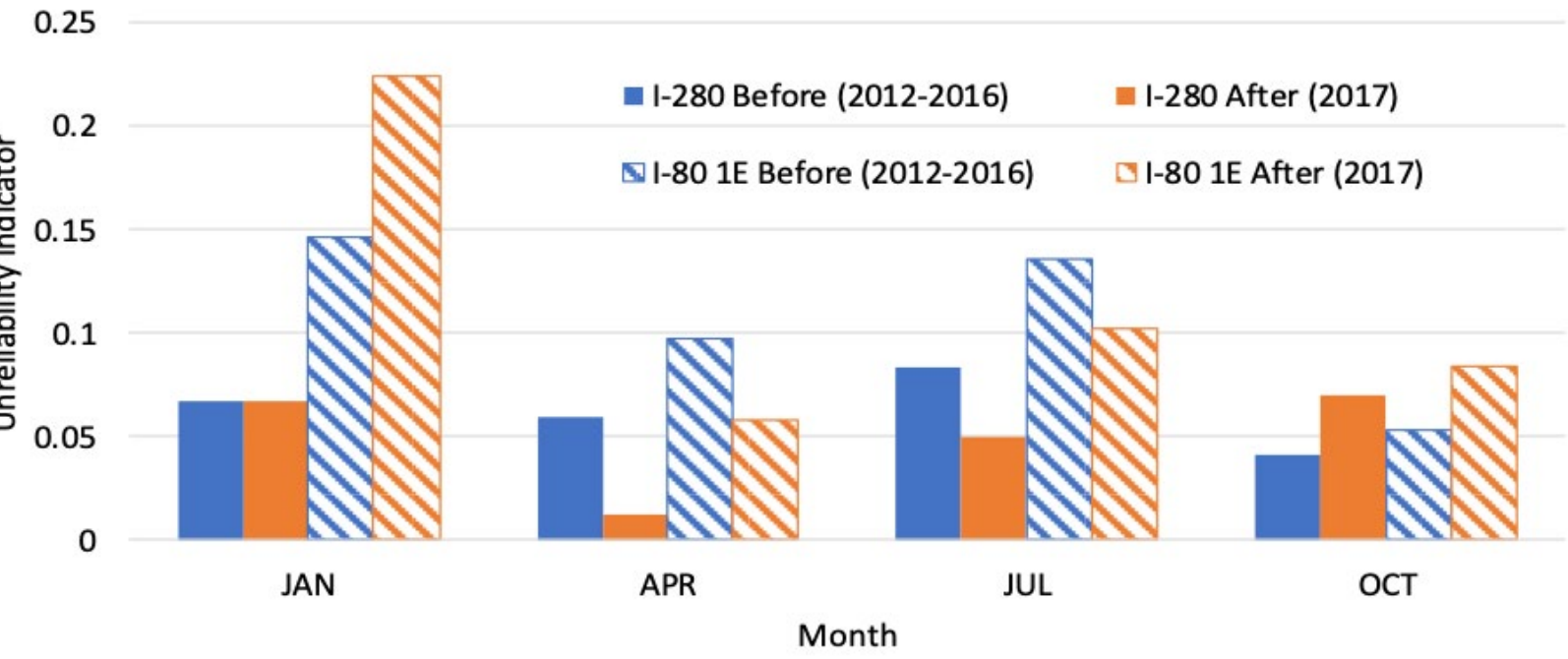

Figure 27. Before/After PM Peak Period Unreliability Indicator on I-80 EB-D4 Corridor and its Control Corridor

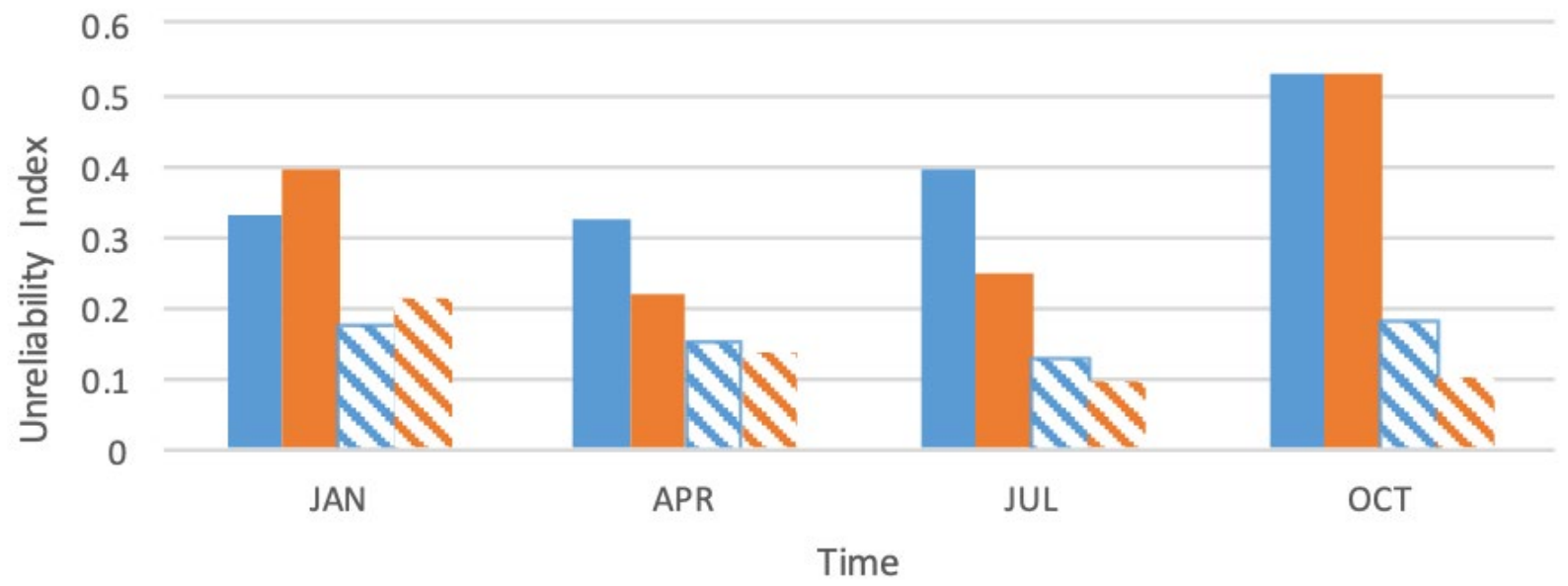

-I-280 NB Before (Jan 2014 - Mar 2017) =I-280 NB After (Apr 2017 - Mar 2019)

จ I-80 WB D4 Before (Jan 2014-Mar 2017) - I-80 WB D4 After (Apr 2017 - Mar 2019)

Figure 28. Before/After AM Peak Period Unreliability Indicator on I-80 WB-D4 Corridor and its Control Corridor 


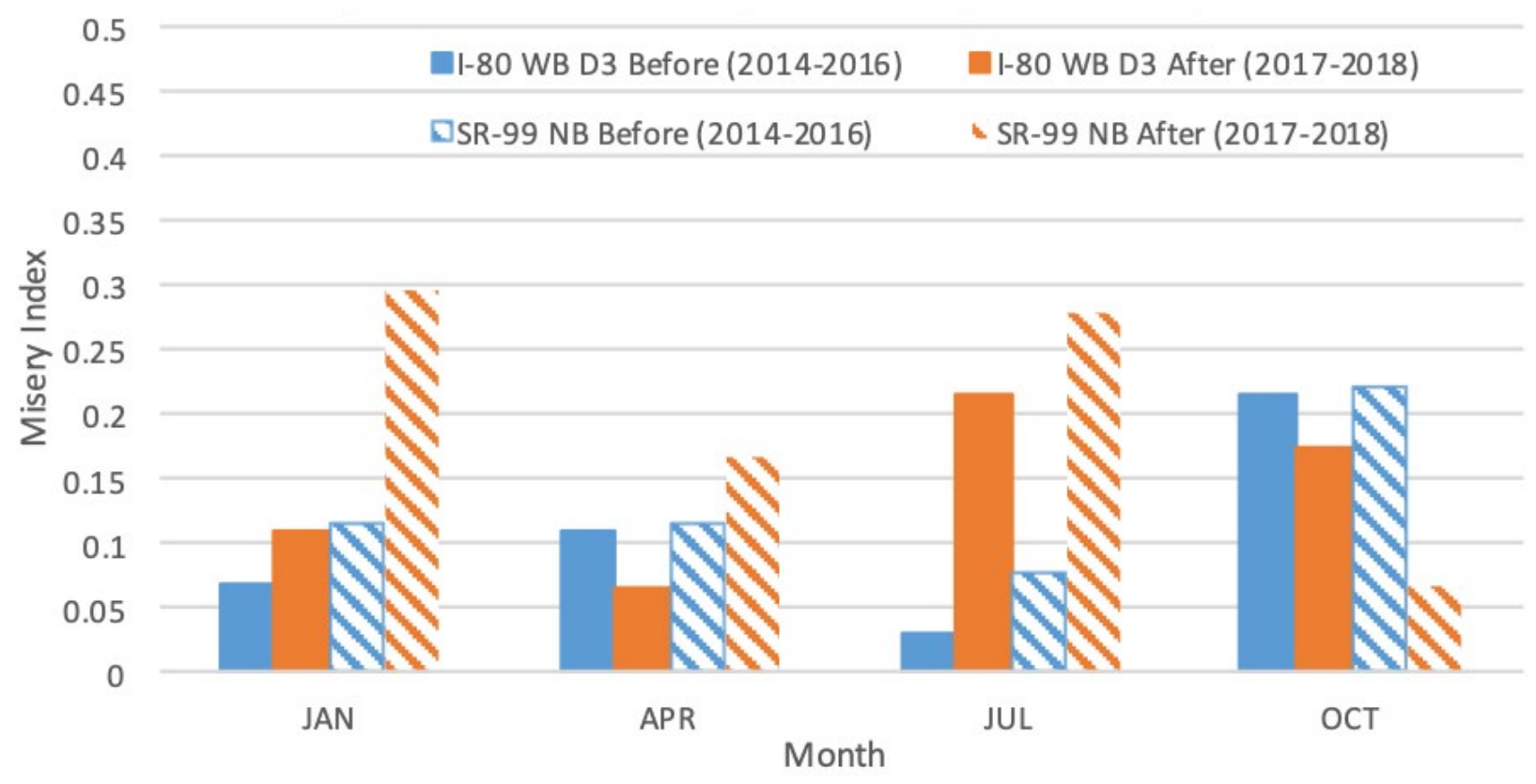

Figure 29. Before/After AM Peak Period Unreliability Indicator on SR-99 NB-D3 Corridor and its Control Corridor
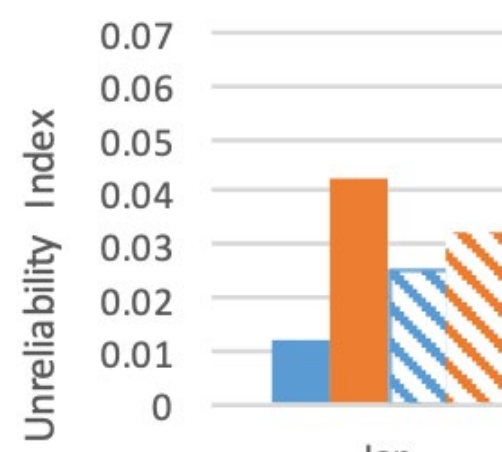

Jan

Apr

Jul

Oct

Time

- I-80 EB D3 Before (Jan 2014 - Sept 2016) I-80 EB D3 After (Oct 2016 - Sept 2018)

$\square$ SR-99 SB Before (Jan 2014 - Sept 2016) SR-99 SB After (Oct 2016 - Sept 2018)

Figure 30. Before/After PM Peak Period Unreliability Indicator on SR-99 SB-D3 Corridor and its Control Corridor ${ }^{6}$

\section{CONCLUSIONS FROM THE RELIABILITY ANALYSIS}

The analysis presented in this chapter indicates that the traditional reliability measures do not show improvement in the post-CRM implementation period. There is some indication

6. Note that SR 99 did not have CRM implemented during PM peak period and hence no difference should be expected between case and control corridor. 
that the Unreliability Indicator has improved during the AM peak period in the month of October for the SR-99 NB-D3. It should be noted that UI is different from traditional metrics of reliability since it accounts for both the width and skew of travel time distribution. In other words, traditional travel time metrics tend to 'improve' even when travel time is consistently bad, while $\mathrm{UI}$ is improves only with lower variability in travel time and a distribution that is skewed toward lower overall travel time. It makes UI a better indicator since it won't show improvement in case of consistently higher travel time. Since the reduction in $\mathrm{UI}$ in the after-period is not a consistent pattern of improvement that holds throughout the year for SR 99 NB corridor, we conclude that CRM has not consistently improved travel time reliability. 


\section{OPERATIONAL ANALYSIS: SYSTEM EFFICIENCY}

\section{DATA, PRELIMINARY EXPLORATION, AND METHODOLOGY}

Data for the efficiency analysis were obtained from the Caltrans' Performance Measurement System (PeMS), which is a centralized traffic database. ${ }^{34}$ Detection is performed by a vehicle detector station (VDS), which is a set of detectors that cover all lanes across one direction of travel for one facility (e.g., entrance ramp, exit ramp, mainline freeway lanes, or HOV lane). Freeway performance throughout California is monitored via over 40,000 installed detectors that measure the number of vehicles that pass over the detector as well as the duration of time for which they remain over the detector.

The measure of efficiency used in this study, "Q," is defined as the ratio of Vehicle Miles Traveled (VMT) to Vehicle Hours Traveled (VHT), where VMT is defined as the total distance traveled by each vehicle on a given section of the freeway and VHT is the corresponding period of time traveled for the same section of the freeway. Based on these two measures, freeway efficiency can be defined as follows: ${ }^{35}$

$$
\mathrm{Q}=\mathrm{VMT} / \mathrm{VHT}
$$

Equation 9

The ratio represents Space Mean Speed, and higher values indicate that the freeway is operating more efficiently. These measures are obtained from the Caltrans PeMS portal for the corridor(s) under consideration. ${ }^{36}$ The same measure was used in the Caltranssponsored field test of Coordinated Ramp Metering for SR-99 in Sacramento (Caltrans District 3). ${ }^{37}$ On I-80, the CRM system was implemented in April 2017. Hence, the "before" period refers to the five-year period from April 2012 to March 2017, while the "after" period refers to the two-year period from April 2017 to March 2019.

\section{Preliminary Analysis}

The annual average value of $Q$ from 3 PM and 8 PM on Tuesdays, Wednesdays, and Thursday was estimated from 2012 (2012 represents the period from April 2012 through March 2013) through 2017 (i.e., April 2017 through March 2018) for the I-80 Eastbound corridor and the I-280 Southbound control corridor. In addition to the full study corridor, for the preliminary analysis, $Q$ estimates were also obtained for the most congested $\sim 9$-mile sub-segment of I-80 Eastbound that was of comparable length to I-280 Southbound. The trends in average $Q$ values during the PM peak period for all three segments are shown in Figure 31. 
50

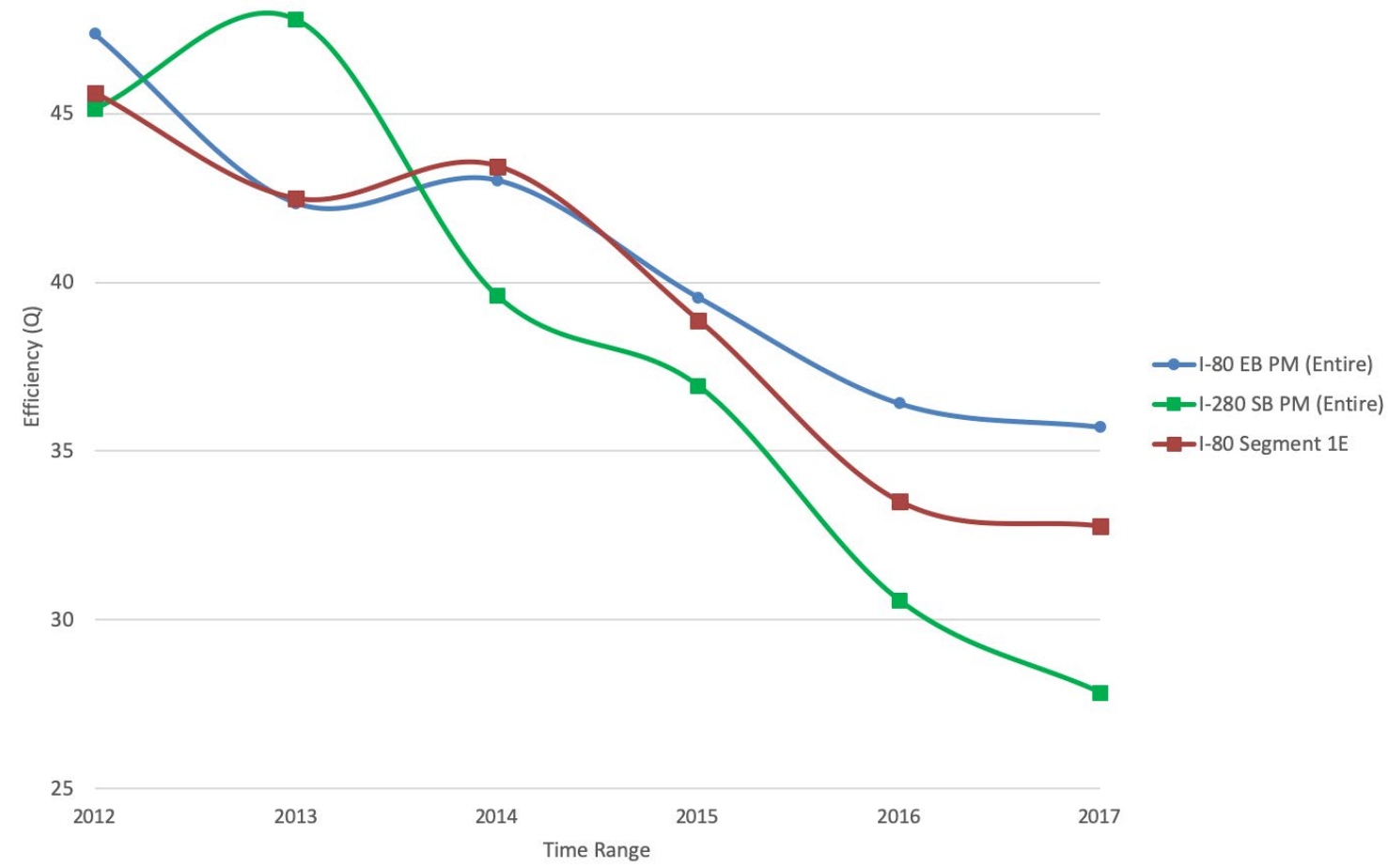

Figure 31. Trends in the Efficiency Measured During the PM Peak Period from 2012 through 2017

According to Figure 31, in the "before" period (2012 through 2016), all three segments demonstrate a declining trend in Q. For the I-280 Southbound, the comparison corridor, the decline continues through 2017 (i.e., the "after" period) at a similar rate, while the reduction in efficiency is much smaller for the two I-80 segments, i.e., both the full corridor and the most congested sub-segment. This indicates that while efficiency on I-80 corridors may have decreased in the "after" period, the decline may have been worse in the "after" period (April 2017 through March 2018) had there been no CRM. It underscored the need for obtaining a robust counterfactual estimate to accurately assess the impact of the CRM deployment on system efficiency.

\section{Methodology}

The Empirical Bayes (EB) approach to evaluate the change in the safety of an entity after a treatment is implemented is well-known to the traffic safety research and practitioner community (see HSM for details ${ }^{38}$ ). According to Hauer et al., ${ }^{39}$ "treatment" is defined as a change meant to reduce crashes: for example, installation of a roundabout at an intersection with the intersection being the "entity" in this case. To estimate how a treatment has affected safety, the researchers need to estimate the counterfactual scenario, i.e., the expected number of crashes, $\mathrm{K}$, that would have occurred had the treatment not been implemented in that entity. Then, this estimated number of crashes, $\mathrm{K}$, can be compared to the actual observed number of accidents during the before period, $k$ Hauer and colleagues ${ }^{40}$ referred to the simple comparison of numberof crashes in the "before" period with the number of crashes in the "after" period as a "naive comparison" affected by confounding factors and statistical biases including regression to the mean. Thus, the empirical Bayes approach is a 
more reliable way to estimate $\mathrm{k}$, since it considers how these factors may have affected the entity, in addition to the treatment of interest.

A similar approach is worthy of consideration in before-and-after studies for the operational impacts of Intelligent Transportation Systems (ITS) deployment. The researchers developed a multivariate regression model to estimate the counterfactual, i.e., what would have happened on the subject corridor in the post-deployment scenario. In this context, the CRM deployment can be regarded as a treatment deployed on I-80 (and SR-99). The researchers apply the same approach to estimate the counterfactual for the control corridor (I-280 in District 4) as well. Since the I-280 corridor had no CRM deployment (i.e., no treatment), the estimated counterfactual should be able to capture the trend in the field value of $Q$ from the PeMS database.

Next, the researchers obtained the empirical Bayes estimates for the post-deployment period on $1-80$ by taking the weighted averages of the counterfactual estimates and the observed values from the pre-deployment period. The $R^{2}$ value of the regression model serves as the weight for the empirical Bayes estimates. ${ }^{41}$ Finally, it is possible to compare the empirical Bayes estimates with the observed values of $Q$ from the post-deployment period on I-80 for a more reliable comparison.

Furthermore, the researchers performed a similar analysis for SR-99 in District 3. The control corridor used for this purpose is I-5, also in District 3. On SR-99 the new CRM system was implemented in September 2016. Hence, the "before" period refers to the four-year period from October 2012 to September 2016, while the "after" period refers to the two-year period from October 2016 to September 2018.

\section{ANALYSIS AND RESULTS}

\section{I-80 Analysis}

The steps for the analysis are listed below:

- Using the data from the 60-month "before" period, estimate a multivariate regression model for $Q$ on the I-80 Eastbound corridor.

- Use the model coefficients to estimate $Q^{*}$ for the 24-month "after" period (the expected value of $Q$ had the CRM system not been implemented, i.e., the counterfactual).

- Compare $Q^{*}$ to the observed values of $Q$ for the 24-month "after" period to measure the efficacy of the CRM implementation.

- Obtain empirical Bayes estimates for after period by taking a weighted average of counterfactuals and observed values from before period. Compare these estimates to observed values from after period.

- Repeat these steps with the data from I-280, the control corridor. 


\section{Regression Model for I-80 Data}

Hourly aggregates of VMT and VHT of the 19-mile eastbound corridor of $\mathrm{I}-80$ were downloaded from the PeMS database. These aggregates were used to compute the average monthly value of $Q$ over the seven-year period from April 2012 to March 2019. Hence, the data set includes 60 months of "before" data and 24 months of "after" data. Figure 32 shows the monthly average of $Q$ for each month. The data used for this aggregation include 24 hours a day, seven days a week, excluding holidays.

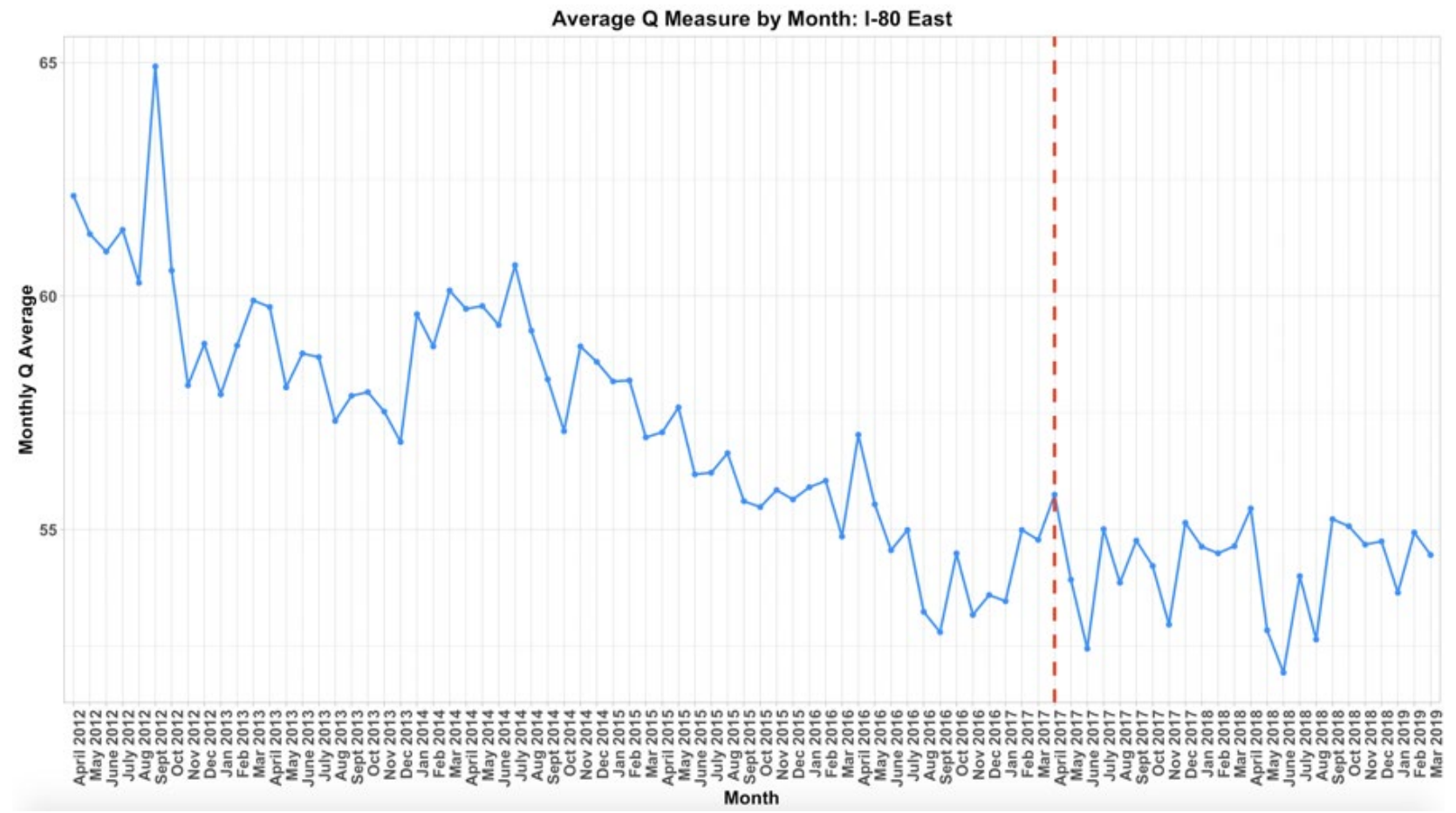

Figure 32. Average $Q$ per Month on I-80 East

The vertical line in Figure 32 at April 2017 separates the before- and after-deployment period. The monthly averages of $Q$ plotted against the corresponding months revealed two patterns: (1) As expected, the monthly average of $Q$ is affected by the month or season, and (2) there was a decreasing trend of the average value of $Q$ regardless of the month. This may be a function of the economic growth and increased home prices that the Bay Area has experienced, leading more and more people to work on the west end of the I-80 corridor and live further east. ${ }^{42}$

To account for the trend and the seasonality of $Q$, the researchers utilized a time series decomposition. ${ }^{43}$ Figure 33 shows the decomposition of the monthly $Q$ averages on I-80 from April 2012 to March 2019. 


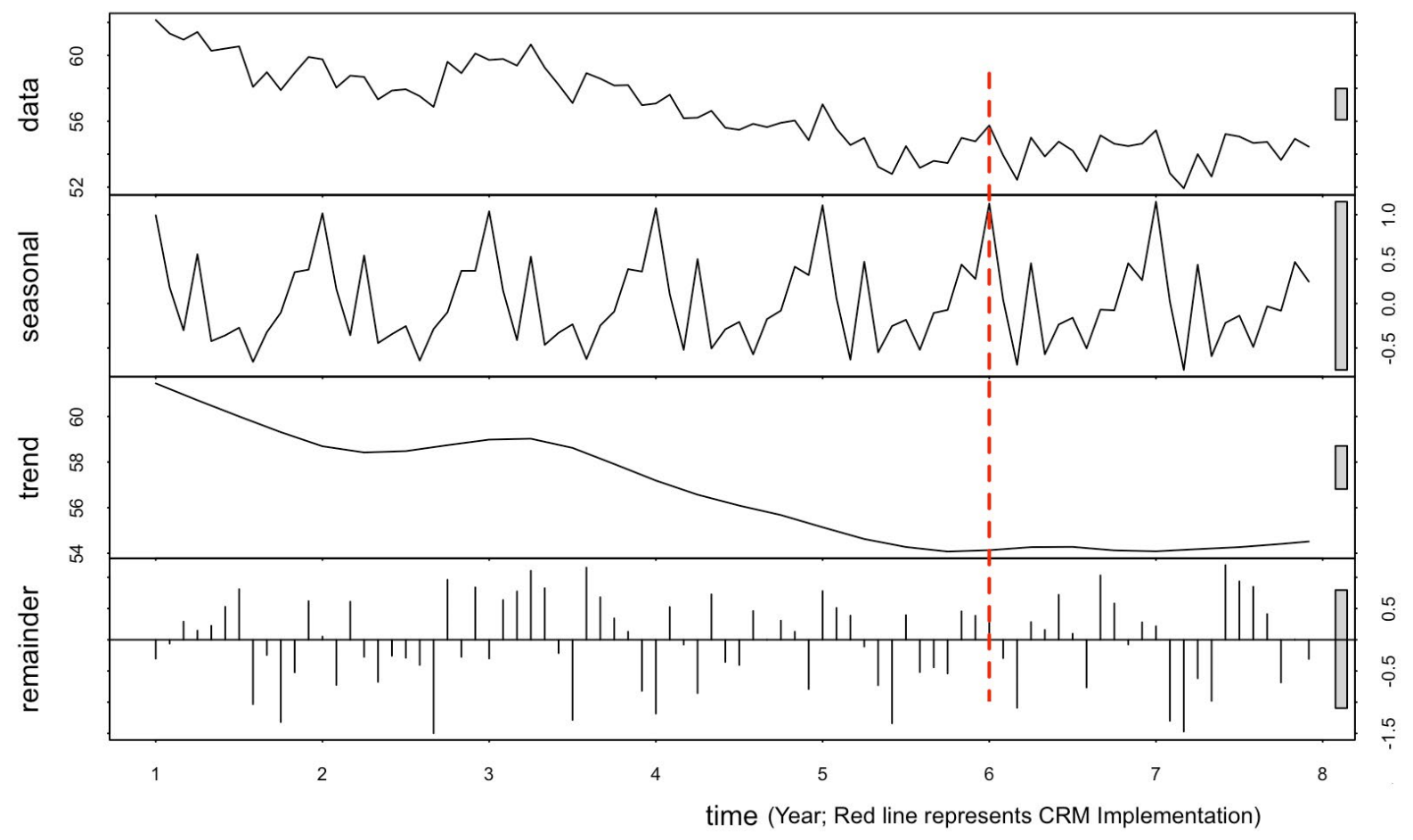

Figure 33. Time Series Decomposition of Average Monthly Q Values of I-80 East

The vertical line in Figure 33 separates the before- and after-CRM deployment periods. The first part of Figure 33 shows the original data as a time series. The next part shows the seasonal component, which refers to the variations in data related to calendar cycles. The third part of Figure 33 shows the trend component. The trend is the overall pattern found in the data, regardless of calendar cycles. The final component is the remainder. These are the variations in the data that cannot be attributed to seasonality or trend. The gray range bars on the right side of each panel show how much variation in the data can be attributed to each component. The seasonal panel has a bar much larger than that of the data panel. If the seasonal panel were condensed so that its bar matched the size of that in the data panel, the variation attributed to seasonality would only play a small part of the variation in the data. Conversely, the bar in the trend panel is almost the same size as the bar in the data panel. Therefore, a significant proportion of the variation in the data can be attributed to the trend. In other words, the efficiency of the system was getting worse month after month for the six-year period prior to the CRM implementation.

For the multivariate regression model, the daily average value of $Q$ was the response variable. Figure 33 confirms the presence of seasonality and trend; therefore, in addition to Annual Average Daily Traffic (AADT) for each segment, the predictor variables chosen for the model included the month (to account for seasonal traffic changes), day of the week, and a linear trend (to account for the continuous decreasing trend). The daily AADT values in PeMS are recorded using VDS on I-80, each of which has a unique ID. The 19mile I-80 Eastbound corridor was broken down into segments, and specific $Q$ and AADT values were recorded for each of those segments. The segment number was treated as a nominal variable. The linear trend was also treated as a nominal variable. Each month was assigned a number for this variable; data from April 2012 were assigned a value of 1, data from May 2012 were assigned a value of 2, and so on, until data from March 2017 were 
assigned a value of 60 . The regression model was estimated using 60-month "before" data from I-80 Eastbound. For convenience, the AADT values were divided by 1,000. The final regression model has the following form, with coefficients and corresponding $p$-value shown in Table 2:

$$
Q=\beta_{0}+\beta_{1} \cdot(A A D T / 1000)+\beta_{2} \cdot \text { month }+\beta_{3} \cdot \text { day of week }+\beta_{4} \cdot \text { segment }+\beta_{5} \cdot \text { trend }
$$

Equation 10

Table 2. Coefficients for I-80 Eastbound Regression Model

\begin{tabular}{llllll}
\hline \multicolumn{1}{c}{ Variable } & Coefficient & \multicolumn{1}{c}{ p-value } & \multicolumn{1}{c}{ Variable } & Coefficient & \multicolumn{1}{c}{ p-value } \\
\hline Intercept & 68.9917 & $<0.0001$ & Month : Oct & 0.1456 & 0.1489 \\
AADT & -0.0473 & $<0.0001$ & Month : Nov & -0.6849 & $<0.0001$ \\
Month: Feb. & 0.7933 & $<0.0001$ & Month : Dec & -0.2557 & 0.01108 \\
Month: Mar. & 0.7412 & $<0.0001$ & Day : Mon & -7.8646 & $<0.0001$ \\
Month: Apr. & 1.5015 & $<0.0001$ & Day : Tues & -9.3085 & $<0.0001$ \\
Month: May & 0.869 & $<0.0001$ & Day : Wed & -9.8544 & $<0.0001$ \\
Month: June & 0.4151 & $<0.0001$ & Day : Thurs & -10.241 & $<0.0001$ \\
Month: July & 1.0631 & $<0.0001$ & Day : Fri & -9.2731 & $<0.0001$ \\
Month: Aug. & 0.1975 & 0.05246 & Day : Sat & -0.546 & $<0.0001$ \\
Month: Sept. & -0.3403 & 0.00152 & Trend & -0.1046 & $<0.0001$ \\
\hline
\end{tabular}

All the predictor variables were significant $(\mathrm{p}<0.0001)$, and the model had an Adjusted $R^{2}$ value of 0.621 . The coefficient of each variable shows how much that variable affects the average value of $Q$. For example, the coefficient for the linear trend is -0.1046 , meaning that during each subsequent month, the average value of $Q$ is expected to decrease by about 0.1046 .

This model is then used to estimate the counterfactual value $Q^{*}$ for each of the 24 months that were part of the post-deployment period. Figure 34 shows the monthly averages of both the predicted values $Q^{*}$ and the observed values $Q$. It may be observed in Figure 34 that the model shown in Table 2 underpredicts $Q$ for the post-deployment period. In other words, the real value of $Q$ in the post-deployment period is higher than the counterfactual estimate $Q^{*}$, especially during the second year of deployment. 


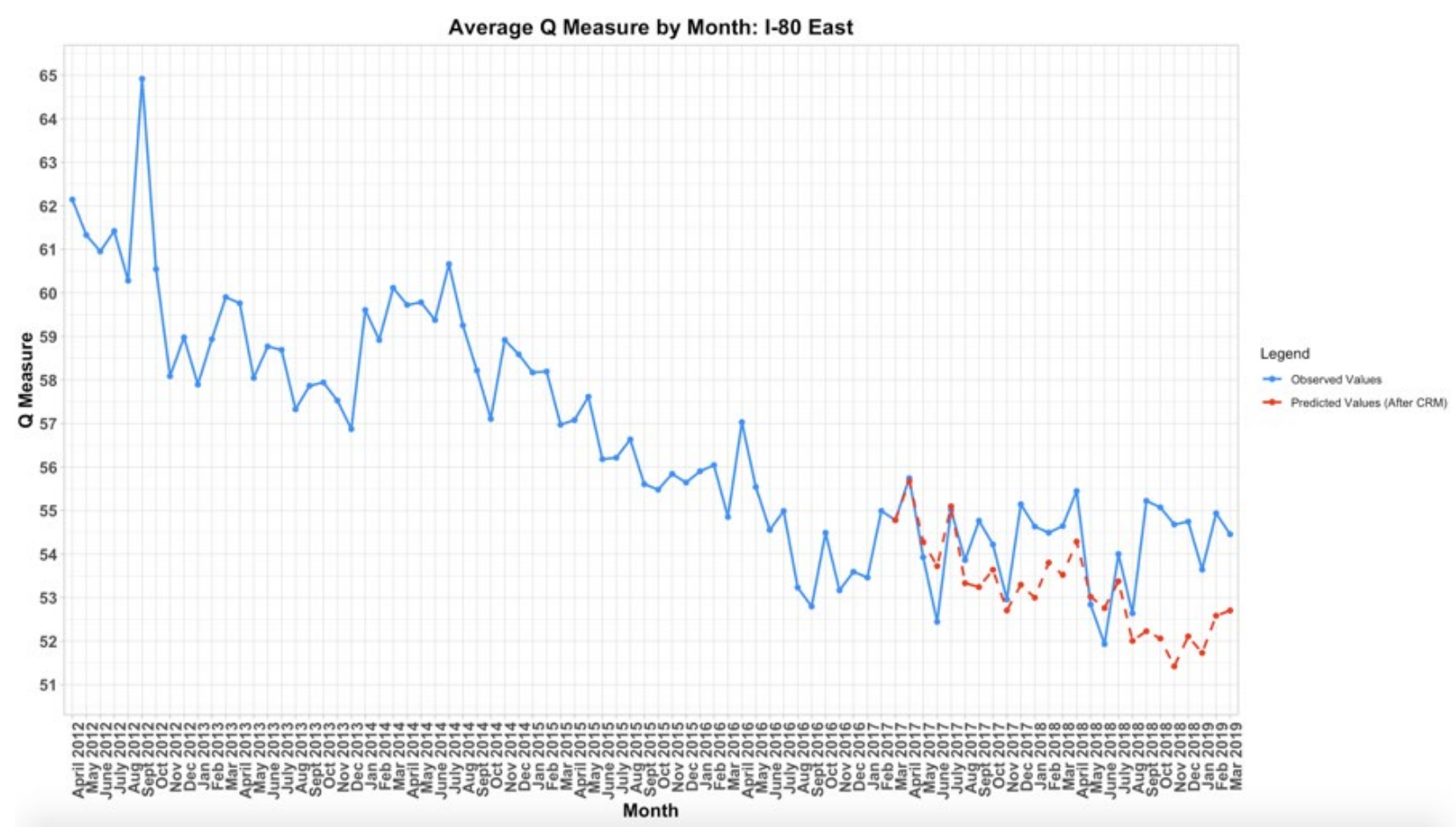

Figure 34. Average Observed Q per Month and Average Predicted Q per Month on I-80 Eastbound

Another regression model was estimated using only the 24-month I-80 "after" data with the same response and predictor variables. The model from the 24-month data had an Adjusted $R^{2}$ value of 0.7071 . Interestingly, the coefficient of the trend variable in this model was -0.0169 ( $p$-value $=0.0022$ ). This reduction in the coefficient for trend compared to the "before" data model, along with the predicted versus observed values shown in Figure 34, indicates that CRM deployment likely alleviated the continuously decreasing trend in $Q$ on I-80.

\section{Empirical Bayes Estimates for I-80}

The researchers obtained the empirical Bayes estimates from the weighted average of the counterfactual values and the observed values of $Q$ from the pre-deployment phase. The weight used is the $R^{2}$ value, which was about 0.62 for the regression model used for I-80 East. Figure 35 shows the monthly averages of the empirical Bayes estimates plotted along with the monthly averages of the observed values for the 24 months in the postdeployment phase. For the first few months after the CRM deployment, the estimates were either greater than or approximately equal to the observed values, indicating that the CRM system did not effectively mitigate the traffic. However, toward the last few months, one can notice that the observed values are higher than the estimates. Out of the 24 months that were considered, 14 months had averaged observed values that were higher than their respective averaged estimates. 


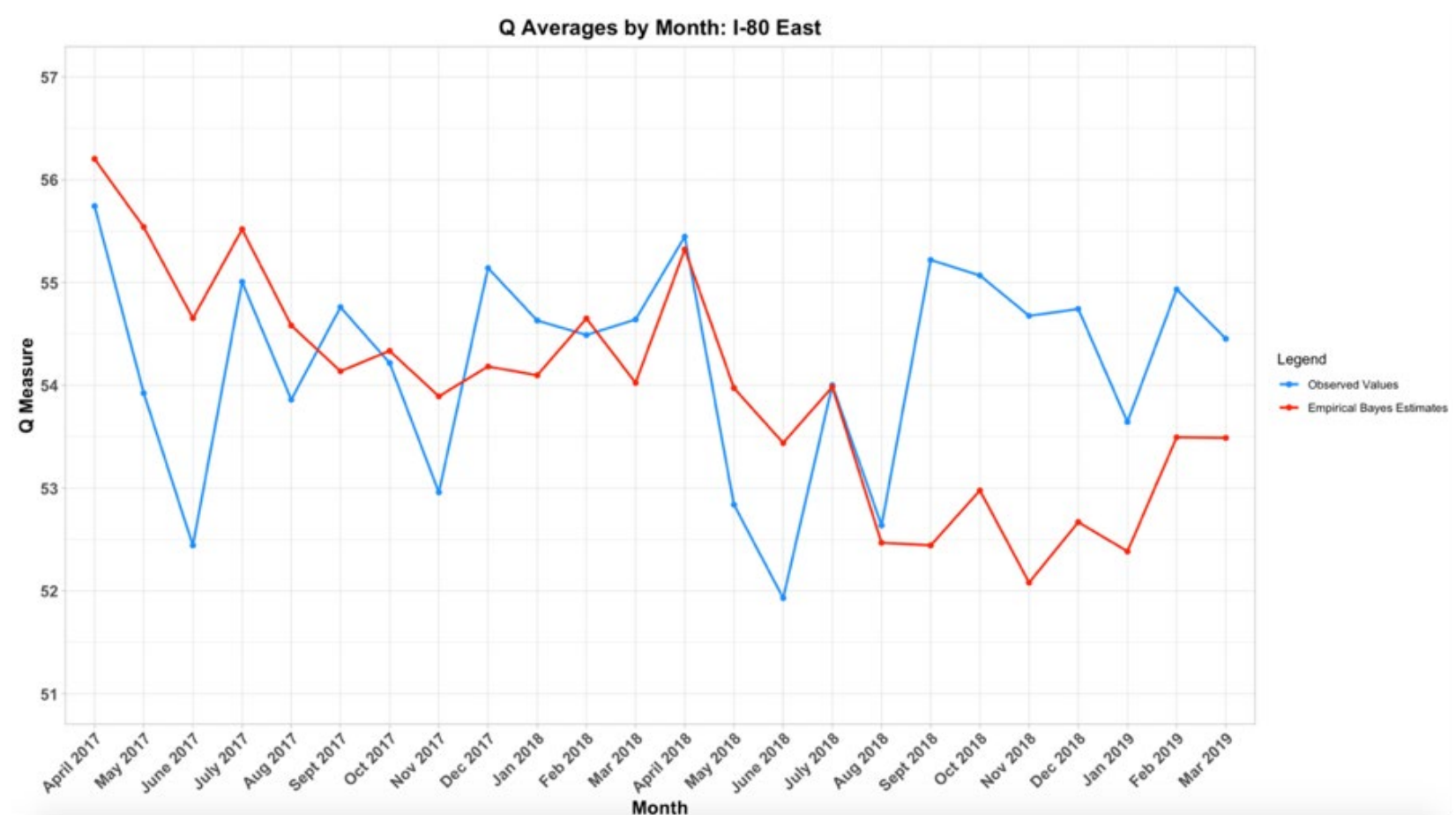

Figure 35. Average Observed $Q$ per Month and Average EB Estimates of $Q$ per Month on I-80 Eastbound

\section{Analysis of I-280 Data}

The next step in the analysis was to validate the approach using data from the control corridor, I-280 Southbound. With no major changes to the corridor, the researchers expect the counterfactual estimate from the model shown in Equation to capture the I-280 "after"period $Q$ data. A regression model similar to the I-80 Eastbound with the same predictor variables was estimated for I-280. Table 3 shows the coefficients for the I-280 model, which had an Adjusted $R^{2}$ value of 0.6178 . There is a decreasing trend in the average value of $Q$, echoing the trend that was observed in the I-80 data along with the seasonal variations. The coefficient for this trend in the regression model was -0.1375 . 
Table 3. Regression Model Coefficients for Estimating $\mathbf{Q}^{*}$ on I-280 Using FiveYear Pre-Deployment Data

\begin{tabular}{llllll}
\hline \multicolumn{1}{c}{ Variable } & \multicolumn{1}{c}{ Coefficient } & \multicolumn{1}{c}{ p-value } & \multicolumn{1}{c}{ Variable } & \multicolumn{1}{c}{ Coefficient } & p-value \\
\hline Intercept & 79.6002 & $<0.0001$ & Month : Oct & -1.3385 & $<0.0001$ \\
AADT & -0.1024 & $<0.0001$ & Month : Nov & -1.892 & $<0.0001$ \\
Month: Feb. & -0.6254 & 0.00187 & Month : Dec & 0.475 & 0.01586 \\
Month: Mar. & -0.0114 & 0.95329 & Day : Mon & -8.386 & $<0.0001$ \\
Month: Apr. & 0.5645 & 0.00424 & Day : Tues & -10.7411 & $<0.0001$ \\
Month: May & 0.163 & 0.40843 & Day : Wed & -11.5197 & $<0.0001$ \\
Month: June & 0.8457 & $<0.0001$ & Day : Thurs & -11.635 & $<0.0001$ \\
Month: July & 1.534 & $<0.0001$ & Day : Fri & -9.1135 & $<0.0001$ \\
Month: Aug. & 0.5272 & 0.00786 & Day : Sat & -0.0269 & 0.86015 \\
Month: Sept. & -0.7253 & 0.00051 & Trend & -0.1375 & $<0.0001$ \\
\hline
\end{tabular}

\section{Comparison of I-80 and I-280 Models}

Comparing coefficients for models shown in Table 3 and Table 4 justifies the choice of I-280 as the control corridor. The coefficients are positive for both models during spring and summer, meaning a higher value of $Q$ is expected for those seasons on both highways. There is also a similar decreasing trend in $Q$ on both corridors, as represented by the coefficients for the trend variable in the I-80 and I-280 regression models: -0.1046 and -0.1375 , respectively.

Another regression model was estimated using just the 24-month "after" data for I-280 Southbound using the same response and predictor variables. Interestingly, the coefficient of the trend variable in the new model was -0.0377 ( $p$-value $=0.00169$ ). Note that the reduction in the magnitude of the model coefficient for the trend variable for I-280 (from - 0.1375 to -0.0377 ) is lower than what was noted for I-80 Eastbound (from -0.1046 to -0.0169 ).

The model coefficients shown in Table 4 were then used to estimate the counterfactual value $Q^{*}$ on I-280 for each of the 24 months that were part of the post-deployment period. Figure 36 shows the monthly averages of both the predicted values $Q^{*}$ and the observed values $Q$ for I-280. It may be observed that the predicted and observed values for the I-280 model in Figure 36 track each other more closely than was the case for the I-80 model (shown in Figure 34). This indicates that CRM has been effective in arresting the declining trend in Efficiency. 


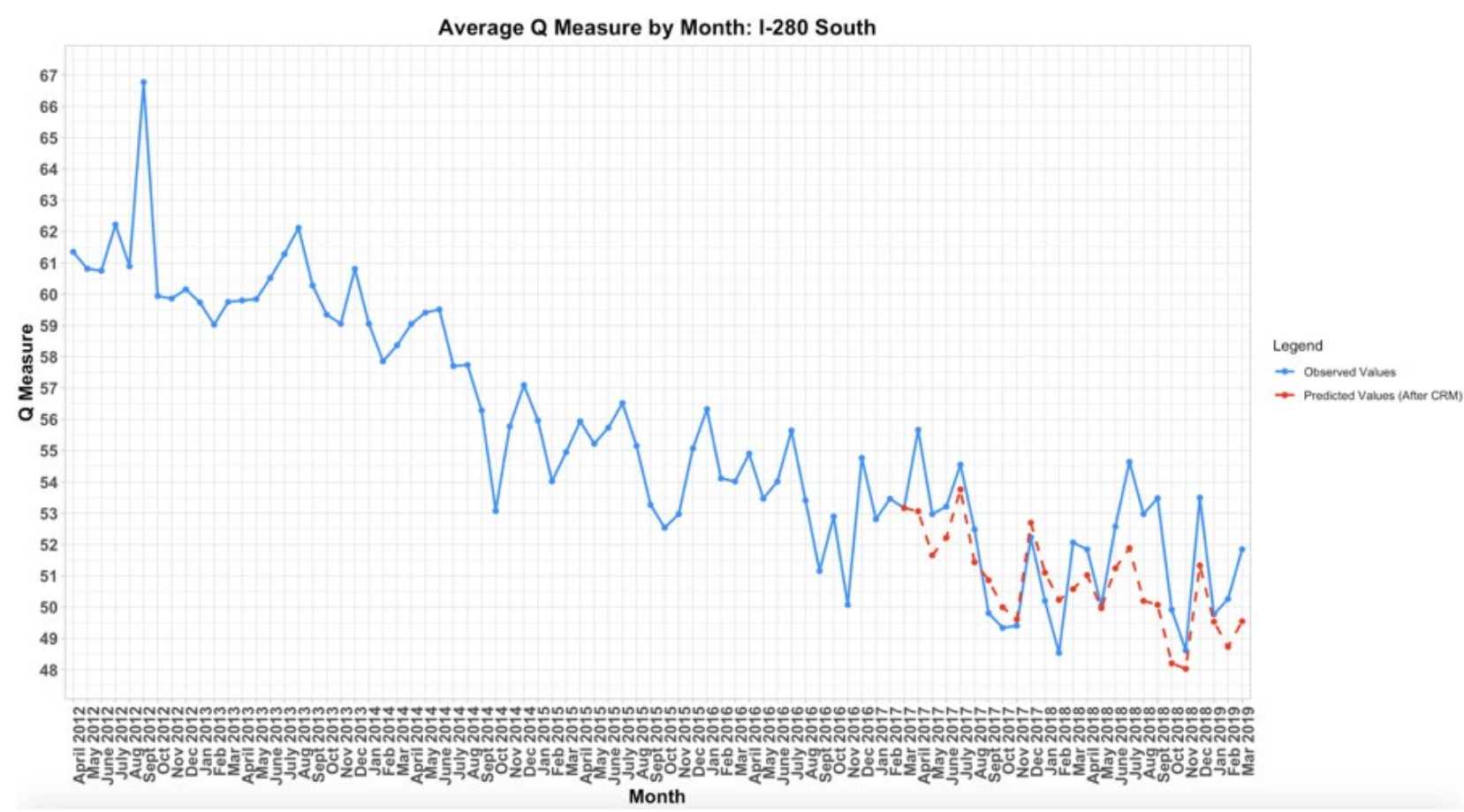

Figure 36. Average $Q$ per Month Along with Predicted Counterfactual Estimates

Table 4 shows the statistical correlation coefficients between $Q^{*}$ and $Q$ for both I-80 and I-280 corridors. The table also shows $p$-values for the null hypothesis of no correlation between $Q^{*}$ and $Q$. In the case of all three correlation coefficients ${ }^{44}$ shown in Table 4, there is sufficient evidence to reject the null hypothesis in the case of I-280 but not in the case of I-80. In other words, the counterfactual versus post-deployment data are correlated for I-280 (the control corridor) but not for I-80 (the treatment corridor). Hence, the estimate for the postdeployment period obtained from the I-80 model shown in Table 2 may be used as a reliable counterfactual estimate.

\section{Table 4. Correlation Between Counterfactual Estimate $\mathbf{Q}^{*}$ and Actual Post- Deployment Values $Q$ on I-80 and I-280}

\begin{tabular}{lcc}
\hline & $\begin{array}{c}\text { I-80 Predicted }\left(\mathbf{Q}^{*}\right) \text { vs. } \\
\text { Actual }(\mathbf{Q})\end{array}$ & $\begin{array}{c}\text { I-280 Predicted }\left(\mathbf{Q}^{*}\right) \text { vs. } \\
\text { Actual }(\mathbf{Q})\end{array}$ \\
\hline Pearson Correlation Coefficients, $\mathrm{N}=24$ & 0.263 & 0.745 \\
p-value (H0: Rho=0) & 0.2151 & $<.0001$ \\
Spearman Correlation Coefficients, $\mathrm{N}=24$ & 0.161 & 0.719 \\
p-value (H0: Rho=0) & 0.4527 & $<.0001$ \\
Kendall Tau B Correlation Coefficients, $\mathrm{N}=24$ & 0.109 & 0.522 \\
p-value (H0: Rho=0) & 0.4568 & 0.0004 \\
\hline
\end{tabular}

\section{Estimating Efficacy of the CRM}

Table 5 shows the difference between the counterfactual estimate and actual value of $Q$ for each month in the "after" period for I-80 Eastbound sorted by the largest increase in $Q$ compared to the counterfactual estimate. Accordingly, the researchers note that while the 
gains vary from month to month, 17 out of the 24 months had efficiency higher by between $1.0 \%$ to $6.3 \%$ compared to the counterfactual scenario, while two months (June 2017 and June 2018 ) show average efficiency lower by $1.6 \%$ and $2.4 \%$.

Table 5. Efficiency Gains on I-80 Eastbound Compared to the Counterfactual Estimates

\begin{tabular}{llcccc}
\hline Rank order & Month & Year & $\begin{array}{c}\text { Real-World } \\
\mathbf{Q}\end{array}$ & $\begin{array}{c}\text { Counterfactual } \\
\mathbf{Q}^{*}\end{array}$ & $\begin{array}{c}\text { \% Increase in Q Over the } \\
\text { Counterfactual Estimate }\end{array}$ \\
\hline 1 & Nov. & 2018 & 54.68 & 51.42 & $6.3 \%$ \\
2 & Oct. & 2018 & 55.07 & 52.06 & $5.8 \%$ \\
3 & Sept. & 2018 & 55.22 & 52.23 & $5.7 \%$ \\
4 & Dec. & 2018 & 54.74 & 52.11 & $5.1 \%$ \\
5 & Feb. & 2019 & 54.93 & 52.58 & $4.5 \%$ \\
6 & Jan. & 2019 & 53.64 & 51.73 & $3.7 \%$ \\
7 & Dec. & 2017 & 55.14 & 53.29 & $3.5 \%$ \\
8 & Mar. & 2019 & 54.45 & 52.70 & $3.3 \%$ \\
9 & Jan. & 2018 & 54.63 & 53.00 & $3.1 \%$ \\
10 & Sept. & 2017 & 54.76 & 53.24 & $2.8 \%$ \\
11 & April & 2018 & 55.45 & 54.28 & $2.1 \%$ \\
12 & Mar. & 2018 & 54.64 & 53.52 & $2.1 \%$ \\
13 & Feb. & 2018 & 54.49 & 53.80 & $1.3 \%$ \\
14 & Aug. & 2018 & 52.64 & 52.00 & $1.2 \%$ \\
15 & July & 2018 & 54.00 & 53.37 & $1.2 \%$ \\
16 & Oct. & 2017 & 54.22 & 53.64 & $1.1 \%$ \\
17 & Aug. & 2017 & 53.86 & 53.33 & $1.0 \%$ \\
18 & Nov. & 2017 & 52.96 & 52.71 & $0.5 \%$ \\
19 & April & 2017 & 55.74 & 55.67 & $0.1 \%$ \\
20 & July & 2017 & 55.01 & 55.09 & $-0.2 \%$ \\
21 & May & 2018 & 52.84 & 53.02 & $-0.3 \%$ \\
22 & May & 2017 & 53.93 & 54.28 & $-0.7 \%$ \\
23 & June & 2018 & 51.93 & 52.76 & $-1.6 \%$ \\
24 & June & 2017 & 52.44 & 53.72 & $-4 \%$ \\
\hline & & & & &
\end{tabular}

\section{Regression Model for SR-99 North}

The researchers fit a regression model with the same predictor and response variables to estimate the counterfactual values of $Q$ for SR-99. However, when the researchers compared the observed values of $Q$ during the pre- and post-deployment phase on SR99 , a sudden increase was noticed in the monthly average value of $Q$ during the postdeployment period, as shown in Figure 37. This sudden increase seems to be due to some unaccounted-for measurement error. Therefore, for District 3 , the researchers analyzed the change in the trend coefficient from the fitted regression model to assess the impact due to the CRM deployment. The issue with the data has been reported to the Caltrans staff, who are following up with the vendor. 


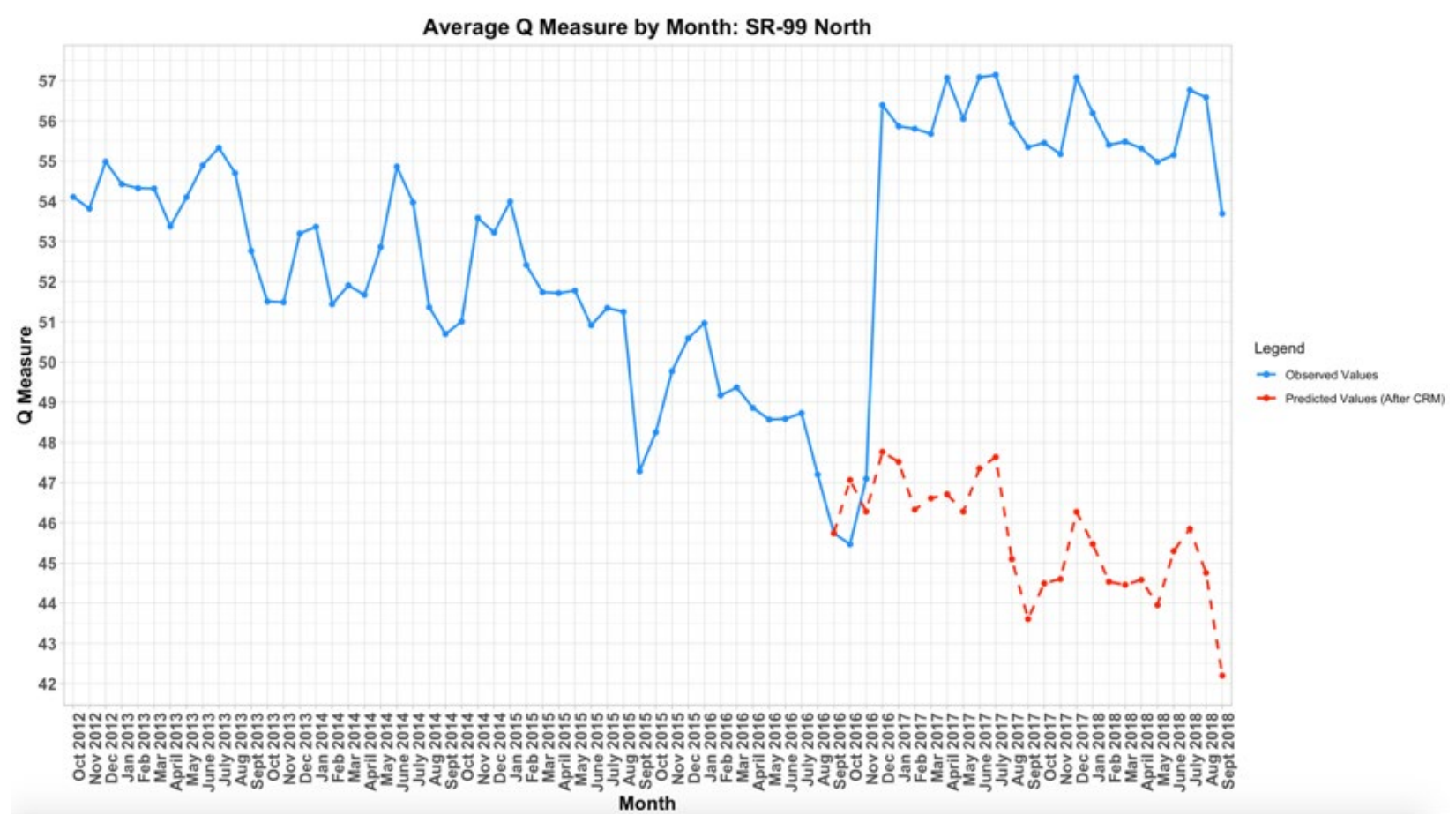

Figure 37. Average $Q$ per Month along with Predicted Counterfactual Estimates for SR-99 NB

Table 6 summarizes the coefficients from the regression model fit using the SR-99 data. The model uses the 48 months of pre-deployment data and had an Adjusted $R^{2}$ value of 0.6985. The trend coefficient for this model is -0.1441 , meaning that during each subsequent month, the average value of $Q$ is expected to decrease by about 0.14 .

The researchers fit another regression model using the 24 months from the post-deployment phase. This model had an Adjusted $R^{2}$ value of 0.5839 , and the researchers found that the trend coefficient has increased to 0.0816 ( $p$-value $<0.0001$ ). This indicates that in the postdeployment phase, the researchers expect the average value of $Q$ to increase by 0.08 every subsequent month.

Table 6. Regression Model Coefficients on SR-99 NB Using Four-Year PreDeployment Data

\begin{tabular}{llllll}
\hline \multicolumn{1}{c}{ Variable } & \multicolumn{1}{c}{ Coefficient } & \multicolumn{1}{c}{ p-value } & \multicolumn{1}{c}{ Variable } & \multicolumn{1}{c}{ Coefficient } & \multicolumn{1}{c}{ p-value } \\
\hline Intercept & 62.798 & $<0.0001$ & Month : Oct & -2.417 & $<0.0001$ \\
AADT & 0.2093 & $<0.0001$ & Month : Nov & -1.8426 & $<0.0001$ \\
Month: Feb. & -1.3432 & $<0.0001$ & Month : Dec & -0.2291 & 0.2262 \\
Month: Mar. & -1.173 & $<0.0001$ & Day : Mon & -8.5895 & $<0.0001$ \\
Month: Apr. & -1.3588 & $<0.0001$ & Day : Tues & -11.0271 & $<0.0001$ \\
Month: May & -1.1677 & $<0.0001$ & Day : Wed & -11.3449 & $<0.0001$ \\
Month: June & -0.0616 & 0.752 & Day : Thurs & -11.2457 & $<0.0001$ \\
Month: July & -0.1289 & 0.5076 & Day : Fri & -9.9223 & $<0.0001$ \\
Month: Aug. & -1.7916 & $<0.0001$ & Day : Sat & -2.6928 & $<0.0001$ \\
Month: Sept. & -3.4722 & $<0.0001$ & Trend & -0.1441 & $<0.0001$ \\
\hline
\end{tabular}




\section{Regression Model for I-5 Northbound (Control Corridor)}

The researchers further validated this approach for SR-99 $\mathrm{N}$ by using the same 48 months of pre-deployment data from I-5 NB to fit a regression model. This model had an Adjusted $R^{2}$ value of 0.6569 . Table 7 summarizes the coefficients from the regression model fit using the I-5 data. The trend coefficient for this model is -0.1193 , meaning that during each subsequent month, the average value of $Q$ is expected to decrease by almost 0.12 .

The researchers fit another regression model using the 24 months from the post-deployment phase for I-5. This model had an Adjusted $R^{2}$ value of 0.5086 , and the researchers found that the trend coefficient has increased to 0.0483 (p-value $<0.0001$ ).

Table 7. Regression Model Coefficients on I-5 Using Four-Year Pre-Deployment Data

\begin{tabular}{llllll}
\hline \multicolumn{1}{c}{ Variable } & \multicolumn{1}{c}{ Coefficient } & \multicolumn{1}{c}{ p-value } & \multicolumn{1}{c}{ Variable } & Coefficient & \multicolumn{1}{c}{ p-value } \\
\hline Intercept & 51.8618 & $<0.0001$ & Month : Oct & -2.6474 & $<0.0001$ \\
AADT & 0.1513 & $<0.0001$ & Month : Nov & -1.9258 & $<0.0001$ \\
Month: Feb. & -1.8078 & $<0.0001$ & Month : Dec & -0.3596 & 0.0391 \\
Month: Mar. & -1.733 & $<0.0001$ & Day : Mon & -7.2836 & $<0.0001$ \\
Month: Apr. & -1.6956 & $<0.0001$ & Day : Tues & -13.204 & $<0.0001$ \\
Month: May & -1.3839 & $<0.0001$ & Day : Wed & -13.4126 & $<0.0001$ \\
Month: June & -1.7359 & $<0.0001$ & Day : Thurs & -12.5762 & $<0.0001$ \\
Month: July & -0.6898 & 0.0002 & Day : Fri & -10.5002 & $<0.0001$ \\
Month: Aug. & -2.2278 & $<0.0001$ & Day : Sat & -5.1022 & $<0.0001$ \\
Month: Sept. & -4.4633 & $<0.0001$ & Trend & -0.1193 & $<0.0001$ \\
\hline
\end{tabular}

\section{Comparison of SR-99 and I-5 Models}

Comparing Tables 6 and 7, the researchers observe the similarities between SR-99 and I-5. For both models, the coefficients are negative for all months. This means that compared to the base month of January, the researchers expect a lower value of $Q$ during the rest of the year. There is also a similar decreasing trend in $Q$ on both corridors as represented by the coefficients of the trend variable in the SR-99 and I-5 regression models, -0.1441 and -0.1193 , respectively. Furthermore, in both freeways, the researchers observe the postdeployment change to a positive trend coefficient. However, the researchers note that the reduction in the magnitude of the coefficient for the trend variable for I-5 Northbound (from -0.1193 to 0.0483 ) is lower than what was noted for SR-99 Northbound (from - 0.1441 to 0.0816). It indicates that CRM implementation has been effective in reducing the decline in Efficiency.

\section{EFFICIENCY ANALYSIS CONCLUSIONS}

Consistent with the recommendation from recent SHRP 2 research, this work uses long-term data on segment space mean speeds as a measure of efficiency for the before-and-after evaluation. The research introduced an empirical Bayesian approach to conduct a before- 
and-after analysis of the operational data post-CRM deployment. Thus far, such an approach has been limited to safety evaluation (used and documented in the next chapter), where it is well-accepted. This analysis represents a more robust approach than the comparisons that use before-period and after-period data from the same facility or designed experiments that use data over a period of only several days.

The results show that the I-80 Eastbound corridor showed an increase in efficiency as high as $6.3 \%$ (during November 2018) compared to the counterfactual scenario, with 17 out of the 24 months in the "after" period showing improvements. The researchers envision that procedures based on the approach presented here would become the state of practice for the before-and-after evaluations of ITS deployments, as is the case with evaluations of crash countermeasures in the realm of traffic safety. 


\section{SAFETY ANALYSIS}

\section{RESEARCH SCOPE}

Ramp metering helps to split up platoons of vehicles so that a large number of vehicles do not have to compete for the same limited gaps in traffic. When the meters are active, smoother merging maneuvers and less stop-and-go movements can be expected, which can ultimately reduce the probability of a collision. Hence, one expects ramp metering installations to lead to safety benefits in addition to the expected operational benefits. This chapter focuses on the before-and-after safety evaluation of SR-99 and I-80 corridors in Districts 3 and 4 in California. First, data preparation and methodology have been elaborated followed by the safety analysis results found in the study corridors.

\section{DATA}

Data needed for the safety analysis were collected using Caltrans' databases (road geometric and traffic volume) and Google Earth. Historical crashes were also collected using Caltrans' Traffic Accident Surveillance and Analysis System (TASAS) database from the respective District staff. The following items were extracted from the Caltrans data sets:

- Annual Average Daily Traffic (AADT),

- Number of crashes,

- Number of traffic lanes,

- Width of the traffic lanes,

- Outside/inside shoulder width,

- Median width,

- Traffic barrier presence.

Also, the following items were found from aerial images from Google Earth: Clear zone length,

- Rumble strips presence (by using Street View),

- Traffic barrier width,

- Distance to traffic barrier face (on the right side of the direction of travel),

- Lengths and locations of ramps,

- Weaving area type (by reviewing existing geometry between ramps). 
In the cases with any missing information regarding road geometric characteristics, AutoCAD 2018 was used to add geometric features of the missing rows in the data set. For example, AutoCAD was used to estimate the radius of horizontal curves. The estimation was done by inserting an image (using Google Earth) into AutoCAD. In the next step, the scale of the image was matched with existing geometry. Then, the radius was estimated by overlapping an arc on the centerline of the road.

\section{METHODOLOGY}

The analysis here is based on an empirical Bayes before-and-after safety evaluation conducted using Enhanced Interchange Safety Analysis Tool (ISATe) developed based on National Cooperative Highway Research Program (NCHRP) Project 17-45. ISATe provides a safety prediction method to estimate average crash frequency considering the relationship among the number of historical crashes, traffic demand, and different road design elements (e.g., lane width, shoulder width, horizontal curve radius). The safety analysis provided in ISATe is intended to be used on freeway facilities, including freeway main lanes and interchanges, to inform decision-makers and engineers about the expected safety performance of different design countermeasures and alternatives.

ISATe uses the empirical Bayes (EB) approach for combining the observed crash data and the prediction model. The EB method increases the accuracy of the estimated average crash frequency by pooling the estimate from a predictive model with the subject location's historical crash data. Figure 38 illustrates a framework of the EB process for safety analysis. The EB method compares the counterfactual estimate of safety (i.e., B in Figure 38) with the actual safety experience post-treatment (i.e., A in Figure 38). More information about Highway Safety Manual-recommended EB safety analysis can be found in Hauer et al.

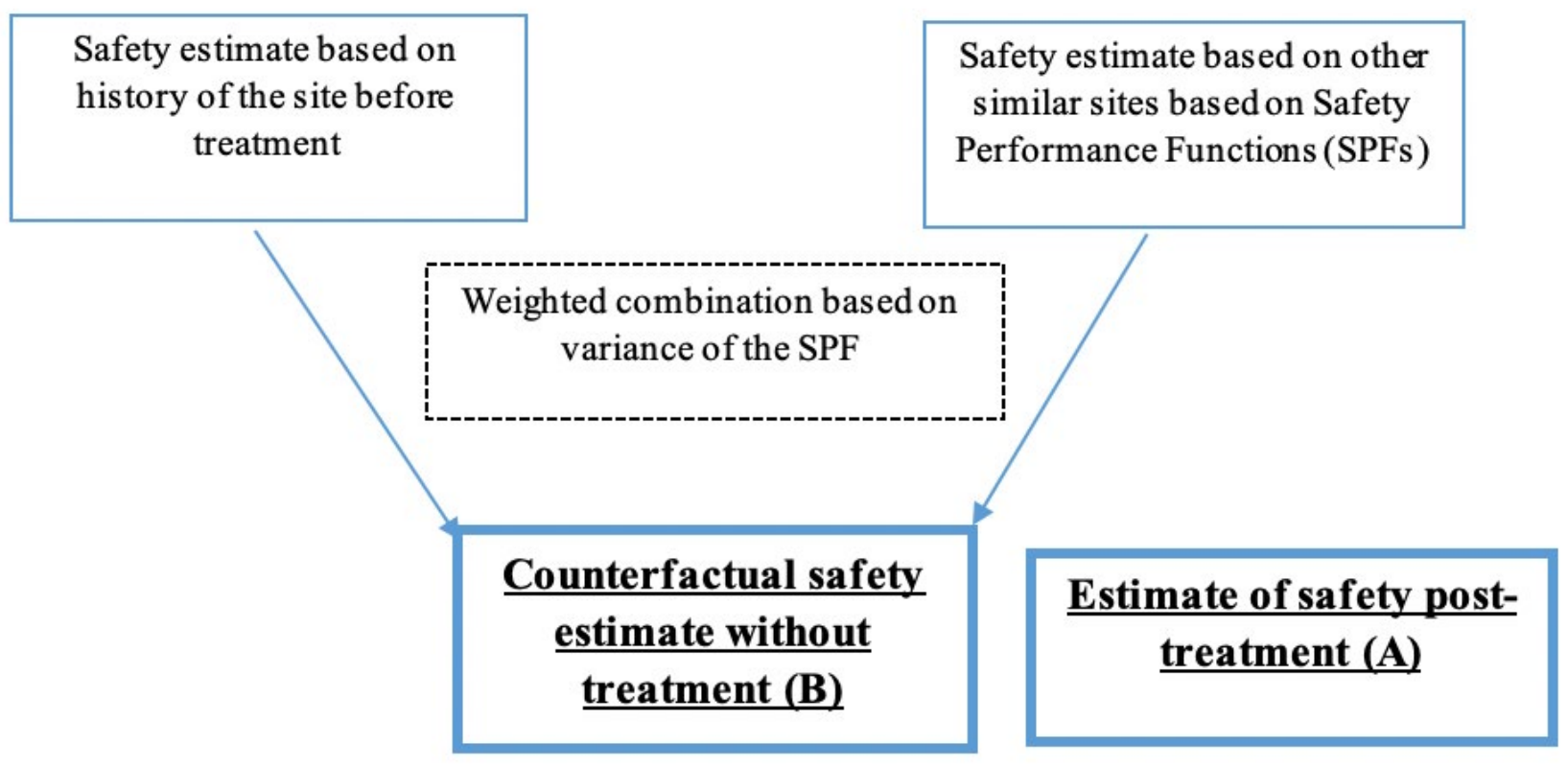

Figure 38. EB-Based Before/After Evaluation Framework

The ISATe model considers the KABCO injury scale ("K"-fatal injuries, "A"-incapacitating injuries, "B"-non-incapacitating injuries, "C"-possible (but not evident) injuries, "O"-no 
injury) developed by the National Safety Council (NSC) to predict the number of crashes based on different levels of crash severity. ${ }^{45}$ The KABCO scale developed by the NSC defines five categories for crashes:

- Type K: the crashes that resulted in at least a fatal injury (FI)

- Type A: the crashes that resulted in at least an incapacitating injury

- Type B: the crashes that resulted in at least a non-incapacitating injury

- Type C: the crashes that resulted in at least a possible injury

- Type O: the crashes that resulted in property damage only (PDO) with no injury

It should be noted that the ISATe predictive method does not account for the presence of the high-occupancy vehicle (HOV) lanes on the freeway. An HOV lane is a travel lane considered for the use of vehicles with a driver and one or more passengers, including carpools, vanpools, and buses. ${ }^{46}$ Based on Colwill, ${ }^{47}$ an increase of $15 \%$ in crashes can be expected after adding HOV lanes; however, the increase will mostly affect the number of no-injury crashes, especially rear-end collisions. In fact, fatal and injury (FI) crashes were found to be unaffected by the addition of HOV lanes, as a CMF equal to 1.01 was estimated in the before-and-after evaluation conducted by Colwill. ${ }^{48}$ Another study estimated a CMF (for all crashes) of 1.19 for adding the High-Occupancy Toll Lanes system (HOT). ${ }^{49}$ (Note that HOT lanes have similar functional performance as HOV lanes with the difference that HOT lanes offer drivers choices to pay a higher toll rate to bypass traffic congestion of conventional travel lanes.) Since both SR-99 and I-80 corridors have HOV lanes on both directions (NB and SB) of their networks, this study applied a crash modification factor (CMF) equal to 1.15 reported in the past studies for all crashes. ${ }^{50}$ It should be mentioned that a CMF of 1.15 implies an increase of $15 \%$ in the number of all crashes after adding HOV lanes to a freeway. For example, a freeway segment with 100 crashes per year is expected to experience 115 crashes after converting one of its lanes to an HOV lane.

The ISATe predictive method does not distinguish between various traffic barrier types (i.e., cable barrier, W-beam guardrail, and concrete barrier) in terms of their different impacts on the severity of crashes hitting traffic barriers. Since both I-80 and SR-99 use types of traffic barriers typical of interstates in the U.S. (concrete barrier on the median and W-beam guardrail on the sides), no CMF or adjustment factor was considered for traffic barriers. However, it may be recommended to consider appropriate CMFs for the locations with other types of traffic barriers (i.e., cable barrier, or box beam guardrail) if future evaluations are conducted at such locations. Also, according to the ISATe manual, ${ }^{51}$ side traffic barriers were ignored in the clear zone width, as the impact of side traffic barriers was addressed in other CMFs for the predictive method (Bonneson et al., 2012). In other words, if the segment has a side traffic barrier on both directions for its entire length, then the clear zone width will not affect the model. 


\section{SAFETY ANALYSIS OF SR-99 CORRIDOR}

Different homogeneous segments should be defined along the entire corridor (freeway) for the empirical Bayes method. The segmentation process develops a group of segments with different lengths, and each segment is homogeneous with respect to features such as traffic demand, road geometric characteristics, and traffic control features. Based on the ISATe manual, ${ }^{52}$ a new homogeneous segment should be considered where there is a major change in at least one of the following features of the corridor: number of lanes, lane width, shoulder width, median width, ramp presence, and clear zone width. Therefore, 59 homogeneous segments were considered along the SR-99 corridor. On average, each segment had a length of approximately 0.38 miles. Since ISATe could fit data only for 20 segments, SR-99 data were entered using three spreadsheets.

Figures 39,40 , and 41 illustrate a summary of outcomes in segments 1-20, 21-40, and 41-59 of the SR-99 corridor, respectively. It should be noted that Figures 39-41 present the raw outcome extracted in ISATe, and no CMF has been applied regarding the HOV lanes. Table 8 shows the results found in the prediction model for the entire SR-99 after applying a CMF of 1.15 for property-damage-only crashes to account for the presence of HOV lanes. 


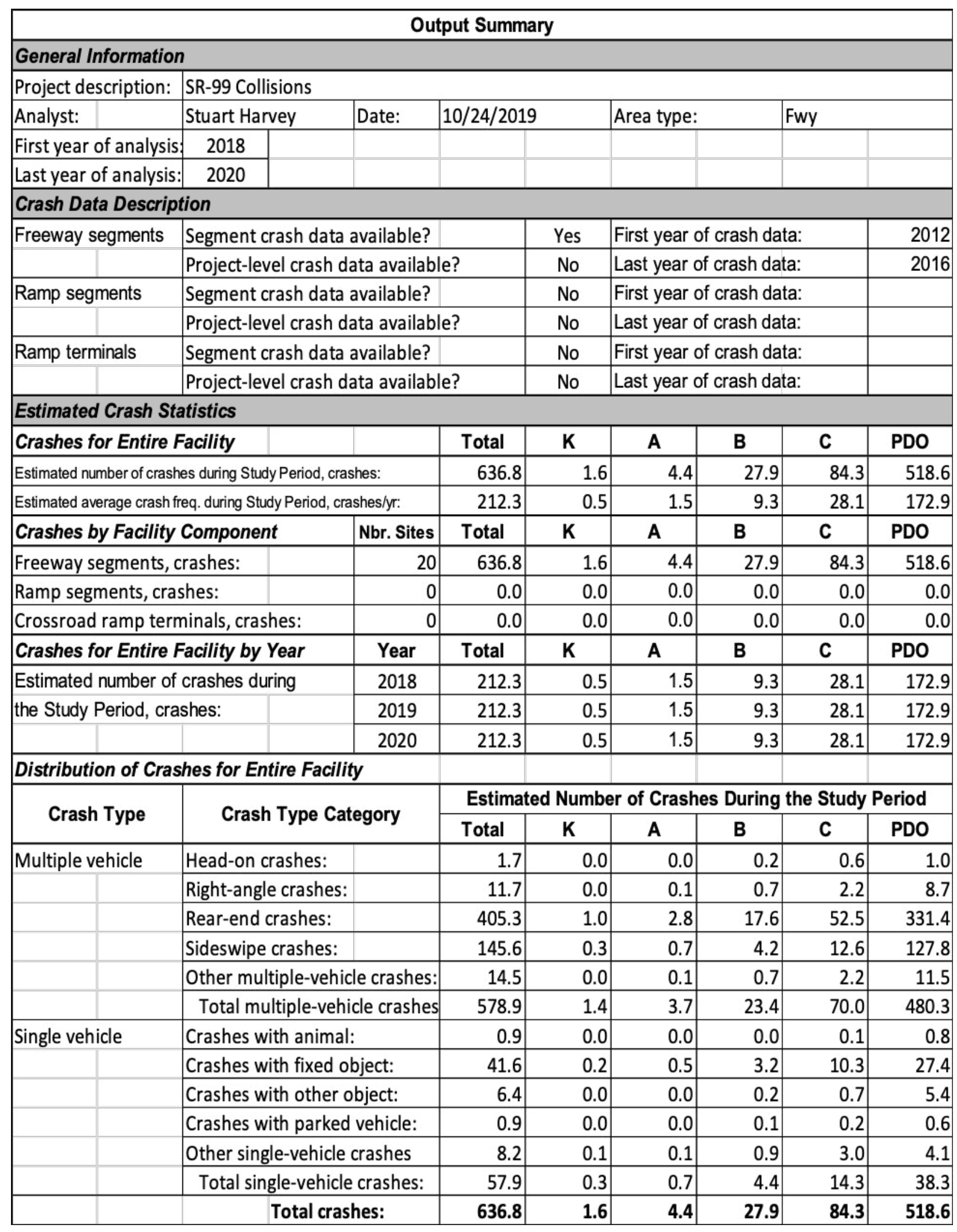

Figure 39. Expected Safety Performance in Segments 1-20 of SR-99 Corridor in 2018-2020 


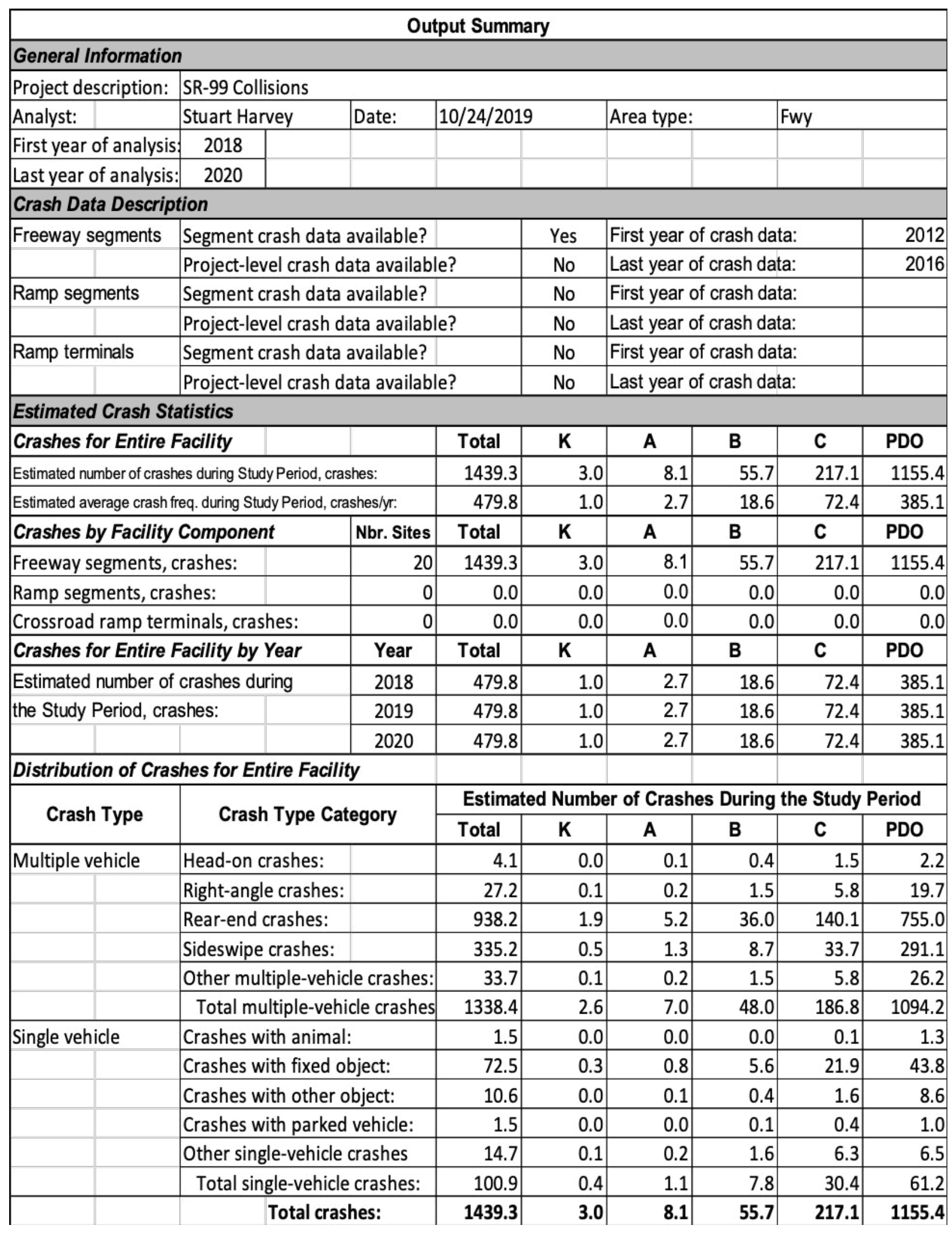

Figure 40. Expected Safety Performance in Segments 21-40 of SR-99 Corridor in 2018-2020 


\begin{tabular}{|c|c|c|c|c|c|c|c|c|c|}
\hline \multicolumn{10}{|c|}{\begin{tabular}{|l|} 
\\
\end{tabular}} \\
\hline \multicolumn{10}{|c|}{ General Information } \\
\hline \multicolumn{10}{|c|}{ Project description: SR-99 Collisions } \\
\hline Analyst: & \multicolumn{2}{|c|}{ Stuart Harvey } & \multirow[t]{2}{*}{ Date: } & \multicolumn{2}{|c|}{$10 / 24 / 2019$} & \multicolumn{2}{|l|}{ Area type: } & \multicolumn{2}{|l|}{ Fwy } \\
\hline First year of analysis: & 2018 & & & & & & & & \\
\hline Last year of analysis: & 2020 & & & & & & & & \\
\hline \multicolumn{10}{|c|}{ Crash Data Description } \\
\hline Freeway segments & \multicolumn{4}{|c|}{ Segment crash data available? } & Yes & \multicolumn{3}{|c|}{ First year of crash data: } & 2012 \\
\hline & \multicolumn{4}{|c|}{ Project-level crash data available? } & No & \multicolumn{3}{|c|}{ Last year of crash data: } & 2016 \\
\hline Ramp segments & \multicolumn{4}{|c|}{ Segment crash data available? } & No & \multicolumn{3}{|c|}{ First year of crash data: } & \\
\hline & \multicolumn{4}{|c|}{ Project-level crash data available? } & No & \multicolumn{3}{|c|}{ Last year of crash data: } & \\
\hline Ramp terminals & \multicolumn{4}{|c|}{ Segment crash data available? } & No & First year 0 & rash dat & & \\
\hline & Project-1 & el crash d & ata available & & No & Last year 0 & rash dat & & \\
\hline Estimate & tistics & & & & & & & & \\
\hline Crashes & acility & & & Total & $\mathbf{K}$ & A & B & C & PDO \\
\hline Estimated & s during $S$ & y Period, cras & shes: & 2528.2 & 4.3 & 12.0 & 80.7 & 319.6 & 2111.6 \\
\hline Estimated & q. during s & dy Period, cra & shes/yr: & 842.7 & 1.4 & 4.0 & 26.9 & 106.5 & 703.9 \\
\hline Crashes & Compon & & Nbr. Sites & Total & $K$ & A & B & C & PDO \\
\hline Freeway & rashes: & & 19 & 2528.2 & 4.3 & 12.0 & 80.7 & 319.6 & 2111.6 \\
\hline Ramp se & hes: & & 0 & 0.0 & 0.0 & 0.0 & 0.0 & 0.0 & 0.0 \\
\hline Crossroa & inals, $\mathrm{cr}$ & hes: & 0 & 0.0 & 0.0 & 0.0 & 0.0 & 0.0 & 0.0 \\
\hline Crashes & acility b & Year & Year & Total & $\mathbf{K}$ & A & B & C & PDO \\
\hline Estimate & crashes & ring & 2018 & 842.7 & 1.4 & 4.0 & 26.9 & 106.5 & 703.9 \\
\hline the Study & hes: & & 2019 & 842.7 & 1.4 & 4.0 & 26.9 & 106.5 & 703.9 \\
\hline & & & 2020 & 842.7 & 1.4 & 4.0 & 26.9 & 106.5 & 703.9 \\
\hline Distribu & es for & tire Facilit & & & & & & & \\
\hline Cras & $\mathrm{Cra}$ & Tyne Cat & eagry & Estimat & d Numbe & r of Crashe & During t & the Study F & eriod \\
\hline Gias & & I Iуре Сat & egory & Total & $K$ & A & B & C & PDO \\
\hline Multiple & Head-or & rashes: & & 7.0 & 0.0 & 0.1 & 0.6 & 2.3 & 4.1 \\
\hline & Right-an & e crashes: & & 48.0 & 0.1 & 0.3 & 2.2 & 8.7 & 36.7 \\
\hline & Rear-en & crashes: & & 1681.9 & 2.8 & 7.9 & 53.6 & 212.2 & 1405.4 \\
\hline & Sideswip & crashes: & & 608.5 & 0.7 & 1.9 & 12.9 & 51.0 & 542.0 \\
\hline & Other $\mathrm{m}$ & tiple-vehic & le crashes: & 60.2 & 0.1 & 0.3 & 2.2 & 8.7 & 48.8 \\
\hline & Total $r$ & Itiple-vehi & cle crashes & 2405.7 & 3.8 & 10.6 & 71.4 & 282.9 & 2037.0 \\
\hline Single ve & Crashes & ith animal & & 1.8 & 0.0 & 0.0 & 0.0 & 0.1 & 1.6 \\
\hline & Crashes & ith fixed o & bject: & 88.0 & 0.3 & 1.0 & 6.7 & 26.5 & 53.5 \\
\hline & Crashes & ith other o & bject: & 12.9 & 0.0 & 0.1 & 0.5 & 1.9 & 10.5 \\
\hline & Crashes & ith parked & vehicle: & 1.9 & 0.0 & 0.0 & 0.1 & 0.5 & 1.2 \\
\hline & Other si & le-vehicle & crashes & 17.9 & 0.1 & 0.3 & 1.9 & 7.6 & 7.9 \\
\hline & Total s & gle-vehicle & crashes: & 122.5 & 0.5 & 1.4 & 9.3 & 36.7 & 74.7 \\
\hline & & Total cras & hes: & 2528.2 & 4.3 & 12.0 & 80.7 & 319.6 & 2111.6 \\
\hline
\end{tabular}

Figure 41. Figure 41. Expected Safety Performance in Segments 41-59 of the SR-99 Corridor in 2018-2020 
Table 8. The Expected Safety Performance of the SR-99 Corridor Based on the ISATe Prediction Model

\begin{tabular}{|c|c|c|c|c|c|}
\hline & & SEGMENT 1 & SEGMENT 2 & SEGMENT 3 & ENTIRE CORRIDOR \\
\hline \multicolumn{2}{|l|}{ Length (Mile) } & 6.68 & 7.98 & 8.10 & 22.76 \\
\hline \multicolumn{2}{|l|}{ AADT (veh/day) } & 108,000 & 161,000 & 191,000 & 159,000 \\
\hline \multirow{3}{*}{$\begin{array}{l}\text { Average Rate of Historical } \\
\text { Crashes } \\
\text { (Per Year btw 2012-2016) }\end{array}$} & FI & 34 & 81 & 125 & 241 \\
\hline & PDO & 168 & 344 & 625 & 1,137 \\
\hline & Sum & 202 & 425 & 750 & 1,379 \\
\hline \multirow{3}{*}{$\begin{array}{c}\text { Expected Crashes (Per Year } \\
\text { btw 2018-2020), }\end{array}$} & K & 0.5 & 1.0 & 1.4 & 2.9 \\
\hline & A & 1.5 & 2.7 & 4.0 & 8.2 \\
\hline & B & 9.3 & 18.6 & 26.9 & 54.8 \\
\hline \multirow{3}{*}{$\begin{array}{c}\text { Considering CMF= } 1.15 \text { for } \\
\text { PDO crashes because of } \\
\text { HOV lanes }\end{array}$} & C & 28.1 & 72.4 & 106.5 & 207 \\
\hline & PDO & 198.8 & 442.9 & 809.5 & $1,451.2$ \\
\hline & Sum & 238.2 & 537.6 & 948.3 & $1,724.1$ \\
\hline
\end{tabular}

Based on the results, it could be expected to note 1,724 crashes on the SR-99 corridor in 2018 if no CRM had been implemented. Of the crashes, 1,451 were estimated to be property-damage-only (PDO) crashes, while the rest (273) could be involved with injuries and fatalities. This shows a ratio of about $19 \%$ for $\mathrm{FI}$ crashes vs. all crashes. The expected number of crashes per year in the after period shows an expected increase of $10 \%$ compared to the number of crashes that occurred in 2016 when 1,657 crashes were reported. This fact could be expected based on the trend observed in historical crashes. To make a clearer view of this issue, Figure 42 compares the number of actual crashes (2012-2016) and the number of crashes predicted by ISATe. Note that; crash data of 2017 was excluded in the safety analysis because CRM was implemented in the last quarter of 2016 (October 2016 on SR-99 corridor). As shown in Figure 42, an increase in the number of crashes was observed since 2014, and this growth could be continued in the next years if no safety improvements (such as CRM) was implemented.

Table 8 also indicated that segment 3 (CA Post-Mile 24.66 to 32.76) has the highest rate of expected crashes on the SR-99 corridor. Overall, 948 crashes were estimated to be reported on segment 3 on SR-99 in 2018, which includes 55\% of all crashes predicted on the entire SR-99. Reviewing data collected, higher traffic demand, presence of two (out of three) horizontal curves, narrower median width, narrower inside shoulder width, and higher frequency of ramps compared to segments 1 and 2 could be the possible reasons for more crashes on segment 3 . 


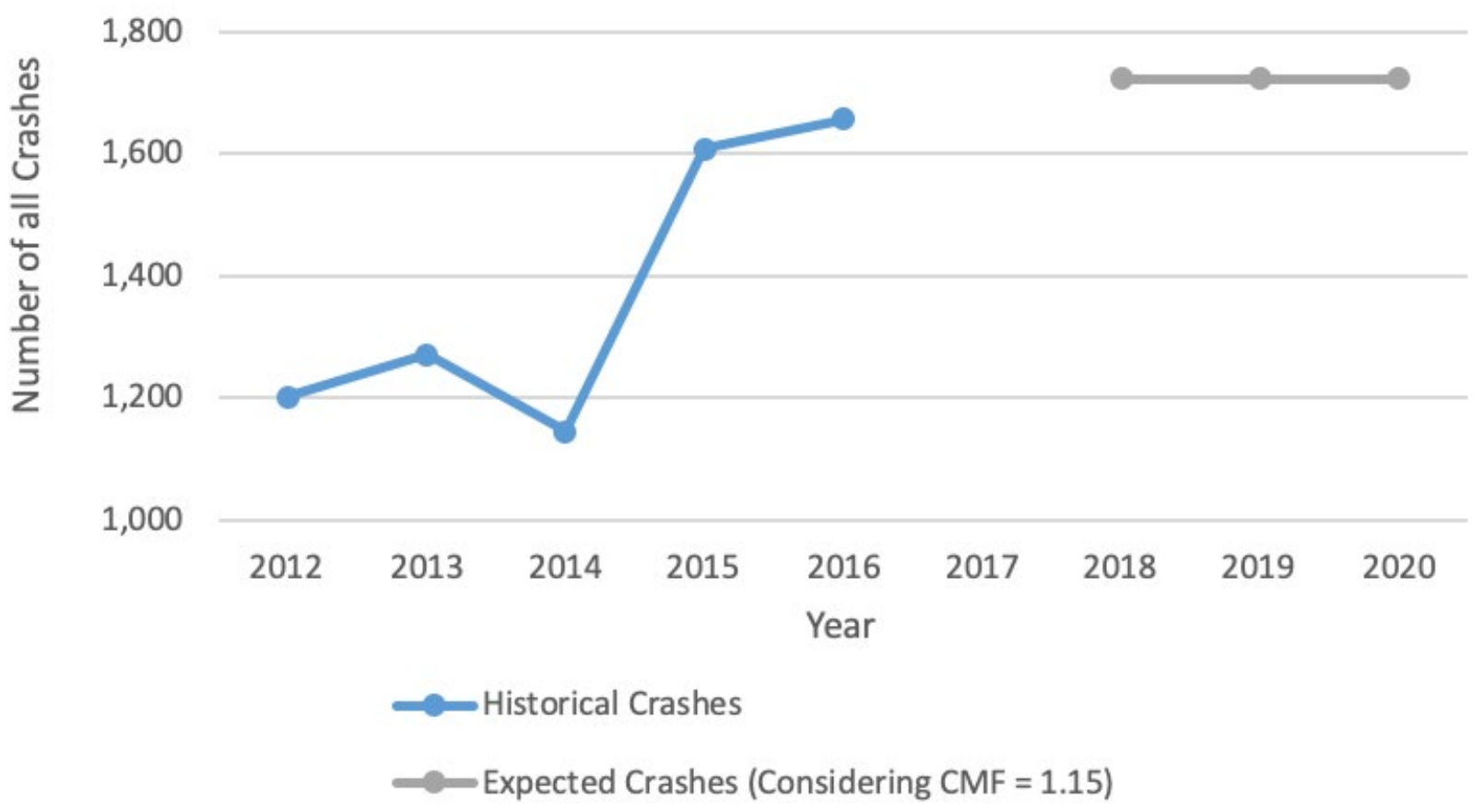

Figure 42. Number of Total Crashes Expected on the SR-99 Corridor in 2018-2020 Based on ISATe Analysis

\section{SAFETY ANALYSIS OF I-80 CORRIDOR}

Similar to the safety analysis done on SR-99, homogeneous segments were defined along the entire I-80 corridor for the EB method. Overall, 98 homogeneous segments were considered on the I-80 corridor. Averagely, each segment had a length of 0.2 miles. Therefore, road geometric, traffic volume, and crash data were entered using five spreadsheets because ISATe could not analyze more than 20 segments.

Figures 43-47 summarize the ISATe findings. Again, it should be mentioned that the results shown in Figures 43-47 did not include any CMF for the HOV lanes. Table 9 illustrates the results after applying a $C M F=1.15$ for PDO crashes in the prediction model of the I-80 corridor. 
Table 9. The Expected Safety Performance of the I-80 Corridor Based on the ISATe Prediction Model

\begin{tabular}{|c|c|c|c|c|c|c|c|}
\hline & & $\begin{array}{c}\text { SEGMENT } \\
1-20\end{array}$ & $\begin{array}{c}\text { SEGMENT } \\
21-40\end{array}$ & $\begin{array}{c}\text { SEGMENT } \\
41-60\end{array}$ & $\begin{array}{c}\text { SEGMENT } \\
61-80\end{array}$ & $\begin{array}{c}\text { SEGMENT } \\
81-98\end{array}$ & $\begin{array}{c}\text { ENTIRE } \\
\text { CORRIDOR }\end{array}$ \\
\hline \multicolumn{2}{|c|}{ Length (Mile) } & 4.25 & 3.55 & 3.86 & 3.74 & 3.91 & 19.67 \\
\hline \multicolumn{2}{|c|}{ AADT (veh/day) } & 253,400 & 181,500 & 189,600 & 179,300 & 119,900 & 186,000 \\
\hline \multirow{4}{*}{$\begin{array}{c}\text { Average Rate } \\
\text { of Historical } \\
\text { Crashes } \\
\text { (per year } \\
\text { between 2012- } \\
\text { 2016) }\end{array}$} & FI & 78 & 38 & 31 & 27 & 22 & 197 \\
\hline & PDO & 533 & 178 & 157 & 110 & 56 & 1,034 \\
\hline & Sum & 611 & 216 & 188 & 137 & 78 & 1,231 \\
\hline & & & & & & & \\
\hline \multirow{5}{*}{$\begin{array}{c}\text { Expected } \\
\text { Crashes (per } \\
\text { year between } \\
\text { 2018-2020), }\end{array}$} & K & 0.9 & 1.4 & 0.5 & 0.4 & 0.4 & 3.6 \\
\hline & A & 2.4 & 3.9 & 1.3 & 1.2 & 1.0 & 9.8 \\
\hline & B & 16.9 & 26.3 & 9.0 & 8.1 & 7.1 & 67.4 \\
\hline & C & 71.5 & 108.8 & 36.2 & 31.3 & 23.1 & 270.9 \\
\hline & PDO & 565.2 & 555.1 & 190.4 & 140.0 & 79.9 & $1,530.7$ \\
\hline $\begin{array}{c}\text { Considering } \\
\text { CMF= } 1.15 \text { for } \\
\text { PDO crashes } \\
\text { because of HOV } \\
\text { lanes }\end{array}$ & Sum & 656.9 & 695.5 & 237.4 & 181 & 111.5 & $1,882.4$ \\
\hline
\end{tabular}

According to the results, 1,882 crashes could be expected to occur on the I-80 corridor in 2018 if no CRM was implemented. Overall, 1,531 property-damage-only and 351 fatal injury crashes were expected to be reported in 2018 on the I-80 corridor. In other words, $23 \%$ of crashes would result in injuries and fatalities. Figure 48 shows the number of actual crashes (2012-2016) and the number of crashes expected in 2018 on the I-80 corridor. It should be mentioned that no crash data were included in this study for 2017 because CRM systems were implemented in April 2017 on the I-80 corridor. Based on Figure 48, crash data shows an increasing trend between 2012 and 2016. Therefore, it could be anticipated that a higher number of crashes would be observed in the after period (period after 2016)if no CRM system had been implemented. 


\begin{tabular}{|c|c|c|c|c|c|c|c|c|}
\hline \multicolumn{9}{|l|}{\begin{tabular}{|r|} 
\\
\end{tabular}} \\
\hline \multicolumn{9}{|l|}{ General Information } \\
\hline \multicolumn{9}{|c|}{\begin{tabular}{|l|l|} 
Project description: & I-80 Corridor
\end{tabular}} \\
\hline \multirow{2}{*}{\begin{tabular}{|l|} 
Analyst: \\
First year of analysis: \\
\end{tabular}} & Stuart & \multirow[t]{2}{*}{ Date: } & \multicolumn{2}{|c|}{$11 / 29 / 2019$} & \multicolumn{2}{|l|}{ Area type: } & \multicolumn{2}{|c|}{ Urban } \\
\hline & 2018 & & & & & & & \\
\hline Last year of analysis: & 2020 & & & & & & & \\
\hline \multicolumn{9}{|c|}{ Crash Data Description } \\
\hline \multirow[t]{2}{*}{ Freeway segments } & \multicolumn{3}{|c|}{ Segment crash data available? } & Yes & \multicolumn{3}{|c|}{ First year of crash data: } & 2012 \\
\hline & \multicolumn{3}{|c|}{ Project-level crash data available? } & No & \multicolumn{3}{|c|}{ Last year of crash data: } & 2016 \\
\hline \multirow[t]{2}{*}{ Ramp segments } & \multicolumn{3}{|c|}{ Segment crash data available? } & Yes & \multicolumn{3}{|c|}{ First year of crash data: } & 2018 \\
\hline & \multicolumn{3}{|c|}{ Project-level crash data available? } & No & \multicolumn{3}{|c|}{ Last year of crash data: } & 2019 \\
\hline \multirow[t]{2}{*}{ Ramp terminals } & \multicolumn{3}{|c|}{ Segment crash data available? } & Yes & \multicolumn{3}{|c|}{ First year of crash data: } & 2018 \\
\hline & \multicolumn{3}{|c|}{ Project-level crash data available? } & No & Last year of & rash dat & & 2019 \\
\hline Estimated Crash Stc & atistics & & & & & & & \\
\hline Crashes for Entire $F$ & Facility & & Total & $\mathrm{K}$ & $\mathrm{A}$ & B & $\mathrm{C}$ & PDO \\
\hline Estimated number of crash & es during Study Period, cras & shes: & 1749.5 & 2.7 & 7.3 & 50.7 & 214.4 & 1474.4 \\
\hline Estimated average crash $\mathrm{fr}$ & req. during Study Period, cra & shes/yr: & 583.2 & 0.9 & 2.4 & 16.9 & 71.5 & 491.5 \\
\hline Crashes by Facility & Component & Nbr. Sites & Total & $\mathrm{K}$ & A & B & $\mathrm{C}$ & PDO \\
\hline Freeway segments, c & crashes: & 20 & 1749.5 & 2.7 & 7.3 & 50.7 & 214.4 & 1474.4 \\
\hline Ramp segments, cras & shes: & 0 & 0.0 & 0.0 & 0.0 & 0.0 & 0.0 & 0.0 \\
\hline Crossroad ramp tern & ninals, crashes: & 0 & 0.0 & 0.0 & 0.0 & 0.0 & 0.0 & 0.0 \\
\hline Crashes for Entire $F$ & Facility by Year & Year & Total & $\mathrm{K}$ & A & $\mathbf{B}$ & $\mathrm{C}$ & PDO \\
\hline Estimated number of & crashes during & 0 & 583.2 & 0.9 & 2.4 & 16.9 & 71.5 & 491.5 \\
\hline the Study Period, cra & shes: & 1 & 583.2 & 0.9 & 2.4 & 16.9 & 71.5 & 491.5 \\
\hline & & 2 & 583.2 & 0.9 & 2.4 & 16.9 & 71.5 & 491.5 \\
\hline Distribution of $\mathrm{Cr}$ & Shes for Entire Facilit & & & & & & & \\
\hline Crach Tyne & Crach Tuno Cat & togary & Estimate & d Numbe & er of Crashe & During & the Study & eriod \\
\hline Crasn Iype & Crasn Iype Cat & egory & Total & $\mathrm{K}$ & $A$ & B & $C$ & PDO \\
\hline Multiple vehicle & Head-on crashes: & & 4.7 & 0.0 & 0.1 & 0.3 & 1.5 & 2.8 \\
\hline & Right-angle crashes: & & 32.3 & 0.1 & 0.2 & 1.3 & 5.7 & 25.0 \\
\hline & Rear-end crashes: & & 1135.1 & 1.7 & 4.7 & 32.6 & 137.9 & 958.1 \\
\hline & Sideswipe crashes: & & 411.8 & 0.4 & 1.1 & 7.9 & 33.2 & 369.3 \\
\hline & Other multiple-vehic & le crashes: & 40.6 & 0.1 & 0.2 & 1.3 & 5.7 & 33.3 \\
\hline & Total multiple-vehi & icle crashes & 1624.4 & 2.3 & 6.3 & 43.5 & 183.9 & 1388.4 \\
\hline Single vehicle & Crashes with animal: & & 2.0 & 0.0 & 0.0 & 0.0 & 0.1 & 1.9 \\
\hline & Crashes with fixed ok & bject: & 89.9 & 0.3 & 0.8 & 5.2 & 22.0 & 61.6 \\
\hline & Crashes with other 0 & bject: & 14.0 & 0.0 & 0.1 & 0.4 & 1.6 & 12.0 \\
\hline & Crashes with parked & I vehicle: & 1.9 & 0.0 & 0.0 & 0.1 & 0.4 & 1.4 \\
\hline & Other single-vehicle & crashes & 17.3 & 0.1 & 0.2 & 1.5 & 6.3 & 9.2 \\
\hline & Total single-vehicle & crashes: & 125.1 & 0.4 & 1.1 & 7.2 & 30.5 & 86.0 \\
\hline & Total crasl & hes: & 1749.5 & 2.7 & 7.3 & 50.7 & 214.4 & 1474.4 \\
\hline
\end{tabular}

Figure 43. Expected Safety Performance in Segments 1-20 of I-80 Corridor in 2018-2020 


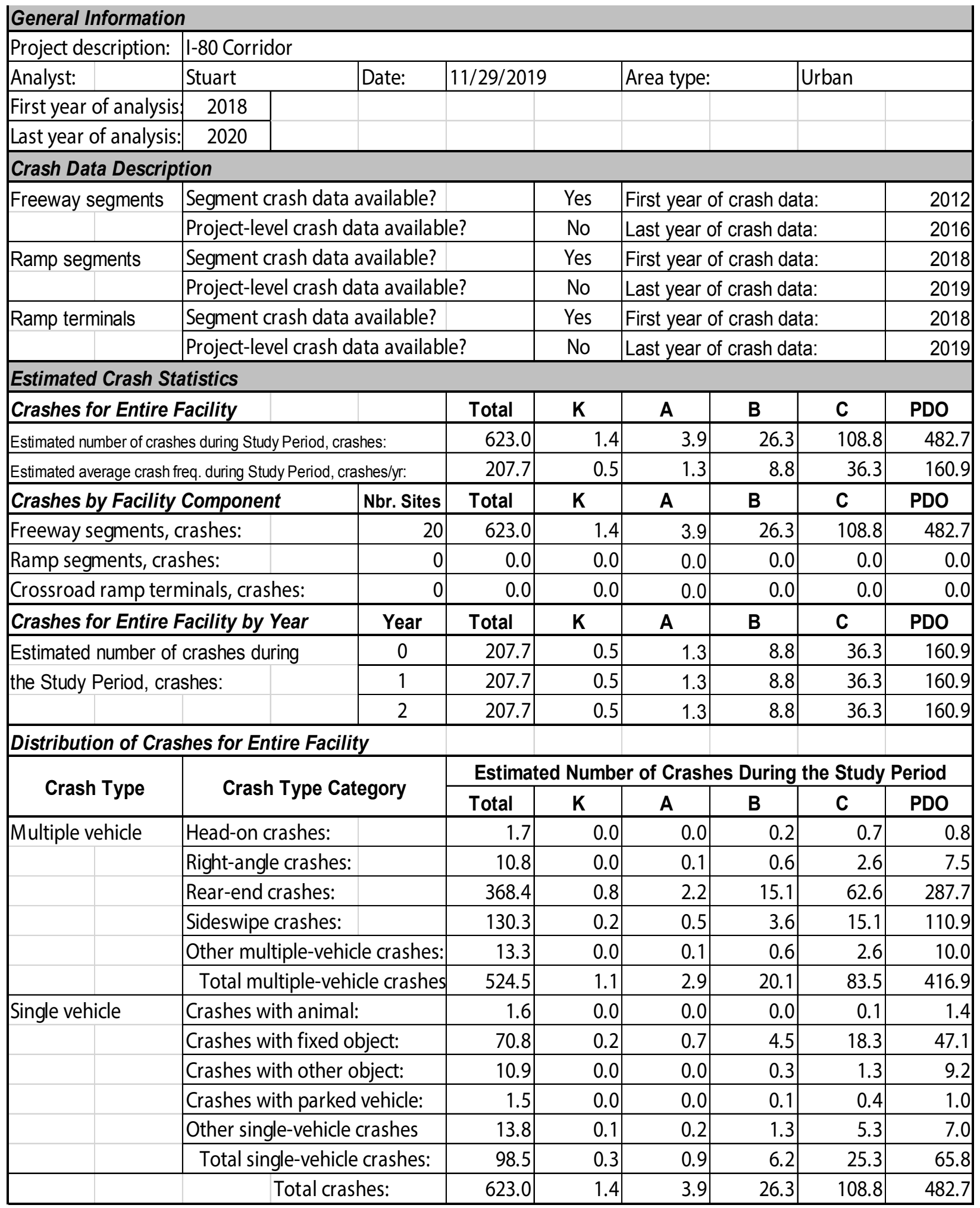

Figure 44. Expected Safety Performance in Segments 21-40 of I-80 Corridor in 2018-2020 


\begin{tabular}{|c|c|c|c|c|c|c|c|c|}
\hline \multicolumn{9}{|l|}{\begin{tabular}{|l} 
\\
\end{tabular}} \\
\hline \multicolumn{9}{|l|}{ General Information } \\
\hline Project description: & \multicolumn{8}{|l|}{ I-80 Corridor } \\
\hline Analyst: & Stuart & \multirow[t]{2}{*}{ Date: } & \multicolumn{2}{|l|}{$11 / 29 / 2019$} & \multicolumn{2}{|l|}{ Area type: } & \multicolumn{2}{|c|}{ Urban } \\
\hline First year of analysis: & 2018 & & & & & & & \\
\hline Last year of analysis: & 2020 & & & & & & & \\
\hline \multicolumn{9}{|c|}{ Crash Data Description } \\
\hline \multirow[t]{2}{*}{ Freeway segments } & \multicolumn{3}{|c|}{ Segment crash data available? } & Yes & \multicolumn{3}{|c|}{ First year of crash data: } & 2012 \\
\hline & \multicolumn{3}{|c|}{ Project-level crash data available? } & No & \multicolumn{3}{|c|}{ Last year of crash data: } & 2016 \\
\hline \multirow[t]{2}{*}{ Ramp segments } & \multicolumn{3}{|c|}{ Segment crash data available? } & Yes & \multicolumn{3}{|c|}{ First year of crash data: } & 2018 \\
\hline & \multicolumn{3}{|c|}{ Project-level crash data available? } & No & \multicolumn{3}{|c|}{ Last year of crash data: } & 2019 \\
\hline \multirow[t]{2}{*}{ Ramp terminals } & \multicolumn{3}{|c|}{ Segment crash data available? } & Yes & First year 0 & rash dat & & 2018 \\
\hline & Project-level crash $\mathrm{d}$ & lata available & & No & Last year 0 & rash dat & & 2019 \\
\hline Estimated Crash Sta & atistics & & & & & & & \\
\hline Crashes for Entire F & Facility & & Total & $\mathrm{K}$ & $\mathrm{A}$ & $\mathrm{B}$ & $\mathrm{C}$ & PDO \\
\hline Estimated number of crashe & nes during Study Period, cras & shes: & 637.9 & 1.4 & 4.0 & 26.9 & 108.7 & 496.9 \\
\hline Estimated average crash fre & req. during Study Period, cra & ashes/yr: & 212.6 & 0.5 & 1.3 & 9.0 & 36.2 & 165.6 \\
\hline Crashes by Facility & Component & Nbr. Sites & Total & $\mathrm{K}$ & $\mathrm{A}$ & B & $\mathrm{C}$ & PDO \\
\hline Freeway segments, c & crashes: & 20 & 637.9 & 1.4 & 4.0 & 26.9 & 108.7 & 496.9 \\
\hline Ramp segments, cras & shes: & 0 & 0.0 & 0.0 & 0.0 & 0.0 & 0.0 & 0.0 \\
\hline Crossroad ramp term & minals, crashes: & 0 & 0.0 & 0.0 & 0.0 & 0.0 & 0.0 & 0.0 \\
\hline Crashes for Entire F & Facility by Year & Year & Total & $\mathrm{K}$ & A & B & C & PDO \\
\hline Estimated number of & crashes during & 0 & 212.6 & 0.5 & 1.3 & 9.0 & 36.2 & 165.6 \\
\hline the Study Period, cras & shes: & 1 & 212.6 & 0.5 & 1.3 & 9.0 & 36.2 & 165.6 \\
\hline & & 2 & 212.6 & 0.5 & 1.3 & 9.0 & 36.2 & 165.6 \\
\hline & & 3 & & & & & & \\
\hline Distribution & $r$ Entire Fac & & & & & & & \\
\hline Crach Trun & Crach Tun Cot & tamaros & Estimate & d Numbe & er of Crash & During $t$ & the Study & eriod \\
\hline Crasn iуре & Crasn Iype cat & egory & Total & $\mathrm{K}$ & A & B & $\mathrm{C}$ & PDO \\
\hline Multiple vehicle & Head-on crashes: & & 1.7 & 0.0 & 0.0 & 0.2 & 0.7 & 0.9 \\
\hline & Right-angle crashes: & & 11.0 & 0.0 & 0.1 & 0.6 & 2.6 & 7.7 \\
\hline & Rear-end crashes: & & 376.3 & 0.8 & 2.3 & 15.6 & 63.1 & 294.5 \\
\hline & Sideswipe crashes: & & 133.1 & 0.2 & 0.6 & 3.7 & 15.2 & 113.4 \\
\hline & Other multiple-vehic & de crashes: & 13.6 & 0.0 & 0.1 & 0.6 & 2.6 & 10.2 \\
\hline & Total multiple-vehi & icle crashes & 535.7 & 1.1 & 3.1 & 20.7 & 84.1 & 426.7 \\
\hline Single vehicle & Crashes with animal: & & 1.7 & 0.0 & 0.0 & 0.0 & 0.1 & 1.5 \\
\hline & Crashes with fixed ok & bject: & 73.4 & 0.2 & 0.7 & 4.4 & 17.8 & 50.3 \\
\hline & Crashes with other 0 & bject: & 11.4 & 0.0 & 0.0 & 0.3 & 1.3 & 9.8 \\
\hline & Crashes with parked & I vehicle: & 1.6 & 0.0 & 0.0 & 0.1 & 0.4 & 1.1 \\
\hline & Other single-vehicle & crashes & 14.1 & 0.1 & 0.2 & 1.3 & 5.1 & 7.5 \\
\hline & Total single-vehicle & crashes: & 102.2 & 0.3 & 0.9 & 6.1 & 24.6 & 70.2 \\
\hline & Total crasl & hes: & 637.9 & 1.4 & 4.0 & 26.9 & 108.7 & 496.9 \\
\hline
\end{tabular}

Figure 45. Expected Safety Performance in Segments 41-60 of I-80 Corridor in 2018-2020 


\begin{tabular}{|c|c|c|c|c|c|c|c|c|}
\hline \multicolumn{9}{|l|}{\begin{tabular}{|l} 
\\
\end{tabular}} \\
\hline \multicolumn{9}{|l|}{ General Information } \\
\hline Project description: & \multicolumn{8}{|l|}{ I-80 Corridor } \\
\hline Analyst: & Stuart & \multirow[t]{2}{*}{ Date: } & \multicolumn{2}{|c|}{$11 / 29 / 2019$} & \multicolumn{2}{|l|}{ Area type: } & \multicolumn{2}{|l|}{ Urban } \\
\hline First year of analysis & 2018 & & & & & & & \\
\hline Last year of analysis: & 2020 & & & & & & & \\
\hline \multicolumn{9}{|c|}{ Crash Data Description } \\
\hline \multirow[t]{2}{*}{ Freeway segments } & \multicolumn{3}{|c|}{ Segment crash data available? } & Yes & \multicolumn{3}{|c|}{ First year of crash data: } & 2012 \\
\hline & \multicolumn{3}{|c|}{ Project-level crash data available? } & No & \multicolumn{3}{|c|}{ Last year of crash data: } & 2016 \\
\hline \multirow[t]{2}{*}{ Ramp segments } & \multicolumn{3}{|c|}{ Segment crash data available? } & Yes & \multicolumn{3}{|c|}{ First year of crash data: } & 2018 \\
\hline & \multicolumn{3}{|c|}{ Project-level crash data available? } & No & \multicolumn{3}{|c|}{ Last year of crash data: } & 2019 \\
\hline \multirow[t]{2}{*}{ Ramp terminals } & \multicolumn{3}{|c|}{ Segment crash data available? } & Yes & First year 0 & rash dat & & 2018 \\
\hline & Project-level crash d & ata available & & No & Last year 0 & rash date & & 2019 \\
\hline Estimated Crash Sta & atistics & & & & & & & \\
\hline Crashes for Entire $F$ & Facility & & Total & $\mathrm{K}$ & A & B & C & PDO \\
\hline Estimated number of crash & es during Study Period, cra & shes: & 488.3 & 1.3 & 3.7 & 24.3 & 93.9 & 365.1 \\
\hline Estimated average crash fr & req. during Study Period, cre & shes/yr: & 162.8 & 0.4 & 1.2 & 8.1 & 31.3 & 121.7 \\
\hline Crashes by Facility & Component & Nbr. Sites & Total & $\mathrm{K}$ & A & B & $\mathrm{C}$ & PDO \\
\hline Freeway segments, $\mathrm{c}$ & crashes: & 20 & 488.3 & 1.3 & 3.7 & 24.3 & 93.9 & 365.1 \\
\hline Ramp segments, cras & shes: & 0 & 0.0 & 0.0 & 0.0 & 0.0 & 0.0 & 0.0 \\
\hline Crossroad ramp tern & minals, crashes: & 0 & 0.0 & 0.0 & 0.0 & 0.0 & 0.0 & 0.0 \\
\hline Crashes for Entire $F$ & Facility by Year & Year & Total & $\mathrm{K}$ & $\mathrm{A}$ & B & $\mathrm{C}$ & PDO \\
\hline Estimated number of & crashes during & 0 & 162.8 & 0.4 & 1.2 & 8.1 & 31.3 & 121.7 \\
\hline the Study Period, cra & ashes: & 1 & 162.8 & 0.4 & 1.2 & 8.1 & 31.3 & 121.7 \\
\hline & & 2 & 162.8 & 0.4 & 1.2 & 8.1 & 31.3 & 121.7 \\
\hline Distribution of Cras & shes for Entire Facili & & & & & & & \\
\hline & & & Estimat & Numbe & er of Crash & During $t$ & the Study & Period \\
\hline Crasn Iуре & Crasn Iype Ca & egory & Total & $\mathrm{K}$ & $\mathrm{A}$ & B & $\mathrm{C}$ & PDO \\
\hline Multiple vehicle & Head-on crashes: & & 1.4 & 0.0 & 0.0 & 0.1 & 0.6 & 0.6 \\
\hline & Right-angle crashes: & & 8.5 & 0.0 & 0.1 & 0.6 & 2.2 & 5.6 \\
\hline & Rear-end crashes: & & 285.1 & 0.8 & 2.1 & 13.9 & 53.6 & 214.8 \\
\hline & Sideswipe crashes: & & 99.9 & 0.2 & 0.5 & 3.3 & 12.9 & 83.0 \\
\hline & Other multiple-vehic & le crashes: & 10.3 & 0.0 & 0.1 & 0.6 & 2.2 & 7.4 \\
\hline & Total multiple-veh & cle crashes & 405.2 & 1.0 & 2.8 & 18.5 & 71.5 & 311.4 \\
\hline Single vehicle & Crashes with animal & & 1.3 & 0.0 & 0.0 & 0.0 & 0.1 & 1.2 \\
\hline & Crashes with fixed 0 & bject: & 59.6 & 0.2 & 0.6 & 4.2 & 16.2 & 38.4 \\
\hline & Crashes with other & bject: & 9.0 & 0.0 & 0.0 & 0.3 & 1.2 & 7.5 \\
\hline & Crashes with parked & vehicle: & 1.3 & 0.0 & 0.0 & 0.1 & 0.3 & 0.9 \\
\hline & Other single-vehicle & crashes & 11.8 & 0.1 & 0.2 & 1.2 & 4.7 & 5.7 \\
\hline & Total single-vehicle & crashes: & 83.1 & 0.3 & 0.9 & 5.8 & 22.4 & 53.7 \\
\hline & Total cras & hes: & 488.3 & 1.3 & 3.7 & 24.3 & 93.9 & 365.1 \\
\hline
\end{tabular}

Figure 46. Expected Safety Performance in Segments $61-80$ of I-80 Corridor in 2018-2020 


\begin{tabular}{|c|c|c|c|c|c|c|c|c|}
\hline \multicolumn{9}{|l|}{\begin{tabular}{|l} 
\\
\end{tabular}} \\
\hline \multicolumn{9}{|l|}{ General Information } \\
\hline \multicolumn{9}{|c|}{ Project description: $\quad$ I-80 Corridor } \\
\hline \multirow{2}{*}{\begin{tabular}{|l|} 
Analyst: \\
First year of analysis \\
\end{tabular}} & Stuart & \multirow[t]{2}{*}{ Date: } & \multicolumn{2}{|c|}{$11 / 29 / 2019$} & \multicolumn{2}{|l|}{ Area type: } & \multicolumn{2}{|l|}{ Urban } \\
\hline & 2018 & & & & & & & \\
\hline Last year of analysis: & 2020 & & & & & & & \\
\hline \multicolumn{9}{|c|}{ Crash Data Description } \\
\hline \multirow[t]{2}{*}{ Freeway segments } & \multicolumn{3}{|c|}{ Segment crash data available? } & Yes & \multicolumn{3}{|c|}{ First year of crash data: } & 2012 \\
\hline & \multicolumn{3}{|c|}{ Project-level crash data available? } & No & \multicolumn{3}{|c|}{ Last year of crash data: } & 2016 \\
\hline \multirow[t]{2}{*}{ Ramp segments } & \multicolumn{3}{|c|}{ Segment crash data available? } & Yes & \multicolumn{3}{|c|}{ First year of crash data: } & 2018 \\
\hline & \multicolumn{3}{|c|}{ Project-level crash data available? } & No & \multicolumn{3}{|c|}{ Last year of crash data: } & 2019 \\
\hline \multirow[t]{2}{*}{ Ramp terminals } & \multicolumn{3}{|c|}{ Segment crash data available? } & Yes & \multicolumn{3}{|c|}{ First year of crash data: } & 2018 \\
\hline & \multicolumn{3}{|c|}{ Project-level crash data available? } & No & Last year of & rash dat & & 2019 \\
\hline Estimated Crash Ste & atistics & & & & & & & \\
\hline Crashes for Entire $F$ & Facility & & Total & $\mathrm{K}$ & $A$ & $\mathbf{B}$ & C & PDO \\
\hline Estimated number of crash & nes during Study Period, cras & shes: & 303.2 & 1.1 & 3.1 & 21.2 & 69.2 & 208.5 \\
\hline Estimated average crash $\mathrm{fr}$ & req. during Study Period, cra & ashes/yr: & 101.1 & 0.4 & 1.0 & 7.1 & 23.1 & 69.5 \\
\hline Crashes by Facility & Component & Nbr. Sites & Total & $\mathrm{K}$ & $A$ & B & $\mathrm{C}$ & PDO \\
\hline Freeway segments, $\mathrm{c}$ & crashes: & 18 & 303.2 & 1.1 & 3.1 & 21.2 & 69.2 & 208.5 \\
\hline Ramp segments, cras & shes: & 0 & 0.0 & 0.0 & 0.0 & 0.0 & 0.0 & 0.0 \\
\hline Crossroad ramp tern & minals, crashes: & 0 & 0.0 & 0.0 & 0.0 & 0.0 & 0.0 & 0.0 \\
\hline Crashes for Entire $F$ & Facility by Year & Year & Total & $\mathrm{K}$ & $\mathrm{A}$ & B & $\mathrm{C}$ & PDO \\
\hline Estimated number of & crashes during & 0 & 101.1 & 0.4 & 1.0 & 7.1 & 23.1 & 69.5 \\
\hline the Study Period, cra & shes: & 1 & 101.1 & 0.4 & 1.0 & 7.1 & 23.1 & 69.5 \\
\hline & & 2 & 101.1 & 0.4 & 1.0 & 7.1 & 23.1 & 69.5 \\
\hline Distribution of Cras & hes for Entire Facilit & & & & & & & \\
\hline Crach Trun & Crach T ung Cot & tamanos & Estimate & d Numbe & er of Crashe & During & the Study & eriod \\
\hline Crasn Type & Crasn Iуре Cat & egory & Total & $\mathrm{K}$ & A & B & $\mathrm{C}$ & PDO \\
\hline Multiple vehicle & Head-on crashes: & & 0.9 & 0.0 & 0.0 & 0.1 & 0.4 & 0.3 \\
\hline & Right-angle crashes: & & 5.0 & 0.0 & 0.1 & 0.5 & 1.5 & 3.0 \\
\hline & Rear-end crashes: & & 164.0 & 0.6 & 1.6 & 11.3 & 36.8 & 113.7 \\
\hline & Sideswipe crashes: & & 56.0 & 0.1 & 0.4 & 2.7 & 8.9 & 43.9 \\
\hline & Other multiple-vehic & le crashes: & 6.0 & 0.0 & 0.1 & 0.5 & 1.5 & 3.9 \\
\hline & Total multiple-vehi & icle crashes & 231.9 & 0.8 & 2.2 & 15.0 & 49.1 & 164.8 \\
\hline Single vehicle & Crashes with animal: & & 1.1 & 0.0 & 0.0 & 0.0 & 0.1 & 1.0 \\
\hline & Crashes with fixed ob & bject: & 51.2 & 0.2 & 0.6 & 4.5 & 14.6 & 31.3 \\
\hline & Crashes with other 0 & bject: & 7.5 & 0.0 & 0.0 & 0.3 & 1.0 & 6.1 \\
\hline & Crashes with parked & I vehicle: & 1.1 & 0.0 & 0.0 & 0.1 & 0.3 & 0.7 \\
\hline & Other single-vehicle & crashes & 10.4 & 0.1 & 0.2 & 1.3 & 4.2 & 4.6 \\
\hline & Total single-vehicle & crashes: & 71.3 & 0.3 & 0.9 & 6.2 & 20.2 & 43.7 \\
\hline & Total crasl & hes: & 303.2 & 1.1 & 3.1 & 21.2 & 69.2 & 208.5 \\
\hline
\end{tabular}

Figure 47. Expected Safety Performance in Segments 81-98 of the I-80 Corridor in 2018-2020

Also, segments 1-40 were found to have a higher crash frequency on the I-80 corridor. Overall, 1,352 out of all 1,882 crashes were predicted to occur on segments $1-40$. In other 
words, $72 \%$ of crashes are expected to occur on segments $1-40$, while these segments include $40 \%$ of the entire corridor. The higher AADT (especially in segments $1-20$ ), narrower inside shoulder with no rumble strips, and considerable changes in the number of traffic lanes could be among the reasons for expecting a higher number of crashes in segments 1-40 compared to segments 41-98.

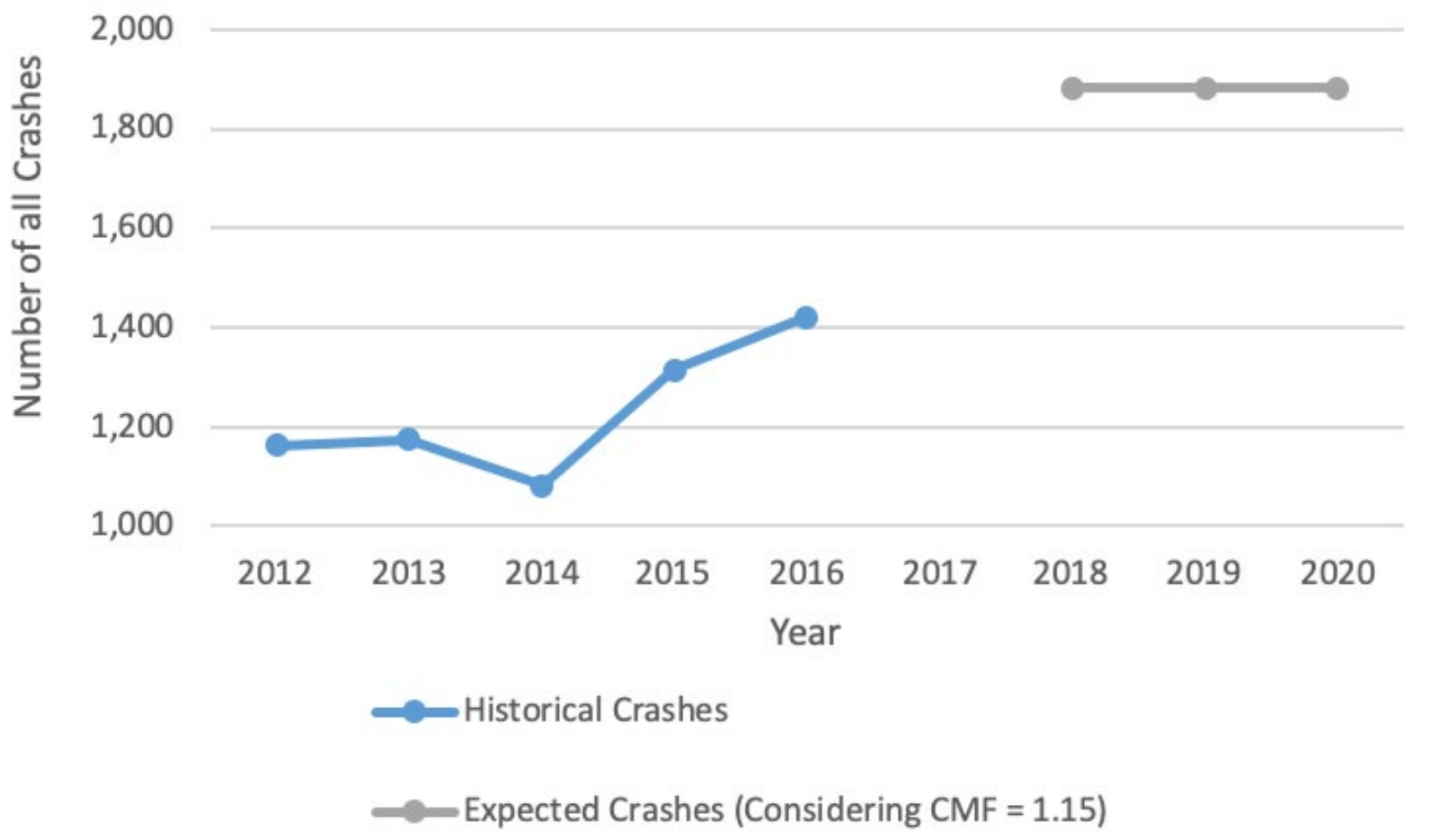
Figure 48. Number of Total Crashes Expected on I-80 Corridor in 2018-2020 Based on Historical Crashes in 2012-2016

\section{CONCLUSIONS FROM SAFETY ANALYSIS}

This chapter estimated the safety performance of SR-99 and I-80 corridors in California. The research team collected road geometric features, traffic volume, and historical crash data of over 40 miles of I-80 and SR-99 corridors in the San Francisco Bay Area and Sacramento area, respectively. The Enhanced Interchange Safety Analysis Tool (ISATe, developed based on research conducted as part of the National Cooperative Highway Research Program) was utilized to predict the counterfactual, i.e., the number of crashes if no Coordinated Ramp Metering (CRM) system was implemented on the corridors. Based on the results, 1,724 and 1,882 crashes were estimated in 2018 on SR-99 and I-80 corridors, respectively, if no CRM system had been implemented. It was found that $19-23 \%$ of those crashes expected could result in injuries and fatalities in 2018. These are counterfactual estimates that can be compared to post-CRM implementation long-term crash counts to obtain an estimate of the safety improvements. It is generally recommended to collect 3-year "after"-period crash data to arrive at a reliable estimation of safety benefits.

Since the crash data from 2018 through 2020 were not available during this study, the research team could not compare the counterfactual estimate with the actual crash data. 
However, it is predicted that the routes will experience a significant decrease in the number of crashes after 2017 due to CRM implementation on SR-99 and I-80 corridors. Based on past studies, ${ }^{53}$ utilizing CRM increases the length and time available for vehicles entering the freeway to adjust their speed to the mean speed of the traffic stream-ultimately resulting in lower speed variation and a safer merging area on the freeway. CRM helps to split up platoons of vehicles. Therefore, a considerable number of vehicles do not have to be involved in sharing the same limited gaps. Also, smoother merging movements and fewer stops could be expected. 


\section{CONCLUSIONS}

The study conducted a comprehensive evaluation of the travel time reliability, efficiency, and safety performance of the two freeways (SR-99 and I-80) before and after the implementation of the CRM systems. Evidence of effectiveness is useful for agencies as they report to elected officials and plan for future implementation of similar ITS technologies. Measures of travel time reliability were estimated in addition to the measure of system efficiency $(Q)$.

Specific measures of reliability used in this study include traditional measures such as Buffer Index, Travel-Time Index, Planning Time Index, and Misery Index. In addition, a relatively new reliability measure, UI, which accounts for both width and skew of the travel time distribution, was also estimated. These measures were estimated using readily available data from INRIX Insights. The comparison between the before and after periods was set up to minimize confounding variables through estimation of the same parameters on a control corridor from the same region.

The efficiency analysis involved the estimation of a counterfactual $Q$ (VMTNHT value) and its comparison with the actual $Q$ value in the post-CRM implementation period. Due to an issue in the data from District 3 , the researchers looked at the change in the trend of $Q$ before and after CRM implementation rather than estimated $Q$ values.

For both Districts 3 and 4, the operation analysis showed that CRM implementation has had a positive impact on system efficiency. In terms of travel time reliability, the traditional measures did not show improvement in the post-implementation period. The only measure that showed some indication of improvement was the UI, which accounts for both width and skew of the travel time distribution. The finding is consistent with the system efficiency improvement indicated by the efficiency analysis.

Safety analysis involved the application of an empirical Bayes approach to estimate the counterfactual estimate of crashes. This approach was implemented using the ISATe tool developed in a recent NCHRP project. The counterfactual estimate may be compared to the actual post-implementation long-term ( $\sim 3$ years) crash counts for the "after" period to estimate the safety effectiveness of CRM.

This research presented a promising approach to the use of granular data for a before-andafter active traffic management performance evaluation. The research examined long-term data, not just from the CRM corridor but from a control corridor as well. This project allowed the researchers to follow the recommendations from the latest research conducted through the SHRP 2 program. ${ }^{54}$ 


\section{ENDNOTES}

1. Caltrans, "2016_aadt_volumes," 2016. [Online]. Available: http://www.dot.ca.gov/trafficops/ census/docs/2016_aadt_volumes.pdf.

2. Cambridge and TTI, "Travel Time Reliability: Making It There On Time, All The Time," 01-Jan2006. [Online]. Available: https://ops.fhwa.dot.gov/publications/tt_reliability/.

3. A. Mizuta, Ki. Roberts, les Jacobsen, and N. Thompson, "Ramp Metering: A Proven, CostEffective Operational Strategy - A Primer: 1. Overview of Ramp Metering," Oct-2014. [Online]. Available: https://ops.fhwa.dot.gov/publications/fhwahop14020/sec1.htm.

4. DKS Associates, "Interstate 80 Integrated Corridor Mobility Project Operation and Maintenance Plan," February 25, 2011. [Online]. Available: https://www.wcctac.org/wp-content/ uploads/2011/03/Draft-OM-Plan-0225112.pdf.

5. Caltrans, "Ramp Metering Design Manual," April 2016. [Online]. Available: http://www.dot. ca.gov/trafficops/tech/docs/RMDM.pdf.

6. Caltrans, "Ramp Metering Development Plan," February 2018. [Online]. Available: http://www. dot.ca.gov/trafficops/tech/docs/RampMeteringDevelopmentPlan.pdf.

7. Caltrans, "80 Smart Corridor," 2019. [Online]. Available: http://www.dot.ca.gov/80smartcorridor/ index.html.

8. T. C. Low, "Master of Science in Civil and Environmental Engineering," p. 81, Sep. 2017.

9. A. Mizuta, Ki. Roberts, les Jacobsen, and N. Thompson, "Ramp Metering: A Proven, CostEffective Operational Strategy - A Primer: 1. Overview of Ramp Metering," Oct-2014. [Online]. Available: https://ops.fhwa.dot.gov/publications/fhwahop14020/sec1.htm;

10. S. Ahn, R. L. Bertini, B. Auffray, J. H. Ross, and O. Eshel, "Evaluating Benefits of Systemwide Adaptive Ramp-Metering Strategy in Portland, Oregon," Transportation Research Record: Journal of the Transportation Research Board 2012 (2007): 47-56;

11. H. Haj-Salem and M. Papageorgiou, "Ramp metering impact on urban corridor traffic: Field results,” Transportation Research Part A: Policy and Practice 29 (1995): 303-319;

12. S. Kang and D. Gillen, "Assessing the Benefits and Costs of Intelligent Tranportation Systems: Ramp Meters," July 1999. [Online]. Available: https://merritt.cdlib.org/d/ ark:\%252F13030\%252Fm5tx5kfw/1/producer\%252FUCB-ITS-PRR-99-19.pdf.

13. Cambridge Systematics, "Twin Cities Ramp Meter Evaluation," February 1, 2001. [Online]. Available: http://www.dot.state.mn.us/rampmeter/pdf/executivesummary.pdf.

14. D. Levinson and L. Zhang, "Ramp meters on trial: Evidence from the Twin Cities metering holiday," Transportation Research Part A: Policy and Practice 40 (2006): 810-828.

15. H. Pham, W. Jreij, C. Otani, H. Kalkatechi, and J. Toorwa, SWARM Study Final Report on W/B Foothill Freeway (W/B LA-210): From Vernon Avenue to Lake Avenue. California Department 
of Transportation, 2002.

16. L. Chu, H. X. Liu, W. Recker, and H. M. Zhang, "Performance Evaluation of Adaptive RampMetering Algorithms Using Microscopic Traffic Simulation Model," Journal of Transportation Engineering 130 (2004): 330-338.

17. S. Ahn, R. L. Bertini, B. Auffray, J. H. Ross, and O. Eshel, "Evaluating Benefits of Systemwide Adaptive Ramp-Metering Strategy in Portland, Oregon," Transportation Research Record: Journal of the Transportation Research Board 2012 (2007): 47-56.

18. I. Papamichail, M. Papageorgiou, V. Vong, and J. Gaffney, "Heuristic Ramp-Metering Coordination Strategy Implemented at Monash Freeway, Australia," Transportation Research Record 2178 (2010): 10-20.

19. 16 Y. Yuan, W. Daamen, S. Hoogendoorn, and J. Vrancken, "Coordination Concepts for Ramp Metering Control in a Freeway Network," IFAC Proceedings Volumes 42(2009, no. 15): 612-618.

20. K. Bogenberger, S. Vukanovic, and H. Keller, "ACCEZZ_Adaptive Fuzzy Algorithms for Traffic Responsive and Coordinated Ramp Metering," in Applications of Advanced Technologies in Transportation (2002), Boston Marriot, Cambridge, MA, 2002, 744-753.

21. T. Lomax, D. Schrank, S. Turner, and R. Margiotta, "SELECTING TRAVEL RELIABILITY MEASURES," May 2003.

22. W. Pu, "Analytic Relationships between Travel Time Reliability Measures," Transportation Research Record: Journal of the Transportation Research Board 2254 (2011): 122-130.

23. J. W. C. van Lint, H. J. van Zuylen, and H. Tu, "Travel time unreliability on freeways: Why measures based on variance tell only half the story," Transportation Research Part A: Policy and Practice 42 (2008): 258-277.

24. J. W. C. Van Lint, H. J. Van Zuylen, and H. Tu, "Travel time unreliability on freeways: Why measures based on variance tell only half the story," Transportation Research Part A: Policy and Practice 42 (2008): 258-277.

25. J. W. C. van Lint, H. J. van Zuylen, and H. Tu, "Travel time unreliability on freeways: Why measures based on variance tell only half the story," Transportation Research Part A: Policy and Practice 42 (2008): 258-277.

26. N. Bhouri, M. Aron, and J. Kauppila, "Relevance of Travel Time Reliability Indicators: A Managed Lanes Case Study," Procedia - Social and Behavioral Sciences 54 (2012): 450-459.

27. J. W. C. Van Lint, H. J. Van Zuylen, and H. Tu, "Travel time unreliability on freeways: Why measures based on variance tell only half the story," Transportation Research Part A: Policy and Practice 42 (2008): 258-277.

28. N. Bhouri, H. Haj-Salem, and J. Kauppila, "Isolated versus coordinated ramp metering: Field evaluation results of travel time reliability and traffic impact," Transportation Research Part C: Emerging Technologies 28 (2013): 155-167. 
29. Caltrans, "80 Smart Corridor," 2019. [Online]. Available: http://www.dot.ca.gov/80smartcorridor/ index.html.

30. Caltrans, "2016_aadt_volumes.pdf," 2016. [Online]. Available: http://www.dot.ca.gov/trafficops/ census/docs/2016_aadt_volumes.pdf.

31. T. C. Low, "Early Empirical Evidence for the Effects of Adaptive Ramp Metering on Measures of Travel Time Reliability," 2017.

32. Cambridge and TTI, "Travel Time Reliability: Making It There On Time, All The Time," January 1, 2006. [Online]. Available: https://ops.fhwa.dot.gov/publications/tt_reliability/.

33. N. Bhouri, H. Haj-Salem, and J. Kauppila, "Isolated versus coordinated ramp metering: Field evaluation results of travel time reliability and traffic impact," Transportation Research Part C: Emerging Technologies 28 (2013): 155-167.

34. T. C. Low, "Master of Science in Civil and Environmental Engineering," p. 81, September 2017.

35. J. W. C. Van Lint, H. J. Van Zuylen, and H. Tu, "Travel time unreliability on freeways: Why measures based on variance tell only half the story," Transportation Research Part A: Policy and Practice 42 (2008): 258-277.

36. J. W. C. Van Lint, H. J. Van Zuylen, and H. Tu, "Travel time unreliability on freeways: Why measures based on variance tell only half the story," Transportation Research Part A: Policy and Practice 42 (2008): 258-277.

37. "Caltrans PeMS." [Online]. Available: http://pems.dot.ca.gov/.

38. S. Shladover and X.-Y. Lu, "Field Test of Coordinated Ramp Metering (CRM)," California, Department of Transportation, 2017.

39. "Caltrans PeMS." [Online]. Available: http://pems.dot.ca.gov/.

40. S. Shladover and X.-Y. Lu, "Field Test of Coordinated Ramp Metering (CRM)," California. Department of Transportation, 2017.

41. American Association of State Transportation Officials, Highway Safety Manual, 1st ed., vol. 1, 3 vols. American Association of State Highway and Transportation Officials, 2010.

42. E. Hauer, D. W. Harwood, F. M. Council, and M. S. Griffith, "Estimating safety by the empirical Bayes method: A tutorial," Transportation Research Record: Journal of the Transportation Research Board 1784 (2002): 126-131.

43. E. Hauer, Observational Before/After Studies in Road Safety. Estimating the Effect of Highway and Traffic Engineering Measures on Road Safety, 1997.

44. C. Morris, "Parametric Empirical Bayes Inference: Theory and Applications," Journal of the American Statistical Association 78 (1983): 47-55.

45. C. Dougherty and A. Burton, "A 2:15 Alarm, 2 Trains and a Bus Get Her to Work by 7 A.M.," The 
New York Times, August 17, 2017.

46. R. J. Hyndman et al., "Forecast: Forecasting functions for time series and linear models; 2017," $R$ package version, vol. 5, 2017.

47. A. Trapletti and K. Hornik, "tseries: Time series analysis and computational finance. R package version 0.10-40," URL: https://CRAN. R-project. org/package= tseries, 2017.

48. M. Colwill and P. Eng, "Moving (More) People Safely: Examining the Safety Impacts of HOV Lanes," in Transportation 2014: Past, Present, Future-2014 Conference and Exhibition of the Transportation Association of Canada // Transport 2014: Du passé vers l'avenir-2014 Congrès et Exposition d'Association des transports du Canada, 2014.

49. J. A. Bonneson, M. P. Pratt, S. Geedipally, D. Lord, T. Neuman, and J. Moller, "Enhanced Interchange Safety Analysis Tool: User Manual," Transportation Research Board, Washington, D.C., 2012.

50. M. Abuzwidah and M. Abdel-Aty, "Effects of using high occupancy vehicle lanes on safety performance of freeways," 2017.

51. M. Abuzwidah and M. Abdel-Aty, "Effects of using high occupancy vehicle lanes on safety performance of freeways," 2017.

52. B. A. Hamilton, A Review of HOV Lane Performance and Policy Options in the United States, 2008.

53. B. A. Hamilton, A Review of HOV Lane Performance and Policy Options in the United States, 2008; M. Abuzwidah and M. Abdel-Aty, "Effects of using high occupancy vehicle lanes on safety performance of freeways," 2017.

54. D. Gettman, L. Pu, T. Sayed, S. Shelby, and I. T. S. Siemens, "Surrogate safety assessment model and validation," United States. Federal Highway Administration. Office of Safety Research and ..., 2008.

55. D. Gettman, L. Pu, T. Sayed, S. Shelby, and I. T. S. Siemens, "Surrogate safety assessment model and validation," United States. Federal Highway Administration. Office of Safety Research and ..., 2008.

56. A. Mizuta, Ki. Roberts, les Jacobsen, and N. Thompson, "Ramp Metering: A Proven, CostEffective Operational Strategy - A Primer: 1. Overview of Ramp Metering," October 2014. [Online]. Available: https://ops.fhwa.dot.gov/publications/fhwahop14020/sec1.htm; National Safety Council. Estimating the costs of unintentional injuries, 2015.

57. List et al., 2014; Sobolewski, Polum, Morris, Loos, \& Anderson, 2015. 


\section{BIBLIOGRAPHY}

Ahn, S., Bertini, R. L., Auffray, B., Ross, J. H., \& Eshel, O. (2007). Evaluating Benefits of Systemwide Adaptive Ramp-Metering Strategy in Portland, Oregon.

Transportation Research Record: Journal of the Transportation Research Board, 2012(1), 47-56. https://doi.org/10.3141/2012-06

AlKadri, M. Y. (1998). Ramp metering: A systems approach pilot survey of acceptability by freeway users. ITE Journal, 75-80.

Bay Area traffic congestion up 80 percent since 2010: Report. (n.d.). Retrieved November 16, 2019, from https://www.mercurynews.com/2017/09/18/report-trafficon-major-freeways-has-grown-80-percent-since-2010/

Benz, R. J., \& Brooks, J. (2017). A User Survey of High-Occupancy Vehicle (HOV)/ High-Occupancy Toll (HOT) Lane Extended Hours and Weekend Operational Evaluation.

Bhouri, Neïla, Aron, M., \& Kauppila, J. (2012). Relevance of Travel Time Reliability Indicators: A Managed Lanes Case Study. Procedia - Social and Behavioral Sciences, 54, 450-459. https://doi.org/10.1016/j.sbspro.2012.09.763

Bhouri, Neila, Haj-Salem, H., \& Kauppila, J. (2013). Isolated versus coordinated ramp metering: Field evaluation results of travel time reliability and traffic impact. Transportation Research Part C: Emerging Technologies, 28, 155-167. https://doi. org/10.1016/j.trc.2011.11.001

Bogenberger, K., Vukanovic, S., \& Keller, H. (2002). ACCEZZ—Adaptive Fuzzy Algorithms for Traffic Responsive and Coordinated Ramp Metering. Applications of Advanced Technologies in Transportation (2002), 744-753. https://doi. org/10.1061/40632(245)94

Bonneson, J. A., Pratt, M. P., Geedipally, S., Lord, D., Neuman, T., \& Moller, J. (2012). Enhanced Interchange Safety Analysis Tool: User Manual. Transportation Research Board, Washington, DC.

Brown, B. (2008). High-Occupancy-Vehicle User Survey: Washington State Freeway HOV System.

Burris, M. W., \& Figueroa, C. F. (2010). Analysis of traveler characteristics by mode choice in HOT corridors. Journal of the Transportation Research Forum, 45.

Caltrans. (n.d.). I-80 Smart Corridor Project. Retrieved November 16, 2019, from http:// www.dot.ca.gov/80smartcorridor/docs/l-80_SMART_Corridor_FactSheet.pdf

Caltrans. (2016a). 2016_aadt_volumes. http://www.dot.ca.gov/trafficops/census/ docs/2016_aadt_volumes.pdf 
Caltrans. (2016b, April). Ramp Metering Design Manual. http://www.dot.ca.gov/trafficops/ tech/docs/RMDM.pdf

Caltrans. (2018a). About the Project | I-80 SMART Corridor Project. from: http://www.dot. ca.gov/80smartcorridor/about-the-project.html

Caltrans. (2018b). FAQs | I-80 SMART Corridor Project. http://www.dot. ca.gov/80smartcorridor/faqs.html\#how-is-it-funded

Caltrans. (2018c, February). Ramp Metering Development Plan. http://www.dot.ca.gov/ trafficops/tech/docs/RampMeteringDevelopmentPlan.pdf

Caltrans. (2019). Smart Corridor. http://www.dot.ca.gov/80smartcorridor/index.html

Cambridge, \& TTI. (2006, January 1). Travel Time Reliability: Making It There On Time, All The Time. https://ops.fhwa.dot.gov/publications/tt_reliability/

Cambridge Systematics. (2001, February 1). Twin Cities Ramp Meter Evaluation. http:// www.dot.state.mn.us/rampmeter/pdf/executivesummary.pdf

Chu, L., Liu, H. X., Recker, W., \& Zhang, H. M. (2004). Performance Evaluation of Adaptive Ramp-Metering Algorithms Using Microscopic Traffic Simulation Model. Journal of Transportation Engineering, 130(3), 330-338. https://doi.org/10.1061/ (ASCE)0733-947X(2004)130:3(330)

Cobanoglu, C., Moreo, P. J., \& Warde, B. (2001). A comparison of mail, fax and webbased survey methods. International Journal of Market Research, 43(4), 1-15.

Devarasetty, P. C., Burris, M., \& Douglass Shaw, W. (2012). The value of travel time and reliability-evidence from a stated preference survey and actual usage. Transportation Research Part A: Policy and Practice, 46(8), 1227-1240. https:// doi.org/10.1016/j.tra.2012.05.002

DKS Associates. (2011a, February 25). Interstate 80 Intergrated Corridor Mobility Project Operation and Maintance Plan. https://www.wcctac.org/wp-content/ uploads/2011/03/Draft-OM-Plan-0225112.pdf

DKS Associates. (2011b, February 25). Interstate 80 Intergrated Corridor Mobility Project Operation and Maintance Plan. https://www.wcctac.org/wp-content/ uploads/2011/03/Draft-OM-Plan-0225112.pdf

Efthymiou, D., \& Antoniou, C. (2012). Use of social media for transport data collection. Procedia-Social and Behavioral Sciences, 48, 775-785.

Haj-Salem, H., \& Papageorgiou, M. (1995). Ramp metering impact on urban corridor traffic: Field results. Transportation Research Part A: Policy and Practice, 29(4), 303-319. https://doi.org/10.1016/0965-8564(94)00034-8 
Hauer, E. (1997). Observational before/after studies in road safety. Estimating the effect of highway and traffic engineering measures on road safety.

Kang, S., \& Gillen, D. W. (1999). Assessing the benefits and costs of intelligent transportation systems: Ramp meters. California PATH Program, Institute of Transportation Studies, University of ....

Lee, C., \& Pino, J. (2012). Hang Up the Phone and Get Online: Measuring the Effectiveness of Web-Based Surveys in Transportation.

Levinson, D., \& Zhang, L. (2006). Ramp meters on trial: Evidence from the Twin Cities metering holiday. Transportation Research Part A: Policy and Practice, 40(10), 810-828. https://doi.org/10.1016/j.tra.2004.12.004

List, G. F., Williams, B., Rouphail, N., Hranac, R., Barkley, T., Mai, E., Ciccarelli, A., Rodegerdts, L., Karr, A. F., \& Zhou, X. (2014). Guide to Establishing Monitoring Programs for Travel Time Reliability.

Lomax, T., Schrabk, D., Turner, S., \& Margiotta, R. (2003). SELECTING TRAVEL RELIABILITY MEASURES. https://trid.trb.org/view/680956

Low, T. C. (2017a). Early Empirical Evidence for the Effects of Adaptive Ramp Metering on Measures of Travel Time Reliability.

Low, T. C. (2017b). Early Empirical Evidence for the Effects of Adaptive Ramp Metering on Measures of Travel Time Reliability.

Low, T. C. (2017c). TIMS - Transportation Injury Mapping System. https://tims.berkeley. edu/

McDonald, N. C., Brown, A. L., Marchetti, L. M., \& Pedroso, M. S. (2011). US school travel, 2009: An assessment of trends. American Journal of Preventive Medicine, 41(2), 146-151.

Mizuta, A., Roberts, K., Jacobsen, L., Thompson, N., \& Colyar, J. (2014). Ramp Metering: A Proven, Cost-Effective Operational Strategy: A Primer. United States. Federal Highway Administration.

NIKOLAIDOU, A., \& PAPAIOANNOU, P. (2017). SOCIAL MEDIA AND TRANSPORT CHOICES: HOW SOCIAL MEDIA CAN AFFECT TRIPMAKERS'CHOICES. WIT Transactions on Ecology and the Environment, 226, 605-616.

Nuworsoo, C. (2009). Providing Senior Citizen Mobility at Minimum Public Cost.

Nuworsoo, C., \& Cooper, E. (2013). Considerations for integrating bicycling and walking facilities into urban infrastructure. Transportation Research Record, 2393(1), 125133. 
Pande, A., \& Abdel-Aty, M. (2006). Comprehensive analysis of the relationship between real-time traffic surveillance data and rear-end crashes on freeways. Transportation Research Record, 1953(1), 31-40.

Papamichail, I., Papageorgiou, M., Vong, V., \& Gaffney, J. (2010). Heuristic RampMetering Coordination Strategy Implemented at Monash Freeway, Australia. Transportation Research Record: Journal of the Transportation Research Board, 2178(1), 10-20. https://doi.org/10.3141/2178-02

Patil, S., Burris, M., \& Shaw, W. D. (2011). Travel using managed lanes: An application of a stated choice model for Houston, Texas. Transport Policy, 18(4), 595-603.

Pham, H., Jreij, W., Otani, C., Kalkatechi, H., Toorawa, I., Kao, J., Dumaplin, A., Akramian, R., Masatsugu, R., \& Benitez-Lopez, R. (2002). SWARM Study Final Report on W/B Foothill Freeway (W/B LA-210). Research Report to California Department of Transportation.

Pu, W. (2011). Analytic Relationships between Travel Time Reliability Measures. Transportation Research Record: Journal of the Transportation Research Board, 2254(1), 122-130. https://doi.org/10.3141/2254-13

Shladover, S., Lu, X.-Y., Wu, C.-J., \& Spring, J. (2017). Field Test of Coordinated Ramp Metering (CRM). California. Department of Transportation.

Sobolewski, M., Polum, T., Morris, P., Loos, R., \& Anderson, K. (2015). Pilot testing of SHRP 2 reliability data and analytical products: Minnesota. National Research Council (US). Transportation Research Board.

Stamatiadis, N., \& Deacon, J. A. (1997). Quasi-induced exposure: Methodology and insight. Accident Analysis \& Prevention, 29(1), 37-52.

U.S. Census Bureau. (n.d.). 2010. Retrieved November 16, 2019, from https://www. census.gov/programs-surveys/acs/guidance/comparing-acs-data/2010.html

van Lint, J. W. C., van Zuylen, H. J., \& Tu, H. (2008). Travel time unreliability on freeways: Why measures based on variance tell only half the story. Transportation Research Part A: Policy and Practice, 42(1), 258-277. https://doi.org/10.1016/j. tra.2007.08.008

Viggiano, C., Koutsopoulos, H. N., \& Attanucci, J. (2014). User behavior in multiroute bus corridors: Analysis by a web-based survey. Transportation Research Record, 2418(1), 92-99.

Washburn, S. S., \& Kirschner, D. S. (2006). Rural freeway level of service based on traveler perception. Transportation Research Record, 1988(1), 31-37.

Xin, W., Michalopoulos, P. G., Hourdakis, J., \& Lau, D. (2004). Minnesota's New Ramp 
Control Strategy: Design Overview and Preliminary Assessment. Transportation Research Record: Journal of the Transportation Research Board, 1867(1), 69-79. https://doi.org/10.3141/1867-09

Yuan, Y., Daamen, W., Hoogendoorn, S., \& Vrancken, J. (2009). Coordination Concepts for Ramp Metering Control in a Freeway Network. IFAC Proceedings Volumes, 42(15), 612-618. https://doi.org/10.3182/20090902-3-US-2007.0039 


\section{ABOUT THE AUTHORS}

\section{AMIR M. MOLAN, PHD}

Dr. Amir M. Molan, Ph.D., P.E., is a Lecturer at California Polytechnic State University (Cal Poly). He obtained his Bachelor of Science and Master of Science degrees from Azad University in Tehran, Iran, and his doctoral degree from Wayne State University (WSU) in 2017. His research has led to new design proposals for improving the performance and extending the serviceability of existing transportation infrastructures, including interchanges and intersections.

\section{NIVEDHA MURUGESAN}

Nivedha Murugesan is working towards her Master of Science degree in Statistics at San Jose State University (SJSU). She hopes to pursue a career in data analytics after completing her studies.

\section{ALIREZA SHAMS, PHD}

Dr. Alireza Shams, Ph.D. is a lecturer at California Polytechnic State University (Cal Poly). He obtained his Ph.D. in Civil Engineering-Transportation from Clemson University in 2018. His research interests include Application of new sensing technologies in Transportation such as Light Detection and Ranging (LiDAR), Transportation Safety, Asset Management, and Geographic Information System (GIS).

\section{CRISTINA TORTORA, PHD}

Dr. Cristina Tortora, Ph.D. is an Assistant professor in the Department of Mathematics and Statistics at San José State University. She completed her Ph.D. in Statistics at the University of Naples Federico II in 2012. Her research focuses on data analysis, specifically, on the development of advanced clustering techniques addressing cluster flexibility, missing data, robustness in the presence of outliers, and high dimensional data sets. She collaborates with experts in applied fields, including transportation and industrial engineering.

\section{FARIDUR RAHMAN}

Faridur Rahman is a transportation engineer at GHD. He obtained his Bachelor of Science and Master of Science degrees from California Polytechnic State University (Cal Poly) in 2019. His research includes analyzing travel time relatability as a performance measures in determining impacts of project in post implementation, travel time reliability as performance measures in alternative selection, travel time reliability as a performance measure in determining impacts of wine tourism in local roadways and local systemic safety implementation. 


\section{JACKY LOH}

Jacky Loh is a traffic designer at RailPros. He obtained his Bachelor of Science and Master of Science degrees from California Polytechnic State University, San Luis Obispo (Cal Poly SLO) in 2019.

\section{ANURAG PANDE, PHD}

Anurag Pande Ph.D., is Professor of Civil Engineering at California Polytechnic State University, San Luis Obispo. He also serves as the Faculty Liaison for Service-Learning and as such manages Cal Poly's outreach efforts to local and regional government and non-profit agencies. 


\section{PEER REVIEW}

San José State University, of the California State University system, and the Mineta Transportation Institute (MTI) Board of Trustees have agreed upon a peer review process required for all research published by MTI. The purpose of the review process is to ensure that the results presented are based upon a professionally acceptable research protocol. 


\author{
Founder, Honorable \\ Norman Mineta (Ex-Officio) \\ Secretary (ret.), \\ US Department of Transportation \\ Chair, \\ Abbas Mohaddes (TE 202I) \\ President \& COO \\ Econolite Group Inc. \\ Vice Chair, \\ Will Kempton (TE 2022) \\ Retired \\ Executive Director, \\ Karen Philbrick, PhD \\ (Ex-Officio) \\ Mineta Transportation Institute \\ San José State University \\ Richard Anderson \\ (Ex-Officio) \\ President \& CEO \\ Amtrak \\ David Castagnetti (TE 202 I) \\ Co-Founder \\ Mehlman Castagnetti \\ Rosen \& Thomas \\ Maria Cino (TE 202 I) \\ Vice President \\ America \& U.S. Government \\ Relations Hewlett-Packard Enterprise
}

\author{
Grace Crunican* \\ (TE 2022) \\ Retired
}

Donna DeMartino (TE 202I)

General Manager \& CEO

San Joaquin Regional Transit District

Nuria Fernandez* (TE 2020)

General Manager \& CEO

Santa Clara Valley

Transportation Authority (VTA)

John Flaherty (TE 2020)

Senior Fellow

Silicon Valley American

Leadership Form

Rose Guilbault (TE 2020)

Board Member

Peninsula Corridor

Joint Powers Board

Ian Jefferies (Ex-Officio)

President \& CEO

Association of American Railroads

Diane Woodend Jones

(TE 2022)

Principal \& Chair of Board

Lea + Elliott, Inc.
Therese McMillan

(TE 2022)

Executive Director

Metropolitan Transportation

Commission (MTC)

Bradley Mims (TE 2020)

President \& CEO

Conference of Minority

Transportation Officials (COMTO)

Jeff Morales (TE 2022)

Managing Principal

InfraStrategies, LLC

Dan Moshavi, PhD

(Ex-Officio)

Dean, Lucas College and

Graduate School of Business

San José State University

Takayoshi Oshima (TE 202 I)

Chairman \& CEO

Allied Telesis, Inc.

Toks Omishakin

(Ex-Officio)

Director

California Department of

Transportation (Caltrans)
Paul Skoutelas (Ex-Officio)

President \& CEO

American Public Transportation

Association (APTA)

Dan Smith (TE 2020)

President

Capstone Financial Group, Inc.

Beverley Swaim-Staley (TE 2022)

President

Union Station Redevelopment

Corporation

\section{Jim Tymon (Ex-Officio)}

Executive Director

American Association of

State Highway and Transportation

Officials (AASHTO)

\section{Larry Willis (Ex-Officio)}

President

Transportation Trades

Dept., AFL-CIO

$(\mathrm{TE})=$ Term Expiration

* = Past Chair, Board of Trustees

\section{Directors}

Karen Philbrick, Ph.D.

Executive Director

Hilary Nixon, Ph.D.

Deputy Executive Director

\section{Asha Weinstein Agrawal,}

\section{Ph.D.}

Education Director

National Transportation Finance

Center Director

\section{Brian Michael Jenkins}

National Transportation Security

Center Director

\title{
Research Associates Policy Oversight Committee
}

Jan Botha, Ph.D.

Civil \& Environmental Engineering

San José State University

Katherine Kao Cushing,

\section{Ph.D.}

Enviromental Science

San José State University

Dave Czerwinski, Ph.D. Marketing and Decision Science San José State University
Frances Edwards,

Ph.D.

Political Science

San José State University

Taeho Park, Ph.D.

Organization and Management

San José State University

\section{Christa Bailey}

Martin Luther King, Jr. Library

San José State University

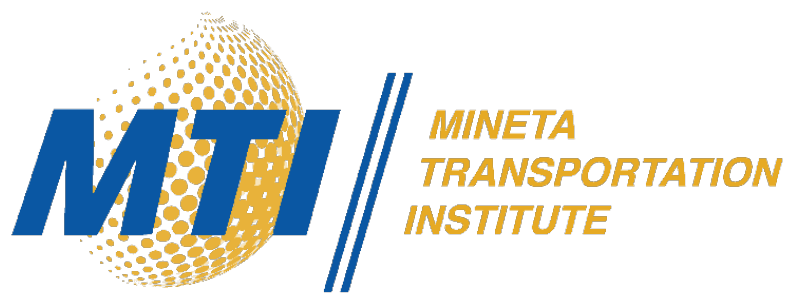

